

\section{DISCLAIMER}

This report was prepared as an account of work sponsored by an agency of the United States Government. Neither the United States Government nor any agency Thereof, nor any of their employees, makes any warranty, express or implied, or assumes any legal liability or responsibility for the accuracy, completeness, or usefulness of any information, apparatus, product, or process disclosed, or represents that its use would not infringe privately owned rights. Reference herein to any specific commercial product, process, or service by trade name, trademark, manufacturer, or otherwise does not necessarily constitute or imply its endorsement, recommendation, or favoring by the United States Government or any agency thereof. The views and opinions of authors expressed herein do not necessarily state or reflect those of the United States Government or any agency thereof. 


\section{DISCLAIMER}

Portions of this document may be illegible in electronic image products. Images are produced from the best available original document. 


\section{Printed in the United States of America. Available from National Technical Information Service \\ U.S. Department of Commerce \\ 5285 Port hoyal Road, Springfield, Virginia 22161 \\ NTIS price codes-Printed Copy: A06 Microfiche A01}

This report was prepared as an account of work sponsored by an agency of the United States Government. Neither the United States Government nor any agency thereof, nor any of their employees, makes any warranty, express or implied, or assumes any legal liability or responsibility for the accuracy, completeness, or usefulness of any information, apparatus, product, or process disclosed, or represents that its use would not infringe privately owned rights. Reference herein to any specific commercial product, process, or service by trade name, trademark, manufacturer, or otherwise, does not necessarily constitute or imply its endorsement, recommendation, or favoring by the United States Government or any ayency thereol. The views and upinions ol aulhors expressed herein du nul necessarily state or reflect those of the United Statc3 Government or any agency thereof. 
Contract No. W-7405-eng-26

\title{
A FIELD STUDY OF MOISTURE DARIAGE IN WALLS INSULATED WITHOUT A VAPOR BARRIER \\ FINAL REPORT FOR THE OREGON DEPARTMENT OF ENERGY
}

\author{
Seton, Johrisori, and Odel1, Inc. \\ Port land, Oregon \\ George A. Tsongas \\ Portland State University \\ Applied Social Research, Inc. \\ Portland, Oregon
}

Part of

The National Program for

Building Thermal Envelope Systems and Insulating Materials

Datc Published: May 1980

Research sponsored by the Office of Buildings and Community Systems, U.S. Department of Energy

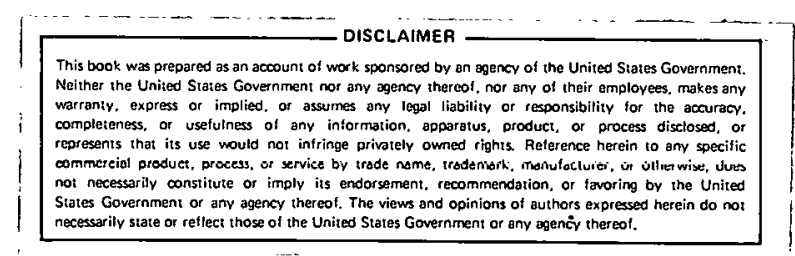

OAK RIDGE NATIONAL LABORATORY

Oak Ridge, Tennessee 37830 operated hy

UNION CARBIDE CORPORATION for the DEPARTMENT OF ENERGY 
THIS PAGE

\section{WAS INTENTIONALLY LEFT BLANK}


FOREWORD

This is one of a series of reports to be published describing research, development, and demonstration activities in support of the National Program for Building Thermal Envelope Systems and Insulating Materials. The National Program involves several federal agencies and many other organizations in the public and private sectors who are addressing the national objective of decreasing energy wastes in the heating and cooling of buildings. Results described in this report are part of the National Program through delegation of management responsibilities for the DOE lead role to the Oak Ridge National Laboratory.

Other reports in this series include the following which are available from NTIS.

1. DOE/CS-0059: The National Program Plan for Building Thermal Envelope Systems and Insulating Materials (January 1979);

2. ORNL/SUB-7556/I: Assessment of the Corrosiveness of Cellulosic Insulating Materials (June T979).

3. ORNL/SUB-7504/3: Recessed Light Fixture Test Facility (July 1979).

4. ORNL/SUB-7559/I: Problems Associated with the Use of UreaFormaldehyde Foam for Residential Insulation (September 1979).

5. ORNL/Sub-7551/I: Interim Progress Report on an Investigation of Energy Transport in Porous Insulator Systems (october 1979).

6. ORNL/Sub-79/13660/I: Minnesota Retrofit Insulation In Situ Test Program Extension and Review (February 1980).

Ted 5. Lundy Program Manager

Building Thermal Envelope Systems. and Insulating Materials Oak Ridge National Laboratory

E. C. Freeman Program Manager, Buildings Division Architectural \& Engineering Systems Branch/BCS

Department of Energy 
THIS PAGE

WAS INTENTIONALLY

LEFT BLANK 


\section{A FIELD STUDY OF MOISTURE DAMAGE IN WALLS INSULATED WITHOUT A VAPOR BARRIER}

\section{ABSTRACT}

Considerable uncertainty has existed over whether or not wall insulation installed without a vapor barrier causes an increased $r$ isk of moisture damage (wood decay) within walls. This report describes the results of one of the first major studies in the country aimed at finding out if such a moisture problem really exists. The exterior walls of a total of 96 homes in Portland, Oregon were opened, of which 70 had retrofitted insulation and 26 were uninsulated and were a control group. The types of insulation included urea-formaldehyde foam (44), mineral wool (16), and cellulose (10): In each opened wall cavity the moisture content of wood was measured and insulation and wood samples were taken for laboratory analysis of moisture content and for the determination of the presence of absence of decay fungi. Foam shrinkage was also measured. To evaluate the possible influence of the relative air tightness of the homes, fan depressurization tests were run using a door blower unit.

The field and laboratory test results indicating the lack of a moisture damage problem in existing homes with wooc siding in climates similar to that of western Oregon are described along with results of a statistical analysis of the data. Related problems of interest to homeowners and insulation installers are noted. The standard operating procedures used throughout the study are discussed, including the home selection process, quantitative and qualitative techniques used to identify wall locations with the highest moisture content, wall opening and data/sample collection methodology, laboratory analysis of samples, data processing and analysis, and applicability of the results. Recommendations for future tests are made. Finally, the potential and desirability for future retrofitting of wali insulation. is explored. 
THIS PAGE

\section{WAS INTENTIONALLY LEFT BLANK}




\section{PREFACE}

This field study had its origins in a number of meetings initiated in 1977 to discuss the problem of possible moisture damage in walls retrofitted with insulation. The meetings were sponsored by the Oregon Department of Energy (ODOE), and members of Oregon utilities, contractor organizations and universities were in attendance. An Oregon ad-hoc committee on wall insulation was formed and chaired by walter Pollock, then of ODOE; shortly thereafter Jim Thompson of ODOE took charge of the project. An initial research proposal to study the problem was developed by Professor Robert Graham of Oregon State University (OSU). A small amount of ODOE funding was then made available to Alan Boner of the University of Oregon to do a literature search, and from ERDA to OSU to analyze the literature and write a second draft of the proposal which would then be submitted to local utilities and the U.S. DOE for funding. Ray Wiley, a consulting architect/engineer, was responsible for researching and writing that proposal. Under the direction of Jim Thompson, a Request for Proposals was then prepared and issued by ODOE to prospective consultants interested in conducting a field study to determine whether a moisture problem really exists.

The contract was awarded by ODOE in November 1978. The prime contractor was the consulting engineering firm of seton, Johnson and Odell from Portland, with Dr. George Tsongas of Portland State University as principal investigator. Funding began in early January 1979; the field testing began on February 2nd and was completed on April lith.

The funding for this study was provided from a number of sources: the U.S. Department of Energy through the Oak Ridge National Laboratory, the Region $x$ office, the office of Buildings and Community systems, and the Bonneville Power Administration; Pacific Power and Light, Portland General Electric, Puget sound Power and Light, Seattle City Light, the Eugene water and Electric Board, and the Oregon state Homebuilders Association. Substantial. in-kind contributions were also received from the Oregon Department of Energy, the Oregon Weatherization Contractors and Manufacturers

Association, and the U.S. Navy Civil Engineering Laboratory. The contract manager for the Oregon DOE was Jim Thompson, and the contract administrator representing the U.S. DOE was Ted $S$. Lundy of the Oak Ridge National Laboratory. Shelley Launey of U.S. DOE's Office of Buildings and Community systems served as the project manager. A client group advisory committee was formed to provide assistance and review of the project's progress. The members are listed below:

Oregon Dept. of Energy Oak Ridge National Lab. U.S. Dept. of Energy
Jim Thompson

Ted Lundy

Shelley Launey 
U.S. Dept. of Energy (Region X)

Bonneville Power Admin.

U.S. Navy Civil Eng. Lab

Eugene water \& Elect. Board

Pacific Power \& Light

Portland General Electric

Seattle City Light

Puget Sound Power \& Light Oregon State Homebuilders Association

Weatherization Contractors

\& Manufacturers Assoc. of oregon
Terry Dolan

Don Davey

John King

John Scofield

Carl Stultz

Dick Hansen

Tom Sadowski

A. Yamagiwa

Hunter Branham

Dale Dyer

Rod Hamilton

A portion of this report was presented at and published in the Proceedings of the Solar 79 Northwest Conference, Seattle, washington, August 10-12, 1979. The findings will also be presented at the U.S. DOE/ASHRAE Thermal Performance of the Exterior Envelopes of Buildings Conference, Orlando, Florida, December 3-5, 1979 and published in the conference proceedings. 


\section{ACKNOWLEDGEMENTS}

This project is indebted to numerous individuals and entities. Obviously, it could not have proceeded without the support of the funding agencies and companies. Special thanks must go to Bob Graham and Ray wiley for their early stimulus and for initiating the drafting of a research proposal, to Jim Thompson for his able coordination of this project and his continuous assistance, to the advisory committee members for their assistance and interest, and to shelley Launey of U.S. DOE, John King of the Navy Civil Engineering Laboratory, Ari Lourenzi of Delmhorst Company, and Deannie Williams of BPA for the loan of necessary specialized equipment.

As the project consultant, Seton, Johnson and Odell is especially appreciative of the efforts of our colleagues Mitzi Scott, George Tsongas and John Stryker. An extraordinary note of appreciation is due to Paul Olson and Russ Goble of the Neil Kelly Company, who provided a level of skill in opening and closing the test holes that more than justified the trust placed in us by the homeowners who participated in the study.

Finally, special thanks must go to the owners and families in the test homes; their interest, support, and patience made this study possible. 
THIS PAGE

WAS INTENTIONALLY

LEFT BLANK 


\section{AIR LEAKAGE DATA ERRATA}

After the study was completed, the blower door supplier noted an error existed in the calibration curve used to reduce the raw data. The results have been corrected as noted in the summary below and the attached tables.

$\begin{array}{lccc} & \text { old } & \text { New } & \frac{\% \text { Change }}{\text { Mean Air Changes/Hour }} \\ \text { Standard Deviation } & 13.1 & 16.2 & 19 \\ \text { Maximum ACH } & 4.63 & 5.09 & 9 \\ \text { Minimum ACH } & 31.0 & 37.5 & 17 \\ \text { * Old minimum incorrectly calculated. }\end{array}$

Mean $\mathrm{ACH}$ By Insul. Type

$\begin{array}{ccc} & \text { Old } & \text { New } \\ \text { UF } & 12.34 & 15.23 \\ \text { CEL } & 10.54 & 13.58 \\ \text { MW } & 12.61 & 16.38 \\ \text { NO } & 15.84 & 18.72\end{array}$

Table Notes:

004 Basement now included, original ach incorrect.

043 Leakage estimated, data off calibration curve

086 Incorrect volume used to calculate air changes per hour

092 Incorrect volume used to calculate air changes per hour

Wall Insulation Types:

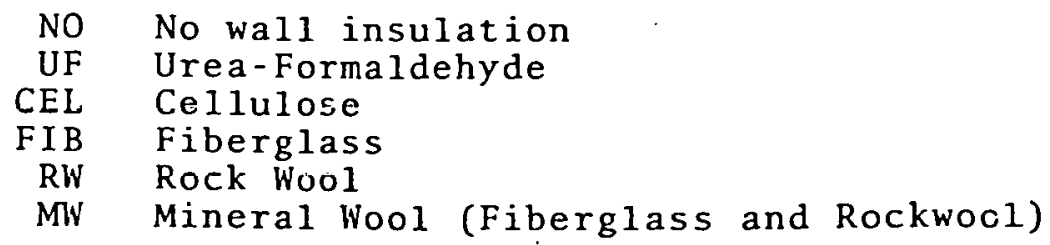




\begin{tabular}{|c|c|c|c|c|c|c|c|c|c|c|c|c|c|c|c|c|c|c|c|c|c|c|c|c|c|}
\hline $\begin{array}{l}0 \\
\tilde{N} \\
0\end{array}$ & $\begin{array}{l}0 \\
N \\
\infty \\
\infty\end{array}$ & & & & & & $\begin{array}{l}0 \\
0 \\
0\end{array}$ & : & $\stackrel{0}{\infty}$ & 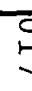 & & & & 吕 & & & & & : & & & : & 只 & \multicolumn{2}{|l|}{ ID No. } \\
\hline \multirow[t]{2}{*}{ z } & \multirow[t]{2}{*}{ z } & & \multirow[t]{2}{*}{$\underset{T}{T}$} & \multirow[t]{2}{*}{ 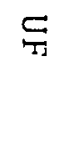 } & \multirow[t]{2}{*}{ 与 } & \multirow[t]{2}{*}{ 空 } & \multirow{2}{*}{ 要 } & \multirow{2}{*}{ 营 } & \multirow[t]{2}{*}{ z } & \multirow[t]{2}{*}{ z } & & \multirow[t]{2}{*}{$\underset{\tau}{\tau}$} & \multirow[t]{2}{*}{ S. } & \multirow[t]{2}{*}{ 돆 } & z & \multirow[t]{2}{*}{5} & & \multirow[t]{2}{*}{ త્తి } & \multirow{2}{*}{\multicolumn{2}{|c|}{$\overline{\bar{\pi}}$ z }} & & \multirow[t]{2}{*}{ 突 } & \multirow[t]{2}{*}{ 苛 } & \multicolumn{2}{|c|}{ Wall Insulation Type } \\
\hline & & & & & & & & & & & & & & & & & & & & & & & & \multicolumn{2}{|l|}{ Notes } \\
\hline \multirow{2}{*}{$\begin{array}{l}\vec{a} \\
\omega \\
\omega \\
\vec{\omega} \\
\dot{\omega}\end{array}$} & \multirow[t]{2}{*}{ 崖 } & \multirow[t]{2}{*}{ 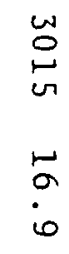 } & \multirow{2}{*}{$\begin{array}{l}\stackrel{\vec{v}}{\tilde{E}} \\
\stackrel{\infty}{c} \\
\stackrel{0}{c}\end{array}$} & \multirow{2}{*}{$\begin{array}{l}\underset{\sim}{\infty} \\
\stackrel{\infty}{c} \\
\sim \\
\sim \\
w\end{array}$} & \multirow{2}{*}{$\begin{array}{l}\stackrel{n}{2} \\
8 \\
0 \\
\stackrel{2}{0} \\
\stackrel{\omega}{v}\end{array}$} & \multirow{2}{*}{$\begin{array}{l}0 \\
\infty \\
0 \\
0 \\
\sim \\
\sim \\
\sim\end{array}$} & \multirow{2}{*}{$\begin{array}{l}\mathcal{N} \\
w \\
0 \\
0 \\
N \\
N \\
\tilde{N}\end{array}$} & \multirow{2}{*}{$\begin{array}{l}\infty \\
\stackrel{\infty}{0} \\
5 \\
5 \\
0 \\
0\end{array}$} & $\begin{array}{l}0 \\
i \\
y \\
c\end{array}$ & 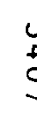 & & E. & $\begin{array}{c}\substack{c \\
c \\
c \\
w \\
w} \\
0\end{array}$ & $\begin{array}{l}\underset{N}{N} \\
w \\
o\end{array}$ & $\begin{array}{c}w \\
\infty \\
v\end{array}$ & 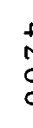 & & & $\begin{array}{l}\text { w } \\
\text { 足 } \\
\text { w }\end{array}$ & & $\underset{\text { w }}{\tilde{y}}$ & 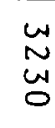 & $\stackrel{\stackrel{N}{\sim}}{\sim}$ & $\begin{array}{l}\text { Cubic Meters } \\
\text { Per Hour }\end{array}$ & $\begin{array}{l}\text { Old } \\
\text { Air }\end{array}$ \\
\hline & & & & & & & & & is & 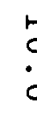 & & 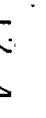 & $\stackrel{-1}{\infty}$ & $\stackrel{5}{5}$ & ?. & : & & & $\stackrel{\infty}{0}$ & م. & $\stackrel{\infty}{0}$ & $\stackrel{5}{\circ}$ & $\stackrel{\infty}{\infty}$ & $\begin{array}{l}\text { Air Changes } \\
\text { Per Hour }\end{array}$ & \\
\hline $\begin{array}{l}\sim \\
\infty \\
0 \\
0\end{array}$ & $\begin{array}{l}\overrightarrow{2} \\
2 \\
0\end{array}$ & 崩 & $\underset{0}{0}$ & $\begin{array}{c}\sigma \\
v \\
v \\
v\end{array}$ & 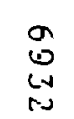 & 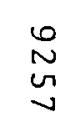 & $\begin{array}{l}\sigma \\
\sigma_{0} \\
a \\
c\end{array}$ & $\begin{array}{l}\stackrel{\Xi}{\Xi} \\
\stackrel{O}{\Xi}\end{array}$ & $\begin{array}{l}0 \\
0 \\
\alpha \\
0 \\
0\end{array}$ & & & 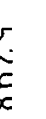 & $\begin{array}{l}9 \\
\text { in } \\
i=1\end{array}$ & $\underset{\stackrel{f}{*}}{\stackrel{a}{a}}$ & 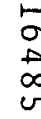 & 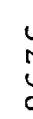 & & & 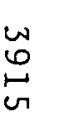 & & $\begin{array}{l}\text { w } \\
\sigma \\
\sigma\end{array}$ & $\begin{array}{l}w \\
\stackrel{w}{ } \\
g\end{array}$ & $\stackrel{\overrightarrow{0}}{\overrightarrow{1}}$ & $\begin{array}{l}\text { Cubic Meters } \\
\text { Per Hour }\end{array}$ & New \\
\hline $\begin{array}{l}\text { 占 } \\
\text { is }\end{array}$ & $\begin{array}{l}0 \\
\dot{\omega}\end{array}$ & $\begin{array}{l}\tilde{N} \\
0\end{array}$ & $\stackrel{F}{c}$ & $\stackrel{\sim}{\stackrel{\sim}{\infty}}$ & $\stackrel{\bullet}{\sim}$ & $\begin{array}{l}\sim \\
0 \\
0\end{array}$ & $\underset{\infty}{\infty}$ & 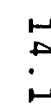 & $i_{0}^{1}$ & ; & & 5 & iv & $\stackrel{\omega}{\omega}$ & ù & ; & & & 占 & 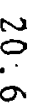 & $\ddot{\infty}$ & $\stackrel{\stackrel{\omega}{\omega}}{c}$ & 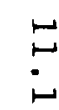 & $\begin{array}{l}\text { Air Changes } \\
\text { Per Hour }\end{array}$ & \\
\hline$\tilde{o}$ & $\tilde{N}$ & $\tilde{\omega}$ & $\stackrel{N}{\circ}$ & $\ddot{6}$ & 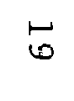 & 尚 & b & $\infty$ & 6 & 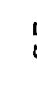 & & $\check{~}$ & sa & $\stackrel{N}{N}$ & 5 & i & & : & $N$ & 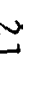 & N & $\overrightarrow{0}$ & $\stackrel{\omega}{\omega}$ & $\begin{array}{l}\text { Cubic Meters } \\
\text { Per Hour }\end{array}$ & Percent \\
\hline$\bullet$ & $N$ & $\tilde{\omega}$ & $\tilde{a}$ & $\bullet$ & $\Xi$ & 占 & $\tilde{a}$ & $\infty$ & ic & $i$ & & ت & בנr & $\tilde{N}$ & 5 & $i$ & & & w & 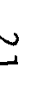 & $\stackrel{\infty}{\infty}$ & 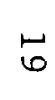 & $\tilde{\omega}$ & $\begin{array}{l}\text { Air Changes } \\
\text { Per Hour }\end{array}$ & \\
\hline
\end{tabular}




\begin{tabular}{|c|c|c|c|c|c|c|c|c|c|c|c|c|c|c|c|c|c|c|c|c|c|c|c|}
\hline à & & & & in & : : & in & On & i & & 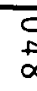 & & & & $\stackrel{D}{\omega}$ & $\stackrel{0}{N}$ & $\stackrel{\circ}{\circ}$ & $\underset{\substack{0 \\
0}}{0}$ & $\underset{\infty}{\substack{0 \\
\infty \\
\infty}}$ & 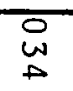 & $\underset{\sim}{\mathcal{W}}$ & $\begin{array}{l}9 \\
\\
0\end{array}$ & \multicolumn{2}{|l|}{ ID No. } \\
\hline \multirow[t]{2}{*}{ 突 } & \multirow[t]{2}{*}{$\pi^{\pi}$} & \multirow[t]{2}{*}{ 忽 } & \multirow[t]{2}{*}{ 空 } & \multirow[t]{2}{*}{ 突 } & \multirow[t]{2}{*}{]$_{\pi}^{2}$} & \multirow[t]{2}{*}{ z } & \multirow[t]{2}{*}{ 苗 } & \multirow[t]{2}{*}{ z } & \multirow[t]{2}{*}{ 吕 } & \multirow{2}{*}{\multicolumn{2}{|c|}{$z$}} & \multirow[t]{2}{*}{ z } & \multirow[t]{2}{*}{ 思 } & \multirow{2}{*}{$\begin{array}{l}z \\
x\end{array}$} & \multirow[t]{2}{*}{ z } & \multirow[t]{2}{*}{ z } & \multirow[t]{2}{*}{ z } & \multirow[t]{2}{*}{ z } & \multirow[t]{2}{*}{$z$} & \multirow[t]{2}{*}{ z } & \multirow[t]{2}{*}{$\frac{\pi}{2}$} & \multicolumn{2}{|c|}{ Wall Insulation Type } \\
\hline & & & & & & & & & & & & & & & & & & & & & & \multicolumn{2}{|l|}{ Notes } \\
\hline $\begin{array}{l}\omega \\
\infty \\
\infty \\
0\end{array}$ & $\stackrel{\substack{\infty \\
\sim}}{\sim}$ & $\begin{array}{l}\infty \\
\infty \\
0 \\
0\end{array}$ & $\begin{array}{l}\text { w } \\
\text { a }\end{array}$ & $\begin{array}{l}\overrightarrow{8} \\
:\end{array}$ & 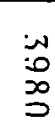 & 岕 & $\begin{array}{c}w \\
w \\
\text { d }\end{array}$ & जू & 占 & 气 & & 点 & 岕 & $\begin{array}{l}\overrightarrow{0} \\
\stackrel{\leftrightarrow}{\Delta} \\
0\end{array}$ & $\begin{array}{l}w \\
\sigma \\
\sigma\end{array}$ & $\stackrel{\vec{a}}{\stackrel{\sim}{\omega}}$ & $\stackrel{\infty}{\stackrel{\infty}{a}}$ & $\begin{array}{l}w \\
o \\
0\end{array}$ & $\begin{array}{l}\text { W } \\
\text { ज़ } \\
0\end{array}$ & $\begin{array}{l}\infty \\
\stackrel{\infty}{\Delta}\end{array}$ & $\begin{array}{l}\infty \\
\stackrel{2}{\circ} \\
\stackrel{\circ}{0}\end{array}$ & $\begin{array}{l}\text { Cubic Meters } \\
\text { Per Hour }\end{array}$ & \multirow{2}{*}{$\begin{array}{c}\text { old } \\
\text { Air } \\
\text { Leakage }\end{array}$} \\
\hline$\stackrel{\stackrel{\sim}{N}}{\stackrel{N}{N}}$ & $\begin{array}{l}\circ \\
\infty\end{array}$ & $\begin{array}{l}\stackrel{\sim}{\sim} \\
\infty\end{array}$ & 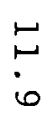 & $\begin{array}{l}\stackrel{n}{N} \\
\dot{0}\end{array}$ & in & $\begin{array}{l}\stackrel{*}{\circ} \\
\stackrel{n}{n}\end{array}$ & in & 岀 & 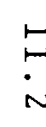 & 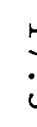 & & $\vec{b}$ & $\stackrel{\leftrightarrow}{\bullet}$ & $\begin{array}{l}\text { W } \\
\text { do }\end{array}$ & $\stackrel{0}{\infty}$ & $\stackrel{\leftarrow}{\sim}$ & $\begin{array}{l}\vec{\sigma} \\
\vdots \\
0\end{array}$ & $\begin{array}{l}\text { w } \\
\text { in }\end{array}$ & $i_{i}^{\infty}$ & $\stackrel{w}{:}$ & $\underset{\sim}{\tilde{\omega}}$ & $\begin{array}{l}\text { Air Changes } \\
\text { Per Hour }\end{array}$ & \\
\hline$\underset{\sim}{\stackrel{B}{N}}$ & 总 & 最. & $\begin{array}{l}\vec{u} \\
0 \\
i\end{array}$ & $\underset{\sim}{\sim}$ & 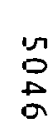 & $\begin{array}{l}\vec{t} \\
\text { a }\end{array}$ & $\begin{array}{l}\overrightarrow{3} \\
\text { a }\end{array}$ & 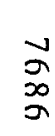 & $\begin{array}{l}w \\
\infty \\
\infty \\
0\end{array}$ & 古 & & 会 & 恿 & 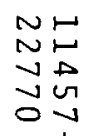 & $\begin{array}{l}\vec{u} \\
\dot{0} \\
i\end{array}$ & $\begin{array}{l}n \\
\stackrel{\infty}{0} \\
\stackrel{\sim}{\sim}\end{array}$ & $\begin{array}{l}\text { O } \\
\text { 品 }\end{array}$ & 응 & 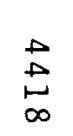 & 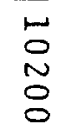 & 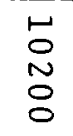 & $\begin{array}{l}\text { Cubic Meters } \\
\text { Per Hour }\end{array}$ & \multirow{2}{*}{$\begin{array}{c}\text { New } \\
\text { Air } \\
\text { Leakage }\end{array}$} \\
\hline in & $\begin{array}{l}\stackrel{\sim}{N} \\
\text { in }\end{array}$ & $\begin{array}{l}\vec{v} \\
\dot{v} \\
i\end{array}$ & 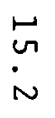 & $\begin{array}{l}\text { 市 } \\
\text { in }\end{array}$ & $\stackrel{\square}{\omega}$ & $\stackrel{\breve{\omega}}{i}$ & $\dot{v}$ & $\begin{array}{l}+\infty \\
\infty\end{array}$ & is & $\vdots$ & & 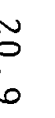 & $\begin{array}{l}\vec{b} \\
\infty \\
6\end{array}$ & 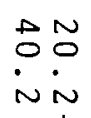 & $\begin{array}{l}\stackrel{L}{N} \\
\text { in }\end{array}$ & $\overbrace{\omega}^{\sim}$ & $\begin{array}{l}\text { O } \\
\text { in }\end{array}$ & $\stackrel{\sim}{\sim}$ & $\begin{array}{l}\tilde{\circ} \\
\infty\end{array}$ & $\begin{array}{l}w \\
\text { in }\end{array}$ & 苞 & $\begin{array}{l}\text { Air Changes } \\
\text { Per Hour }\end{array}$ & \\
\hline$\approx$ & $\tilde{\sim}$ & $\tilde{\check{c}}$ & $\sim$ & $\widetilde{\sim}$ & N & $\tilde{N}$ & $\tilde{N}$ & $\approx$ & $\tilde{\omega}$ & $i$ & & 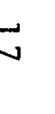 & $\tilde{N}$ & $\vdots$ & $\stackrel{N}{\sim}$ & $\tilde{o}$ & $\omega_{\infty}$ & $\sim$ & $N$ & $\stackrel{\infty}{\infty}$ & $\stackrel{\omega}{\infty}$ & $\begin{array}{l}\text { Cubic Meters } \\
\text { Pex Hour }\end{array}$ & \multirow{2}{*}{$\begin{array}{c}\text { Percent } \\
\text { Change }\end{array}$} \\
\hline$\sim$ & $\tilde{N}$ & ש & $N$ & $\stackrel{\sim}{\sim}$ & $\stackrel{\sim}{\sim}$ & $N$ & $N$ & $\tilde{v}$ & $\tilde{\omega}$ & $i$ & & $\omega$ & $\tilde{\sim}$ & : & $\tilde{\sim}$ & $\approx$ & $\overleftrightarrow{\infty}$ & $\stackrel{\sim}{\sim}$ & $\tilde{\sim}$ & $\stackrel{\sim}{\sim}$ & $\stackrel{\infty}{\infty}$ & $\begin{array}{l}\text { Air Changes } \\
\text { Per Hour }\end{array}$ & \\
\hline
\end{tabular}




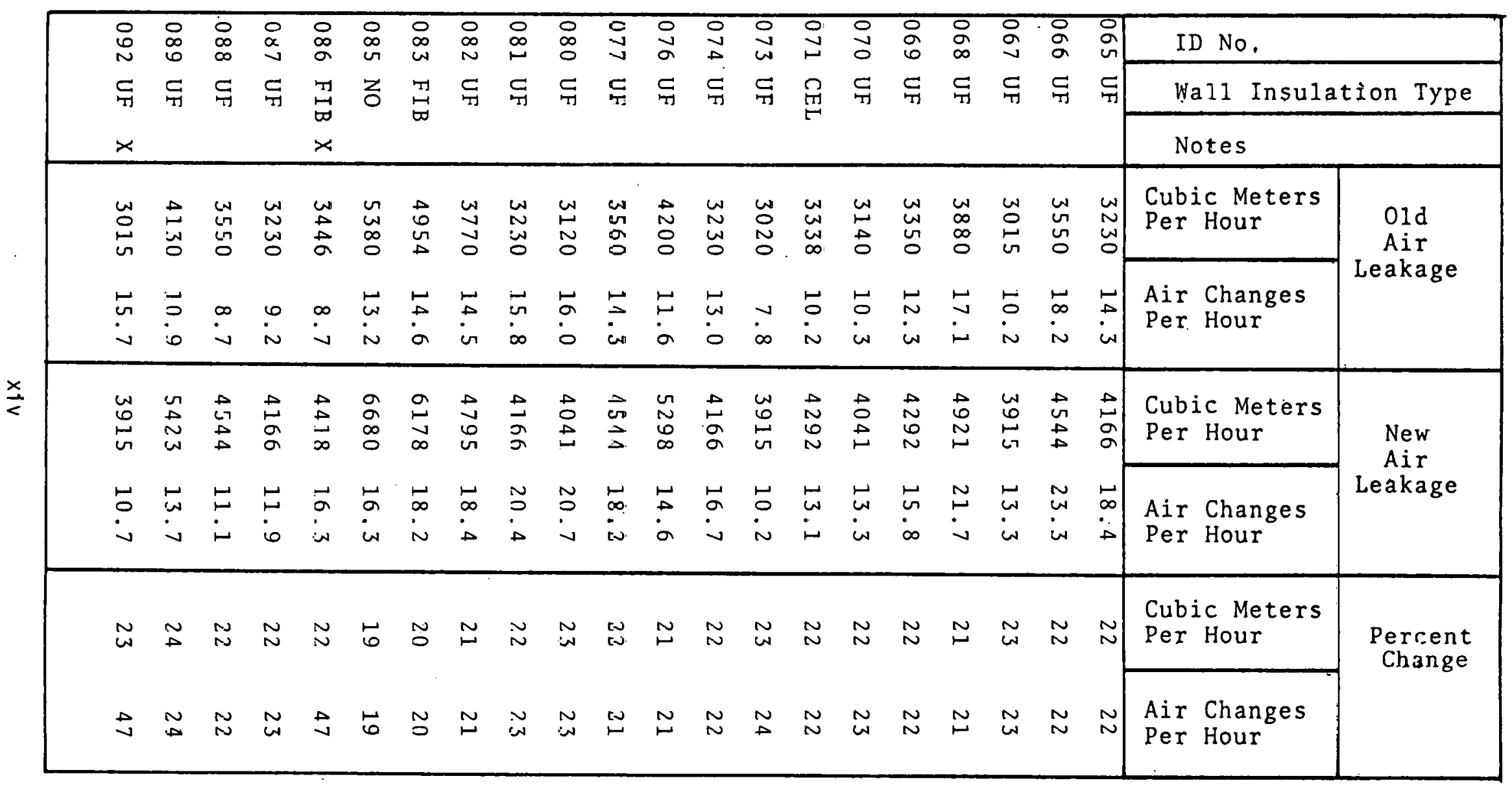




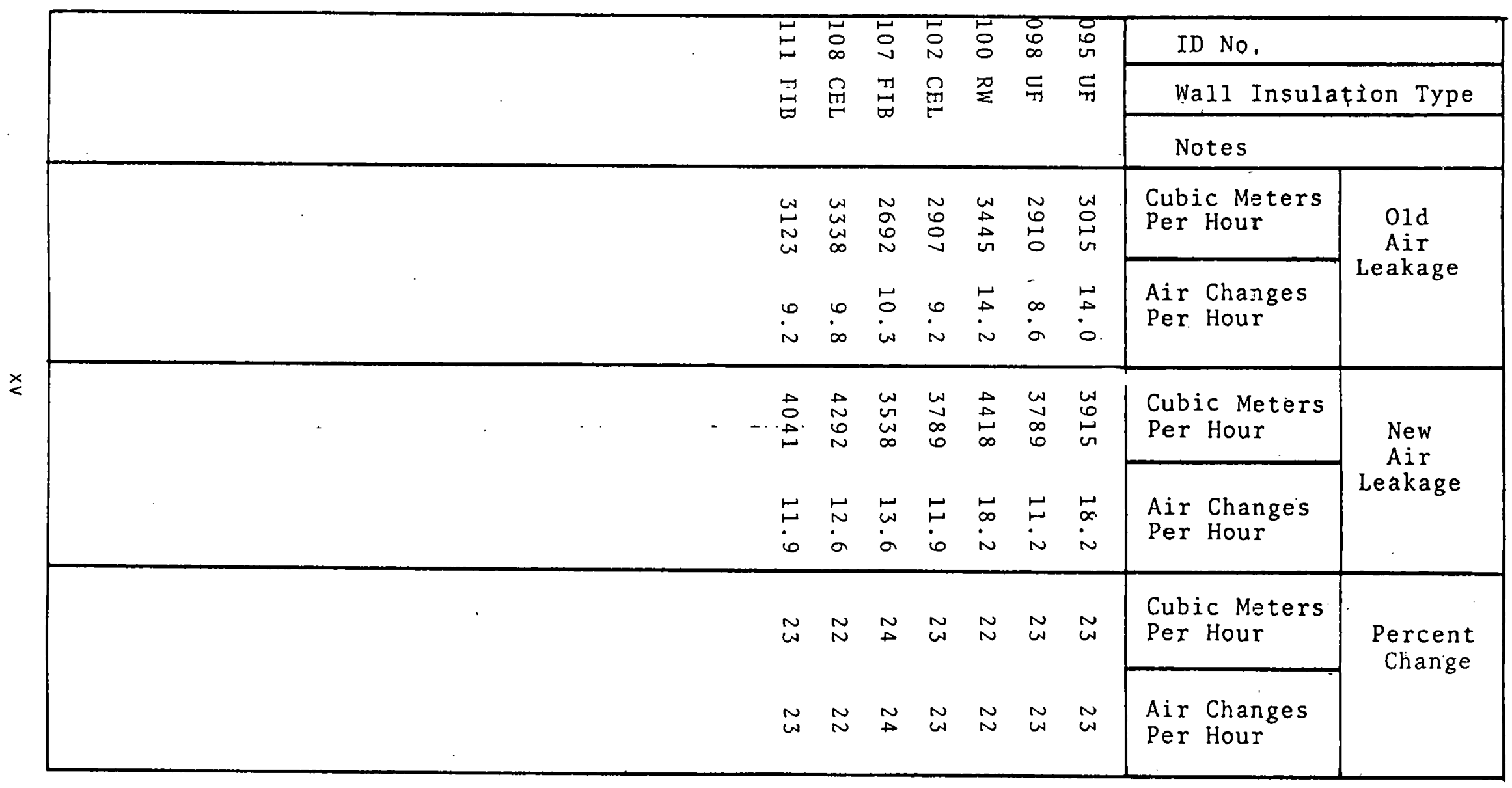




\section{THIS PAGE}

WAS INTENTIONALLY

LEFT BLANK 
ABSTRACT

PREFACE

ACKNOWLEDGEMENTS

LIST OF FIGURES AND TABLES

$\underline{\text { Page }}$

$v$

vi i

ix

1. PROJECT DESCRIPTION AND PURPOSE

$x i x$

1.1 Background

1.2 Study design and criteria

1.3 Project organization

2. FINDINGS AND CONCLUSIONS

2.I Wood and insulation moisture content findings 2.1.1 Field results

2.1 .2 Laboratory results

2.2 Moisture damage $\mathrm{f}$ indings

2.3 Moisture problem conclusions

2.4 Retrofit insulation characteristics

2.4.1 U-F foam shrinkage

2.4.2 Insulation installation and settling

2.5 Fan depressurization air leakage tests

2.6 Overall desirability of retrofitting wall 11

2.7 Methodology for future studies

3. RECOMMENDATIONS FOR FUTURE STUDIES 13

4. SELECTION AND DESCRIPTION OF TEST HOMES 14

$\begin{array}{lll}4.1 \text { Introduction } & 14\end{array}$

4.2 Criteria for selection 15

4.2.1. Initial criteria 15

4.2.2 Relaxed criteria. and other 16

4.3 Solicitation of test homes 18

4.3.1 Selection of target populations 18

4.3.2 Introductory letter and questionnaire 20

4.3.3 Response to solicitation 22

4.4 Screening, interviewing, and scheduling 22

4.4.I Initial review and telephone $\quad 22$ prequalificaton

4.4.2 Qualification interview and 23

4.4 initial house inspection $\quad 24$

4.4.4 Scheduling of wall openings 25

$\begin{array}{lll}4.4 .5 & \text { Followup } & 26\end{array}$ 
5. TEST METHODOLOGY

Development of test methodolgy

5.2 Wall opening

5.3 Data collection and recording 27

5.4 Wall closure

$\begin{array}{ll}5.5 & \text { Laboratory analysis. } \\ & 28\end{array}$

6. STATISTICAL DATA ANALYSIS METHODOLOGY 28

6.1 Data analysis procedure 28

6.2 Variables included 29

6.3 Choice of statistical tests 29

6.4 Structure of the analysis 30

6.5 Interpretation of the analysis findings 30

7. RESULTS 31

i.1 Wood and insulation moisture contents

7.1 .1 Field results 31

$\begin{array}{lll}7.1 .2 & \text { Laboratory results } & 33\end{array}$

7.1.3 Statistical analysis results 35

7.2 Moisture damage. 38

7.2 .1 Types 38

7.2.2 Visual observations 38

7.2.3 Presence of decay fungi 39

7.3 Other damage 40

7.4 U-F foam shrinkage and voids 40

7.5 Observations of installation quality and settling 43

7.6 Wiring corrosion 43

7.7 Fan depressurization air leakage tests 44

7.8 Potential for wall insulation retrofitting 45

8. APPLICABILITY OF RESULTS 45

8.1 General 45

8.2 Analysis of condensation potential 46 during 1978-79 winter
8.2 .1 Results

8.3 Representativeness of 1978-79 winter 51

8.4 Applicability of results to other geographical areas 51

9. REFERENCES 54

10. APPENDICES

10.I Condensation in walls: a discussion of the 56

problem (with bibliography)

10.2 Samples of introductory letter, questionnaire, 62

10.3 Statistical analysis results 79

10.4 Summary of test house characteristics and data 93 


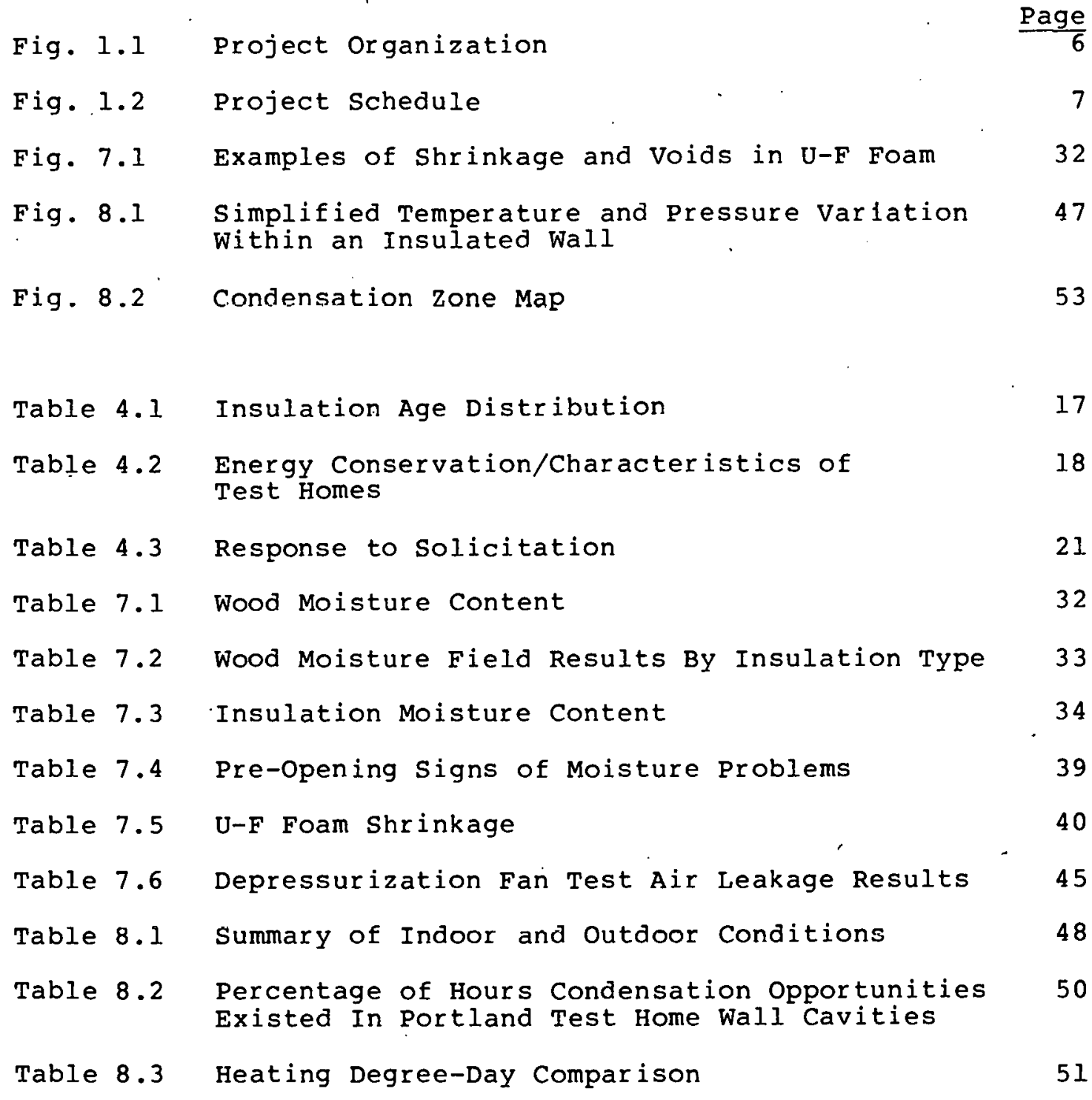




\section{PROJECT DESCRIPTION AND PURPOSE}

\section{I Background}

Since the 1973 oil embargo there has been an increasing awareness of the need to conserve energy. In the residential sector this awareness has resulted in a strong push by governmental agencies and utilities to upgrade new and existing homes in order to reduce their energy requirements, particularly for space heating. Considerable emphasis and publicity has been given to increasing insulation levels. Accordingly, many owners of existing homes have responded by adding insulation in ceilings, floors, and walls. Walls have been retrofitted with a variety of types of insulation blown through small holes into wall cavities. The predominant insulation types include cellulose, mineral wool (rock wool and fibrous glass wool or fiberglass), and urea-formaldehyde (U-F) foam.

While numerous existing homes have been insulated, major questions increasingly have been raised over the possible effects of moisture migration through walls on the thermal performance of the insulation and on moisture damage in the wall structure. Moisture is continually added to the warm air inside a house and escapes in part by leaking or diffusing into or through a wall cavity that has no vapor barrier on the inside wall surface to reduce moisture migration (as is applied in new construction). The addition of insulation lowers the temperature of the outer portion of the wall and can cause the dew point to move into the insulation such that water vapor can condense inside the wall cavity. Accordingly, more condensation is likely to occur in an insulated wall than in an uninsulated one (further details of this process are given in Appendix 10.1). Furthermore, natural drying may be reduced because circulation is impaired.

If these processes do occur, then water could conceivably accumulate on the sill plate or other wood members. In addition, if the insulation has settled, shrunk, or was not filled to the top of the wall cavity, the warm water vapor might condense near the top plate as it moves through the colder air there. Thus, not only could the thermal. performance of the insulation be impaired by condensation within. it, but also the possibility of structural damage would be present due to wood decay produced as a result of the high moisture content in the wood.

There is, of course, the possiblity that insufficient quantities (total mass) of water are produced by the postulated mechanism to create the necessary high moisture content conditions required for growth of the fungi that create wood decay. A variety of other factors may also affect this question, such as the structural tightness of interior walls and exterior siding. Moreover, even if moisture does condense, little is known about the extent of natural drying processes within the wall cavity. The condensed water vapor 
could be revaporized by the warming of the wall that occurs during the winter daytime in mild climates such as that of the Pacific Northwest. Finally, wood decay requires both high moisture content in the wood (greater than about 20\%) and also high wood temperature (greater than about 75 degrees F) for periods long enough for the decay to progress (Ref. 1). By the time of the year that extended periods of high temperature are sustained within the wall cavity, the water may be vaporized. such might not be the case, however, if water has leaked into the wall cavity and accumulated during the warm summer months.

Although there is some uncertainty in the present knowledge of the physical processes leading to potential moisture accumulation and fungal decay inside wall cavities, there are many reported cases of wood decay or rot occurring in walls insulated without a vapor barrier. For example, the files of the Oregon Department of Veteran Affairs have yielded inspection reports offering evidence of moisture-induced decay within the walls of existing homes. Documentation of these observations is uneven, however, and provides no information as to whether the addition of wall inculation was rcoponjible for beginning or accelerating the decay or whether the decay was produced by other causes such as roof, gutter, or bathroom leaks.

It should be noted that because of the uncertainty over possible moisture damage and because of the closely related failure of retrofitted wall insulation to perform as well as expected in at least one test involving two Northwest homes under actual living conditions (Ref. 2), for the past few years many Northwest utilities have not been recommending that wall insulation be installed. In addition, wall insulation has not been included in the new zero-interest loan weatherization programs of Pacific Power and Light and Portland General Electric.

It is against this backqround that the oregon Department of Energy, with the cooperation of the U.S. D.O.E. and a variety of utilities and contractor groups concerned with improving the energy efficiency of homes, developed the specifications for this field study aimed at objectively determining whether the addition of wall insulation without a vapor barrier in existing homes in the western region of the pacific Northwest significantly increases the probability of moisture damage within wall cavities. The major focus was to be on structural damage within the wall cavity due to wood decay, although other possible moisture-induced effects that are less critical such as blistering and peeling of paint and warping of siding were to be examined. The critical need to answer this question was obvious. Many homeowners had already insulated their walls and needed to know if there was a possibility of structural problems occurring, and whether or not to add a vapor barrier or take some other corrective action. Others were considering inculating their walls and they needed to know whether it was 
safe to do so. The cost of repairing any damage could easily outweigh the economic advantages of adding insulation to conserve energy. Of course, many homeowners were not insulating their walls, and yet if there was no problem, they should perhaps be doing so as an energy conservation measure.

Finally, it should be noted that the concern about possible moisture damage in walls retrofitted with insulation is not limited just to the Pacific Northwest. There is similar concern in many other areas of the nation, and much study and effort has gone into trying to better understand the problem. The U.S. Department of Energy has considered it a problem of major importance in their assessment of building thermal envelope systems (Ref. 3 ). However, this field study is the first major one of its $k$ ind in the nation specifically designed to determine scientifically and objectively if, in fact, there really is a potential for moisture damage due to the addition of wall insulation in existing houses in climates like that of the western region of the Pacific Northwest. The study hopefully would provide answers regarding the advisability of insulating walls without a vapor barrier. In that sense both regional and national conservation programs for wall insulation depend on the results and implications of this study.

\subsection{Study Design and Criteria}

In order to determine whether moisture damage is caused by insulation blown into a wall cavity without a vapor barrier, a field study was designed whereby portions of the walls of 96 homes in Portland, oregon were to be opened and examined. Wood moisture content was to be measured directly and wood and insulation samples were to be taken for laboratory tests to determine moisture content and the presence or absence of decay fungi. The details of the wall data/sample collection and inspection procedures are presented in section 5.3.

Walls with the most commonly used kinds of insulation were to be inspected and tested, and they had to have been insulated for at least three years prior to the start of the study. Uninsulated walls were also examined as a control group to see if there was a greater likelihood of a problem with insulated walls than with uninsulated walls. No homes were considered with vapor barriers on the inside of the walls or in the wall cavity. Thus, homes were excluded if they had any kind of wall paper or covering or gypsum board with aluminum foil backing. The usual exterior plywood sheathing or 3.5 pound felt was considered a moisture (liquid) barrier rather than a vapor barrier (strictly speaking, exterior plywood acts like a vapor barrier). Paint on the inside wall surfaces might have provided a vapor barrier, but the water vapor permeance of the paint was not measured. Selecting homes without vapor barriers was done intentionally to determine whether or not a problem existed in the first place. If no significant problem was discovered in walls without vapor barriers, there would be no need to look further. If a problem was discovered, then 
further studies could be prepared to determine whether a vapor barrier is an effective method of dealing with that problem.

Moreover, homes with a variety of types of heating systems were to be examined, including those with and without infiltration caused by the need for combustion air. Only homes with either a basement or a crawl space with a ground cover were considered. There is already substantial evidence which shows that in the Northwest, ground covers are necessary in crawl spaces to prevent excessive moisture from entering homes. Moreover, slab floor construction is not common in the area.

Ninety-six test homes were selected as the minimum number required to produce statistically valid findings within the constraints of a reasonable budget. Four holes were to be opened from the outside in each house, providing what appeared to be a sufficiently large data set. A clear effort was made to avold the kind of study that looks at just a few homes and then makes heroic assumptions to qeneralize to the larger population of homes. Nonetheless, it was realized that even with four holes in each of 96 homes the sample size was still relatively small, and the data simply might not provide clearcut answers. At the very least, however, the results would be of great use in deciding what sample size would be necessary if further studies were required and in developing a methodology that could be used in future studies.

While the original study design provided for test homes to be situated in several communities in oregon and Washington west of the Cascade Range, it was decided to select test homes only within the Portland metropolitan area in order to complete the study program within the allocated budget and time constraints. Furthermore, if homes were selected from more than one urban area, differences in weather during the test period could lead to significant uncontrolled variance in the test results. Looking to the possible outcomes of the study, there would he little lost in limiting the test to one city. A cunclusive finding that the lack of a vapor barrier in insulated homes in Portland definitely does or does not create moisture problems probably would be accepted as applicable throughout the Northwest, west of the Cascades, since the weather and construction methods are quite similar. If it were concluded from the study that problems definitely exist in Portland, that would likely justify code or legislative changes throughout the western portion of the region. On the other hand, either indefinite or ambiguous findings could result in additional study that might include an evaluation of intraregional variances such as those between arnas enst and west of the Cascades. Actually, it was anticipated that a similar study looking at conditions east of the mountains or in other colder climates would be considered at a later date.

Since project funding was not begun until early January 1979, walls were scheduled for opening in February, March and early April at a rate of two to three homes (four holes per home) per 
day. It was presumed that the highest moisture content would be found during those months (Ref. 4). Moreover, it was assumed that there was considerable opportunity for condensation to occur within the insulated wall cavities of Portland homes. An analysis of the opportunities for condensation to occur during the test year in Portland and elsewhere in the region is presented in section 8 .

In addition to looking for actual moisture damage such ás wood decay, high moisture content and the presence of decay fungi were also looked for as possible indicators of future problems. This was felt to be important since some of the homes would have had insulation in the walls for only three years, and in those situations the chances of $f$ inding advanced cases of moisture damage might not be good.

\subsection{Project Organization}

Seton, Johnson and Odell, Inc. (SJO) served as the prime contractor for this study, with Glen Odell as SJO's Principal in Charge. Dr. George Tsongas of Portland State University, working as a consultant to SJO, served as Project Manager with responsibility for overall direction of the technical program. Mitzi Scott organized and supervised the telephone prequalification survey and conducted the in-home interviews associated with the final qualification survey. SJo's project engineer, Charles Hoar, served as logistical coordinator for the field program as well as inspecting engineer for many of the home openings. Kevin Marshall and John Garrick provided engineering backup to $\mathrm{Mr}$. Hoar on coordination and field work. Professional assistance. in developing methods of opening and closing test areas, as well as provision of skilled carpenters for the field program, was provided by the Neil Kelly Co., Portland contractors specializing in residential remodeling. Dr. John Stryker of Applied Social Research, Inc. was in charge of statistical data analyses. Bode inspection Company was engaged for bioassays of wood core samples, while Aquatech Laboratories determined the moisture content of insulation and wood samples.

The organization of these assignments is shown graphically in Figure 1.1. It also indicates the role of representatives of the various agencies, utilities, and contractor associations contributing to the study as participants in a client group advisory committee. Jim Thompson of the Oregon DOE served as the contact between the contractor and this advisory group as well as being the contract monitor for the project.

The work steps occurred in four main phases: planning, field survey, data analysis, and reporting. The schedule of these steps is shown in Figure 1.2 . 


\section{FIGURE I.I PROJECT ORGANIZATION}

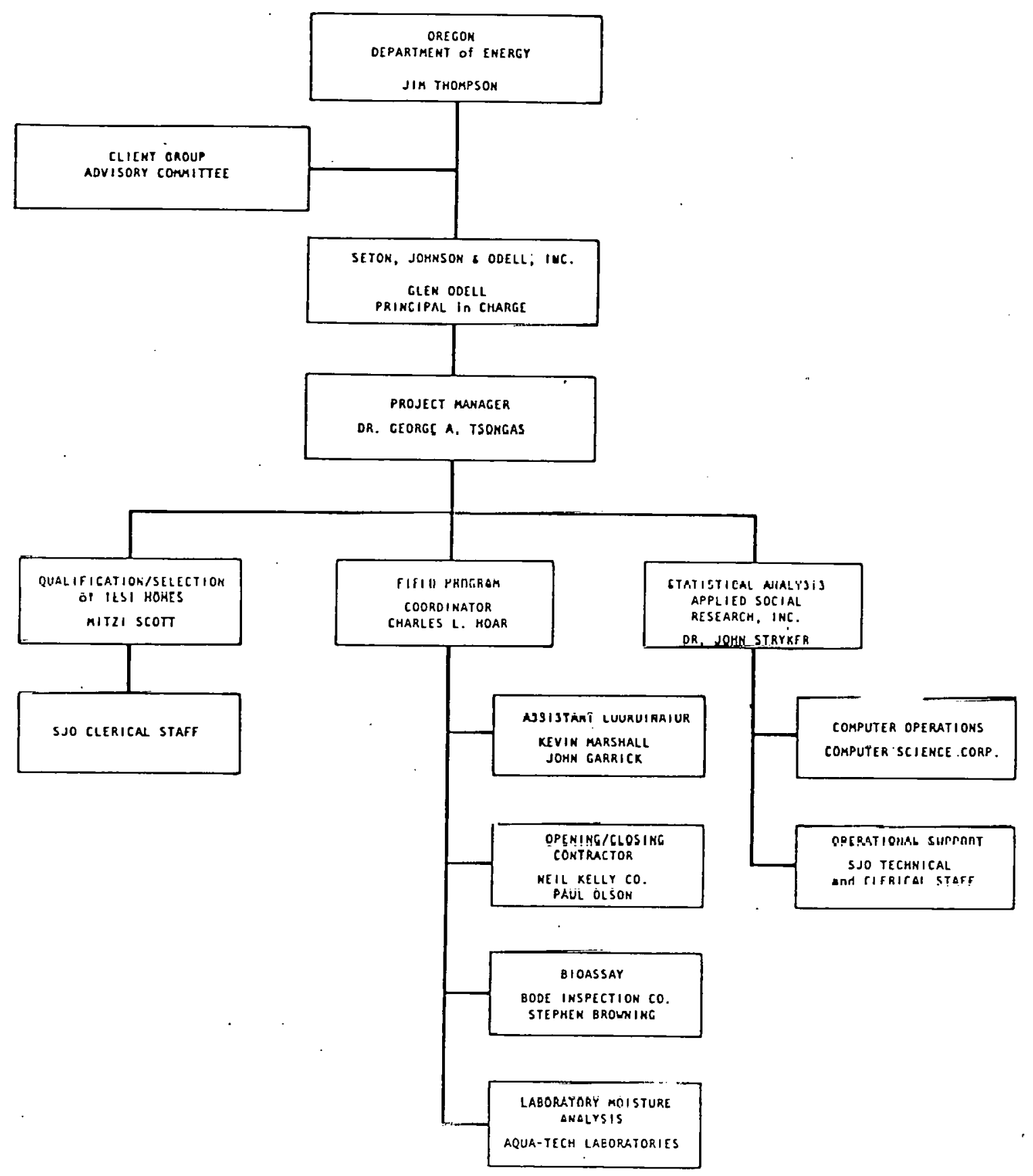


FIGURE 1.2 SCHEDULE

\begin{tabular}{|c|c|c|c|c|c|c|c|c|c|}
\hline PHASE $1-$ PLANNING & JAN & FEB & MARCH & APRIL & MAY & JUNE & JULY & $A \cup G$ & SEPT \\
\hline \multicolumn{10}{|l|}{ Literature Review } \\
\hline \multicolumn{10}{|l|}{ Selection of test homes } \\
\hline \multicolumn{10}{|l|}{ Criteria } \\
\hline \multicolumn{10}{|l|}{ Notice to Homeowners } \\
\hline \multicolumn{10}{|c|}{ Telephone Prequal, Survey } \\
\hline \multicolumn{10}{|c|}{ Qualification Visit/Inspection } \\
\hline \multicolumn{10}{|l|}{$\cdot$} \\
\hline \multicolumn{10}{|l|}{ Develop methodology } \\
\hline \multicolumn{10}{|l|}{ Draft S.O.P. } \\
\hline \multicolumn{10}{|l|}{ S.O.P. Review } \\
\hline \multicolumn{10}{|l|}{ Field Test S.O.P. } \\
\hline \multicolumn{10}{|l|}{ Finalize S.O.P. } \\
\hline \multicolumn{10}{|l|}{ Prepare data analysis } \\
\hline \multicolumn{10}{|l|}{ Statistical criteria } \\
\hline \multicolumn{10}{|c|}{ Data processing methodology } \\
\hline \multicolumn{10}{|l|}{ Raw data needs } \\
\hline \multicolumn{10}{|l|}{ PHASE 2 - FIELD SURVEY } \\
\hline \multicolumn{10}{|l|}{ Field openings } \\
\hline \multicolumn{10}{|l|}{ Laboratory analysis } \\
\hline \multicolumn{10}{|l|}{ PHASE 3 - DATA ANALYSIS } \\
\hline \multicolumn{10}{|l|}{ Data preparation } \\
\hline \multicolumn{10}{|l|}{ Initial data analysis } \\
\hline \multicolumn{10}{|l|}{ Final analysis } \\
\hline \multicolumn{10}{|l|}{ PHASE 4 - REPORTIHG } \\
\hline \multicolumn{10}{|l|}{ Eraft report } \\
\hline \multicolumn{10}{|l|}{ Review } \\
\hline Final Report & & & & & & & & & \\
\hline
\end{tabular}




\section{FINDINGS AND CONCLUSIONS}

This section summarizes the major findings of the field study and the conclusions drawn from them. The basic conclusions are presented in the following order:

- moisture content and moisture damage: no moisture problem is related to wall insulation retrofitting in Pacific Northwest homes with wood siding.

- retrofit insulation characteristics: installation quality was observed to be poorer than expected and considerable foam shrinkage was observed.

- air leakage rates: adding wall insulation markedly reduce air leakage.

- overall desirability of adding wall insulation to existing homes: questions raised in this report, including differences in moicture content among insulated types, gualiey of installation, shrinkage, and others, need to be answered before this issue can be conclusively decided.

\subsection{Wood and Insulation Moisture Content Findings}

\section{1 .1 Field Results}

Valid data were obtained from 93 of the 96 test homes evaluated in the study. The average indoor relative humidity of 56.28 was relatively high. The wood moisture content both on the surface and in the interior of the plate, sheathing, and a stud was measured in four exterior wall openings in each of the 93 homes. An RF surface type moisture meter was used to locate the wall opening sites in the areas of highest moisture content within the total wall surface of each home. Of major importance to this study is the fact that there were very few readings of high moisture content, with no values greater than 208 found in 1559 measurements. The mean values for all stud, plate, and sheathing measurements were $11.68,11.98$, and 12.18 , respectively. The overall average of $11.8 \%$ is typical of moisture contents found in framing members in the Pacific Nor thwest (Ref. 5, 6).

It is important to note that the data from 22 holes ( 12 houses) out of the total of 372 holes were not used because in each of those cases some type of water leak was found, such as a roof leak or gutter leak or bathroom leak that might have biased the data. In come of those caseg moisture conlifint. aliur 2 no anoinr moisture damage was found. In addition, numerous other leaks were found during the initial home inspections when the RF type moisture meters were used to select opening sites with the highest mosture content; no openings were made in those leaky areas. 


\subsubsection{Laboratory Results}

Wood samples were taken and laboratory analyzed for moisture content as a check of the Delmhorst moisture meter used in the field tests. The two sets of results are in close agreement, with the laboratory results consistently slightly lower

(by $0.7 \%$ ) as expected.

Insulation samples were also taken from each hole and analyzed for moisture content. The average moisture contents for 50 samples of mineral wool, 33 samples of cellulose, and 159 samples of U-F foam are $0.18,13.48$, and 11.78 , with ranges of $0-28,6-18 \%$, and 6-228, respectively. The results for mineral wool are in good agreement with those from summer wall openings in Minnesota (Ref. 7), as are the results for cellulose and U-F foam. The fact that the mineral wool stays relatively quite dry may mean that it will provide the best thermal insulating properties of the three types tested in walls with moisture migration since it is generally recognized that the thermal properties of insulation degrade with increased moisture content (see, for example, Ref. 8).

\subsection{Moisture Damage Findings}

During the home inspection prior to the wall openings, a number of signs of possible moisture damage were visually observed, including wood decay, warped siding and dry wall, blistering and peeling paint, wood staining or discoloration, mold and mildew, rusting of nails, and leaks around water, sewer, and electrical connections. Moreover, almost half the homeowners said that they had had previous moisture problems. These signs of moisture damage were especially prevalent where leaks were found during the home inspection or during wall openings. Even in those leak cases, however, there was relatively little actual wood decay. However, in spite of the frequent occurrence of those external signs of moisture damage, for those wall openings where leaks had not occurred there was essentially no evidence of high moisture content or moisture damage within the wall cavities.

Thus, while there were numerous suggestions of moisture damage outside the wall cavities, there was no correlation between them and the existence of moisture damage within the cavities. There was no visual evidence that the addition of wall insulation in existing homes leads to moisture damage inside or outside the wall cavity. In fact, just the opposite may be true. Comparison between insulated homes and uninsulated homes of the occurrence of pre-opening signs of moisture problems indicates that evidence of moisture in the attic, blistering paint, and previous moisture problems were found less frequently in the homes with insulation than in those without. There was no significant different in the frequency of occurrence of the other signs noted. 
Since decay fungi must be present in or on wood for decay to occur, three wood core samples from each hole were collected and cultured in the laboratory to determine if decay fungi were present. Only two samples out of 1071 had decay fungi present. One of those was in a foam-insulated house and the other in an uninsulated home, and neither was accompanied by high moisture content measurements or visual signs of decay.

\subsection{Moisture Problem Conclusions}

The purpose of this study was to determine scientifically and objectively if the addition of wall insulation without a vapor barrier caused moisture damage in existing homes in the western portion of the Pacific Northwest. The fact that virtually no incidence of high moisture content, moisture damage or decay fungi was found inside the walls of homes opened during this field study strongly suggests that there is no such problem. While moisture damage was found in both insulated and uninsulated walls, it was always caused by a leak of one sort of another that usually was not noticed by the homeowner. There also was a fair amount of moisture damage on the exterior of the walls, but there was no corresponding damage inside the wall cavities. Moreover, the external damage could not be attributed to the addition of wall insulation.

An analysis of the opportunities for condensation to occur in the insulated walls of the portland test homes during the test winter and in previous winters was conducted, and considerable opportunities were found to exist. Furthermore, the field test results and conclusions should apply throughout the western portion of the Pacific Northwest because of the similiarities in climate and housing construction. It is not obvious that the results of this study can be extended to colder climates.

These field test results suggest that it is not necessary to add a vapor barrier when insulating the walls of existing homes in the Pacific Northwest. However, it should be emphasized that vapor barriers are beneficial in newly constructed homes to keep some insulation materials dry so they can provide their maximum thermal benefit and to substantially reduce

infiltration losses and save energy - especially since in well-insulated homes infiltration losses still can be the major source of energy loss.

\subsection{Retrofit Insulation Characteristics}

\subsubsection{Uj-F Foam Shrinkage}

During the wall openings, U-F foam shrinkage was measured. The foam was 3-5 years old in 798 of the cases. The mean shrinkage in thickness (nominal 3-5/8") measured in 78 holes in 32 homes was $10.5 z$, with a range of 38 to 258 . The mean shrinkage in width (nominal 14-1/2" cavity spacing between studs) from 109 holes in 41 homes was 8.18 , with a range of 3 to 198 . 
Measuring vertical shrinkage (nominal $8 \mathrm{ft}$. height) was attempted, but it was hard to distinguish between actual shrinkage and a possible void at the top of the wall cavity due to incomplete filling. Partial voids due to incomplete filling were often found. In the roughly two dozen cases where it was reasonably sure that only shrinkage had occurred, the mean value was about 88 ; unfortunately, it was not possible to tell if that value was too small due to insulation cracks hidden between the upper and lower holes.

It should be pointed out that such shrinkage and cracking of U-F foam can have a considerable effect on the thermal performance of walls insulated with foam. Based on the fact that shrinkage does occur, the U.S. Department of Housing and Urban Development and the Canadian government have derated the nominal R-value of U-F foam by $28 \%$ and $40 \%$, respectively (Ref. $9,10)$; in a conventional wall that corresponds to an increase in heat loss of about $33 \%$ or 548 , respectively (Ref. 11). The shrinkage measured in this study would correspond to an even larger increase in heat loss.

\subsubsection{Insulation Installation and settling}

Generally speaking the quality of installation of all types of insulation was poorer than expected. Numerous empty cavities between studs were observed in many of the insulated homes during the wall openings, in spite of the fact that there was essentially no special effort to locate such voids. Infrared thermography was used in a few cases to check for incomplete filling, and in those cases many voids were noted.

In addition to finding completely empty wall cavities, numerous cases of only partially filled wall cavities were noted with U-F foam. A few instances of what appeared to be incomplete filling, rather than settling, were also observed in the installation of cellulose and mineral. wool.

The finding of voids in many of the Portland test homes means that the heat loss from retrofit insulated walls is very likely much greater than the heat loss that would occur if the wallswere completely filled with insulation. While the amount of uninsulated area as a function of the total wall area was. not determined in this study, it is important to note that the influence of insulation voids on the magnitude of wall heat loss can be surprisingly substantial. For example, for a wall with R-1l insulation, if 108 of the total area of the wall is uninsulated (which is not uncommon), the heat loss increases by about slightly more than one-third (Ref. 11). This fact emphasizes that need for improved quality control of insulation installation.

\subsection{Fan Depressurization Air Leakage Tests}

Believing that the relative air tightness or leakiness of the test homes might be an important parameter in this moisture 
study, air leakage tests were run on many of the test homes using a door-type fan depressurizaton unit. However, there was no statistically significant correlation between the measured leakage rates and the moisture content of either wood or insulation.

For the 71 homes tested (vents and fireplace dampers closed, furnace off), air leakage rates determined at the standard pressure differential of 50 Pascals $\left(0.200\right.$ inches $\left.\mathrm{H}_{2} \mathrm{O}\right)$ ranged from 2,370 to 19,170 cubic meters per hour, with a mean value of 4,444 ; the number of air changes per hour ranged from 5.5 to 31.0 with a mean value of $13.1 / \mathrm{hr}$. That mean value agrees closely with values measured elsewhere in similar homes using essentially the same test equipment (Ref. 12), but it is consideraby larger than the current Swedish standard of $3.0 / \mathrm{hr}$ maximum that requires continuous plastic vapor barriers as an effective energy conservation measure (Ref. 13).

A possibly important and serendipitous finding of the study is that, based on a comparison nf infiltration ratce of 18 unjinsulated homes and 53 insulated homes, the addition of wall insulation appears to reduce air leakage significantly. Thus, the energy loss associated with infiltration would be reduced; and yet this energy saving is seldom, if ever, accounted for when analyzing conservation options. Cellulose reduced air leakage the most and mineral wool the least; however, even the addition of mineral wool provided a substantial reduction relative to leakage in uninsulated homes. The reduced infiltration would appear worthy of further study to determine how it affects the cost effectiveness of wall insulation.

Finally, these results provide further evidence that considerable air leakage occurs through walls, at least in older homes without vapor barriers. Methods of calculating infiltration rates based only on window and door leakage most likely produce incorrect answers.

\subsection{Overall Desirability of Retrofitting Wall Insulation}

The findings and conclusions of this field study appear to resolve the question of possible moisture damage associated with the addition of wall insulation in existing homes wlthout a vapor barrier, at least for most homes in the western regions of the Pacific Northwest. However, the advisability of retrofitting wall insulation is still not completely settled since numerous other problems exist, and many questions are yet unresolved. Of major importance is the fact that the effect of moisture migration on the thermal performance of wall

insulation is still not well understood. It would appear that mineral wool remains quite dry and thus should perform as rated. While settling appears minimal, incomplete filling of all types of insulation in wall cavities is a critical problem that strongly influences the overall performance of insulated walls. The performance of $U-F$ foam is further degraded to a considerable extent because of the existence of voids due to shrinkage. 
In the face of these and other problems, the present study can offer no firm guidance on the ultimate question of whether retrofitting wall insulation is worthwhile. That moisture damage is not produced by the addition of wall insulation (at least in the western region of the Pacific Northwest) seems clear; that some insulation types are preferable to others also is evident. Pending further studies of the questions outlined above, however, the energy and cost effectiveness of retrofitted wall insulation can appropriately be considered an open question.

As a policy recommendation it seems appropriate to suggest that retrofitted wall insulation continue to be viewed as it is currently viewed - a relatively low priority conservation technique that is probably worthwhile doing in the long $r$ un. Intensive promotion or acceleration of installations, however, should be delayed, until it is conclusively determined that it is advantageous to do so, from both an economic and energy conservation point of view. The importance of making such a determination is underscored by the incidental finding of this study that there is a very large population of houses in Portland that have uninsulated walls and hence offer a potentially large market for wall insulation.

\subsection{Methodology For Future Studies}

Procedures have been developed during this field study that should aid others in future studies of a similar nature. Especially important are methods for soliciting and screening participants, meters for locating high moisture content or moisture damage in walls, and procedures for data/sample collection, recording, and statistical analysis.

\section{RECOMMENDATIONS FOR FUTURE STUDIES}

Based on the results of this study and others, a number of topics appear worthy of continued or new study. A repeat of this study in a colder climate should have a high priority. There is reasonable doubt as to whether or not similar findings would occur in a more severe climate with greater condensation opportunities. Spokane, Washington might be an ideal city because the climate is considerably colder than that of Portland, it is large enough to get a sufficient number of test homes, and results from there should apply to most of the middle west and northeastern United States (Condensation zone II).

It would also appear worthwhile to undertake a series of limited moisture etudies in Portland homes having construction characteristics substantially different from those tested in the present study. Most of the Portland test homes had wood exterior siding, with a few having a combination of wood and brick (all wall openings were in wood siding only). Yet homes with aluminum, brick or T-l-ll plywood siding have a 
considerably lower permeability of the outside portion of the wall cavity. In some cases, aluminum siding is applied directly over a continuous layer of aluminum foil. In such cases the opportunities for moisture condensation are greatly increased and the opportunities for natural drying are decreased. Mobile homes might be particularly susceptible to such moisture problems, especially in view of their relatively small surface area. In such cases, the results of this study might not be appropriate. Thus, a small follow-up study on homes with aluminum siding would be worthwhile.

Based on the fact that numerous insulation voids and empty wall cavities were found in this study, a more thorough multi-faceted investigation of installation quality would seem in order. First, an in-depth infrared thermography study (uccd in conjunction with a blower door unit during mild weather) of walls could be performed on a relatively large sample of retrofitted homes to determine the mean uninsulated void area. Those results could then be combined with avajlahle tata on the relationship between insulation voids and incrcased heat luss to provide a re-evaluation of the economic attractiveness of wall insulation as it is actually being installed. The results of such a study would tell utilities or government agencies how much they could afford to finance for wall insulation retrofitting programs. Finaliy, various means of improving j.nstallation quality control. could then be investigated.

Last of all, it is important to emphasize the need for more study of the effect of moisture as it migrates through walls on the thermal performance of the wall insulation. Some studies have been undertaken, but the state of knowledge in this area is still incomplete. It wolld he extremely worthwhile to measure local heat flux and insulation moisture content simultaneously and more or less continuously in a wall. section for an extended period of time, and then correlate the resul.ts.

\section{SELECTION AND DESCRIPTION OF TEST HOMES}

\subsection{Introduction}

The study called for examining the walls of 96 homes in the Purtland metropolitan area. Because the success of the study was entirely dependent upon voluntary participation hy individual homeowners, a specific and careful.ly targetted public information and citizen participation program was developed to enlist the interest and support of the public. Each home was selected through a series of four sequential processes: a direct mail effort to inform and solicit potential study participants; examination and screening of questionnaires to determine eligibijity of volunteered homes; completion of in-home interviews to determine and verify technical data; and finally, opening walls for inspection and collection of data and samples. 


\subsection{Criteria for Selection}

The initial study design reflected in the ODOE Request for Proposals document prescribed a set of criteria for selection of test homes. This initial set of criteria was successively modified or relaxed during the course of the home solicitation process in order to provide a total sample population of adequate size. This section describes the selection criteria as initially formulated and as they were relaxed.

\subsubsection{Initial Criteria}

The original study design proposed a test sample of 96 homes meeting the following criteria:

a) Distribution among insulation types was to be as follows:

24 - homes not insulated

24 - homes insulated with urea-formaldehyde foam

24 - homes insulated with cellulose

24 - homes insulated with mineral wool (either rock wool or fiberglass)

b) In each group of 24,12 were to have forced air, ducted systems consisting of:

1) Combustion systems utilizing inside air

2) Combustion systems utilizing outside air

3) Electric forced air with ducts outside the heated space

These were grouped together and labelled "ducted" because all three systems tend to reduce the amount of moisture in the air inside the home because of infiltration through the building shell or through ducts.

The remaining 12 houses out of each group of 24 were to have "non-ducted" systems which included primarily electric resistance heaters that distribute warm air by convection without ducts, and also any electric forced air systems with all ducts within the heated space. These systems tend to have higher indoor humidities due to the absence of infiltration through ducts and the lack of infiltration due to a need for combustion air.

c) All insulated homes were to have been retrofit with insulation at least 3 years earlier.

d) All homes were to have no vapor barriers in the walls.

e) All homes were to have a crawl space with a ground cover (vapor barrier).

f) All homes were to be occupied by three of four persons.

g) All homes were to have less than 1300 square feet of floor space. 


\subsubsection{Relaxed Criteria and Other Test Home Characteristics}

Shortly after the solicitation and screening process began it became apparent that the desired total sample of 96 homes would not be met if the original criteria were maintained. Finding a sufficient number of homes that met the original criteria proved to be most difficult. Selected criteria were successively relaxed, with ODOE and advisory committee approval. The final sample met the following criteria, listed in order corresponding to $(\mathrm{a})-(\mathrm{g})$ in 4.2 .1 above.

a) Distribution among insulation types:

$\begin{array}{ll}\text { Uninsulated } & 25 \\ \text { U-F foam } & 43 \\ \text { Cellulose } & 10 \\ \text { Mintral wnnl } & \frac{15}{93}\end{array}$

The last of the 96 houses opened was found to have a vapor barrier inside the wall cavity and so its data was not included. In addition, the data from two other houses (one uninsulated and one $U-F$ foam) was voided because leaks were found in the vicinity of all four openings. The final number of valid test homes for which data was included was 93.

b) Of the entire sample population only eleven homes were non-ducted, while 82 had ducted systems. Nonetheless, the average indoor relative humidity of $56.2 \%$ for all the homes was relatively high. The breakdown of the various heating system typee ic as follows:

Ducted systems:

Oil forced air

Oil hot water/steam

Natural gas

Wood stove

Oil stove

38

14

27

2

1

Non-ducted systems :

Electric resistance

Electric forced air, all

ducts within heated spaoc:

Non heat pump

Heat pump
5

4

The test home solicitation process gemonetrated one intuitively assumed characteristic of Portland's housing stock - that the vast majority of uninsulated and retrofit-insulated homes are older homes heated with gas and oil forced air systems; 538 of the homes were between 20 and 40 years old, while 408 were over 40 years old. The majority of electrically heated (unducted systems) homes are newer units built originally with wall insulation, and hence not available to the study population. 
c) All insulated homes were retrofitted at least 3 years prior to the study. The average age of the insulation is shown in Table 4.1 below.

Table 4.1 INSULATION AGE DISTRUBUTION

\begin{tabular}{lccc}
\hline Age (yrs) & U-F & Cellulose & Mineral Wool \\
\hline $3-5$ & 798 & 908 & 538 \\
$6-9$ & 168 & - & 208 \\
GT10 & 58 & 108 & 278 \\
\hline
\end{tabular}

d) All homes had no vapor barrier on the inside wall surface, such as plastic sheet, aluminum foil, or vinyl wallpaper. All except one home had wood (or wood and brick) exterior siding. Most all had a 15\# felt moisture barrier just inside the siding. The majority had lapboard sheathing, but 12 homes had plywood sheathing.

e) 75 homes had full or partial basements and 29 homes had heated basements. Among the 37 homes with a full or partial crawl space were 11 homes without ground covers in the crawl spaces; they were included as a means of testing for overt moisture effects of not having a ground cover.

f) No limitations were placed on the number of occupants. The average sample home was occupied by 3 persons, with $93 \%$ housing 4 or fewer persons.

g) No limitations were placed on size of home; however, $88 \%$ had 2200 square feet of living area or less, while $57 \%$ of the test homes had less than 1500 square feet.

In addition to the above characteristics which were controlled in the selection process, an additional group of factors with direct bearing on energy consumption and moisture accumulation were identified in the course of the study. Taken together, they provide a profile of the typical portland study test home as one which:

- had ceiling insulation and storm windows but no underfloor insulation

- had weather stripping around doors but not around windows

- did not have air conditioning

- had a fireplace or wood stove in use 
A statistical summary of these and other variables is included in Table 4.2.

TABLE 4.2 ENERGY CONSERVATION CHARACTERISTICS OF TEST HOMES

\begin{tabular}{lc} 
& Yes $(q)$ \\
\hline Lower thermostat at night & 91.1 \\
Use fireplace & 63.4 \\
Use wood stove & 14.0 \\
Use humidifier & 6.5 \\
Use dehumidifier & 3.2 \\
Central air conditioning & 12.9 \\
Window air conditioner & 17.4 \\
Kitchen exhaust instal.led & 77.2 \\
Use kitchen fan & 56.9 \\
Use bathroom exhaust fan & 46.2 \\
Showerhead restrictor & 16.1 \\
Ceiling insulation & 95.6 \\
Ceiling insulation vapor barrier & 27.5 \\
(kraft or foil) & 14.0 \\
Floor insulation & 15.7 \\
Duct insulation & 72.8 \\
Storm windows & 16.3 \\
Window weatherstripping & 96.7 \\
Door weatherstripping & \\
\hline
\end{tabular}

\subsection{Solicitation of Test Homes}

\subsubsection{Selection of Target Populations}

Those persons first contacted and solicited to participate in the study were employees of three sponsors of the project: Bonneville Power Administration (BPA); Pacific Power \& Light Co. (PP\&L); and Portland General Electric Co (PGE). In-house letters were prepared by appropriate staff members and sent to all employees residing in the immediate portland area. The letter informed people about the project, briefly explained its methodology and purpose, and solicited participation through an accompanying questionnaire which was to be filled out and retilrned.

While the number of questionnaires returned from BPA, PP\&L, and PGE was encouraging, it became apparent almost immediatcly that with less than 18 of the volunteered insulated homes qualifying, there would have to be a substantial increase in the size of the pool from which volunteers could be solicited. There was no problem obtaining an ample supply of uninsulated homes for the control group from the initial solication.

In order to obtain additional insulated homes, Seton, Johnson \& Odell (SJO) embarked on an extensive public information participation cffort. Various mailing lists were reviewed and it was determined with the cooperation of the oregon 
Environmental Council (OEC) that all OEC members should receive an invitation to participate in the study. The strategy in targetting these particular groups for solicitation was based on their immediate accessibility, as well as on the belief that a high response rate could be achieved from individuals who had demonstrated an interest in the environment and/or energy conservation.

Through the efforts of Dr. Tsongas, all Portland state University faculty and staff received a similar mailing. Neil Kelly Co. also expanded the size of the potential pool by contacting and soliciting various building contractors and home insulators, seeking the names of past clients. Unfortunately, the building contractors and home insulators proved, ajmost without exception, uncooperative in supplying the names of homeowners who had insulated their walls. All pleaded legal restrictions in abstaining from participation, on the grounds of possible lawsuits arising from findings (which might or might not be moisture related) of the study.

While the response from this additional mailing was excellent, the problem of identifying and securing a sufficient number of insulated homes remained critical. This difficulty was discussed at length at the February meeting of the advisory committee. Options for solving the dilemma included: decreasing the required number of insulated homes, relaxing certain criteria to allow more homes to qualify, producing a mass mailing to solicit more participants, lengthening the time period allotted for conducting wall openings, and terminating the study for lack of sufficient insulated homes. The consensus of the group was to conduct a mass mailing to some 30,000 PP\&L customers, and to lengthen the time period (to capitalize on the mailing) for conducting the openings by two weeks to mid-April. It was hoped that, although the PP\&L list was not targetted in any way and the anticipated response rate was thus very low, a return rate of $1 / 2$ to 18 would produce enough insulated homes to complete the study, justifying the effort and expense. The clark County (Washington) Public Utility District also provided a mailing to its employees. When these efforts failed to produce the needed homes, a final mailing to sierra club members was made to help secure the final few houses.

Unfortunately, the response rate from the final mass mailings fell well below 18 , leaving the study short of its required number of insulated homes. In an effort to pick up more homes, the decision was made to further relax some criteria specifically the requirement of a vapor barrier in crawl spaces, Equally instrumental in the decision, it should be noted, was the desire to secure more mineral wool and cellulose houses. Nearly double the initially required number of foam houses had been inspected due to the lack of non-foam homes. Opening more foam-insulated houses was unlikely to produce any findings that had not already been uncovered. Opening more mineral wool and cellulose homes was important in order to give better balance to the mixture of insulation types in the data base. 
To complement the direct mail effort throughout the study period, press releases were prepared and distributed to radio, $T V$, and print media in the portland area. Information about the study was accompanied by an appeal to homeowners to volunteer for the study by contacting the Oregon Department of Energy by a toll-free number; persons making this contact were mailed an informational letter and questionnaire. One press "event" was programmed by inviting local TV stations to witness the wall opening process at a predetermined house. Although only one station covered the story (another station subsequently attended another opening), the newspapers also picked up and carried news of the project. Although neither the media coverage nor the public response to it reached the levels hoped for by the study team, it was unquestionably helpful and resulted in a number of homes being volunteered for the study and a significant number of openings.

\subsubsection{Introductory Letter and Questionnaire}

Inltial contact with potential participants was purposely made in writing, rather than by telephone. It was felt that individuals would need a qood deal of backqround information before feeling secure enough to volunteer their homes. Such information was far too lengthy and complex to try and deliver in a phone conversation. Specific strategy was utilized in constructing the contents of the letter and accompanying questionnaire. Its message was threefold: inform about the study; briefly explain its purpose, methodology, and potential findings; and clearly and persuasively articulate the advantages of participating in the project. A copy of the letter and questionnaire is included in Appendix J.0.2. While a choice of qifts (hot water heater wrap or shower flow restrictor) was offered to participants, this was not intended to be the main vehicle of persuasion; rather, the emphasis was on providing a one-time-only opportunity for the homeowner to benefit from a free, professional service which could reveal unique information about his/her home.

The fact that the study was sponsored by the oregon Department of Energy, rather than by a private business, minimized suspicions of unknown or hidden profits (and costs), adding substantial credibility to the project. Letters were printed on ODOE stationery and while it was something of a logistical headache, all questionnaires and phone calls were directed to ODOE, then forwarded to Seton, Johnson \& Odell for processing. Credibility with the public more than compensated for this inconvenience. In retrospect, and judging from volunteered responses, the two points that proved most appealing and persuasive were: no one else (business, agency, etc.) was available to do these inspections and provide information on such a personal basis; the service was free, resulting in a frequently voiced "why not?" response from homeowners. 


\subsubsection{Response to Solicitation}

Table 4.3 summarizes the results of the solicitation process in terms of response to the initial letter. It shows clearly the importance of both the targetted and untargetted efforts to secure the total sample population. In retrospect, one is tempted to conclude that a computerized mass mailing to 100,000 utility customers, combined with a media program to stimulate interest and visibility, might have been the most cost effective and timely means of securing the sample population.

\subsection{Screening, Interviewing and Scheduling}

\subsubsection{Initial Review and Telephone Prequalification}

As noted earlier, all questionnaires were sent by homeowners directly to the Oregon Department of Energy, which immediately forwarded them to seton, Johnson \& Odell. for screening. This additional step delayed processing for a few days, but to have had the return address be that of a private company might have seemed contradictory to information presented in the letter, possibly jeopardizing the credibility of the study. Similarly, all phone calls were directed (in the letter and media) to ODOE, which provided information and sent questionnaires if requested, but did no actual screening.

For purposes of control. and uniformity, all questionnaires were reviewed by one person, the project coordinator. While it was easy to determine at a glance if a home did not qualify, identifying homes that did meet all criteria was quite a lot more difficult and time consuming. Consistency was assured by having one person making all judgmental decisions regarding estimates, variations in criteria, and analysis. Most questionnaires were quickly discarded after a cursory review because the home failed to meet one or more of the major criteria. The common areas of shortcoming were: no insulation (the quota for these homes was quickly satisfied); insulation that was installed too recently; crawl spaces that had no vapor barrier (a criteria that was later relaxed). Of those that survived the first screening, very few decidedly appeared to mcet all criteria; most fell into a "possible" category and had to be checked further to fill in unanswered or ambiguously answered questions on the form. While most of the "possibles" were eventually eliminated, all homes that appeared to have the slightest chance of qualifying were checked with a follow-up phone call.

Most of the follow-up telephoning had to be conducted in the evening or on weekends in order to find the homeowner at home. The purpose of the call was to verify information that had been given on the guestionnaire, fill in any empty blanks, and ask a few further questions. A copy of the phone checklist is included in Appendix 10.2 . 
TABLE 4.3 RESPONSE TO SCLICITATION

Questionnaires Number No. Qualified for Opaning

Sent Resfonding Insulated Uninsulated Gross Response Net Response

Employees of Sponsors

$\begin{array}{lrr}B P A & 1800 & 94 \\ P P \& L & 2080 & 223 \\ P G E & 26 C 0 & 104\end{array}$

PGE

$26 C 0$

223

104

CCPUD

$3<0$

\section{Direct Mailings}

\section{OEC Members}

PSU Staff

Neil Kelly

PP\&L Customers

$\stackrel{1}{N}$

Sierra Club Members

$\begin{array}{rr}1100 & 264 \\ 1500 & 58 \\ 150 & 5 \\ 30.000 & 945 \\ 200 & 21\end{array}$

16
4
4
21
2

Rate I

Rate 2

Response to Media Appeals

135

10

$5 \%$
10
4
.02

$1 \%$

1

24

0

02

40,365

1.756

$77^{3}$

1614

lGross resporse represents the percentace of lette:s sent cut wich resulted in a questionnaire being returned.

${ }^{2}$ Net response represents the percentaje of letters sent out which resulted in a home being qualizied for opening.

3Quota of insulated homes was 72. This ficure incilides 5 foam houses t.2at qualified, but were not opened due to an excess of fzam romes.

${ }^{4}$ Quota for uninslilated homes was 24. - This figure irdicated the large excess of qualified uninsulated homes. 
Fewer than $5 \%$ of the "possibles" actually qualified for inspection. Most homes were disqualified at this point in the process because, a] though the home was insulated, insulation had been installed at the time of construction and almost without exception had a vapor barrier. Even though it was clearly stated on later questionnaires that the study required only retrofit houses, homeowners. failed to see or understand this requirement. Many homes, therefore, that initially appeared to qualify or were "possibles" had to be discarded.

It is worth noting that the follow-up phoning produced far less hesitance or reluctance from homeowners than had been anticipated. Because the letter of notification had clearly spelled out the purpose and process of the study, people were not surprised or frightened at the prospect of the actual. openings. A few homeowners expressed reservations, had questions or needed reassurance; a very few decided they were not interested in the study after all. Almost without exception, such reluctance was expressed by persons who had not, for one reason or another, received the initial letter and therefore had no background information. Such negative responses also confirmed the belief that random telephone solicitation to persons unaware of the study - a process that would be exceedingly time-consuming and expensive - would likely have proved fruitless. People who received the letter apparently made a fairly firm commitment to participate in the study at the time they returned the questionnaire.

\subsubsection{Qualification Interview and Initial House Inspection}

If the follow-up phone call verified that a house appeared to meet all necessary criteria, the homeowner was asked to set a time at his/her convenience when representatives from seton, Johnson \& Odell (an interviewer and an engineer) could inspect the home and gather necessary data prior to scheduling the wall openings. While the engineer inspected the attic, basement or crawl space, checked the interior and exterior walls of the house for signs of moisture damage, and took temperature readings, the interviewer asked questions and filled out a checklist profiling characteristics of the house as well as the lifestyle (e.g. use of fireplaces, kitchen fans, etc.) of its occupants. Copies of the checklists used are included in Appendix 10.2

While the primary purpose of the initial inspection was to gather technical data about the home, a secondary, yet extremely important task, was to establish person-to-person contact between Seton, Johnson \& Odell - which was identified as responsible for the final inspection and wall openings - and the homeowner. People wanted to know exactly who would be opening the walls before entrusting the exterior of their homes to would-be strangers. An important objective of the interview, therefore, was to instill in the homeowner a sense of familiarity and trust about the project in general and the consultant in particular. 
Special efforts were made to enable the homeowner to feel comfortable with the project. At the outset of the interview, the homeowner was handed an "Information Sheet" explaining the study and listing the name and phone number of the project coordinator at Seton, Johnson \& Odell. to contact should any questions come up. Although few people actually called in with questions, the fact that they knew they could was reassuring, and these gestures of openness, cooperation, and willingness to explain were greatly appreciated. In addition, during the interview/inspection both sJo representives made a special effort to explain what they were doing, why they were asking such questions, how equipment worked, etc.

At the conclusion of the interview, if the house continued to meet criteria, homeowners were asked to read and sign a consent form provided by Neil Kelly Co., whose carpenters would actually be doing the openings. A copy of the consent form is included in Appendix 10.2. This form, it was explained, was mainly a formality and detailed how the openings would be accomplished. It also contained a mutual self-protection clause, stating that should moisture problems be found, the owner would not hold Neil. Kelly responsible; conversely, should Neil Kelly prove negligent in any way, the homeowner would have due recourse. While nearly all people were willing to sign after reading the form, a few expressed reluctance, a desire to share it with a spouse, or time to reread it. If such resistance was encountered, homeowners were never pushed or pressured to sign, but given a self-addressed stamped envelope and asked to mail in the form. The homeowner was given a copy of the form and before leaving, the engineer advised people exactly where the openings would be made. If objections or questions were raised, changes or accomodations were made then, rather than at the time the carpenters arrived for the openings.

\subsubsection{Determination of Opening Locations}

One of the major tasks accomplished during the inspection was the determination of the two main locations for wall openings. The selection of wall sites with the highest moisture content, where decay would be most likely to occur, was based upon readings from two similar RF surface type moisture meters. The Delmhorst Model RF-2 (a prototype model with increased sensitivity on loan for the project duration) and the Moisture Register Company Model PM8F meters were moved along the inside sheet rock surface of all outer perimeter walls (high and low), and the relative moisture content of the walls was mapped out. The meters indicated the location of studs or other wood members, and also areas of high moisture content within the wall cavity. When high moisture content was noted, the wall and its surroundings were carefully inspected. In all cases, excessively high moisture content was subsequently traced to such things as roof. or gutter leaks into the wall cavity or leaks around bathtubs. Walls were not opened in those locations where high moisture content was clearly due to leaks. When no leaks were found the location was noted as an opening site. Later during the opening a further check was made for leaks. 
It should be noted that the RF meters used might not always sense high moisture content on the far side of the wall cavity (e.g. in the sheathing) due to limitations in their range of penetration. However, it was felt that if high moisture content (say above 20\%) existed in the sheathing, wicking would occur such that the studs or plates or even the dry wall would also have relatively high moisture content that would be detectable. The field experience and wood moisture content data subsequently seemed to verify this point.

An Omega Controls microwave moisture meter was also tried but did not appear to work as well and was extremely inconvenient to use; its use was discontinued after the first ten houses were inspected. In addition a Hughes probeye infrared thermographic unit was tested in several cases as a possible aid in locating regions of high moisture content. However, its use was limited during the periods of mild winter weather characterizing much of the study period, because the temperature difference across a wall was not large enough to provide a good image without the simultaneous use of a blower door. In general the RF meters provided a reasonable indication of any high moisture accumulations, whereas the results with the probeye were inconclusive.

The results of the visual inspection and/or homeowner interviews also identified exterior signs of possible moisture or rot (e.g., blistered paint, warped siding, and termite or dry rot damage), and openings were often located in those areas. When no regions of relatively high moisture content were discerned with the various instruments, or when external signs of moisture damage were not visible, an effort was made to make openings in walls of high moisture production rooms such as bathrooms and kitchens, or in north walls where moisture would be most likely to accumulate (Ref. 4). However, other factors such as accessibility, visibility, ease, or homeowner desires sometimes became most important in the choice of opening locations when no signs of high moisture or damage were apparent. Whatever the method for selecting the location of the wall openings, two main sites were selected and noted for the opening crew. As it turned out, the wall openings were very even]y distributed in all four or ientations (N, W, E, S).

\subsubsection{Scheduling of Wall Openings}

Wall openings were scheduled approximately a week after the initial inspection was completed. Two and sometimes three houses per day were opened, with a schedule for the entire week prepared in advance. The openings began on February 2, 1979 and were completed on April 11, 1979; 26, 43 and 27 homes were opened in the months of February, March, and April, respectively. The major logistical problem encountered was scheduling openings at homes where no one was home during the daytime. Other problems arose when the homeowner insisted on being present at (and was available only at certain times) or participating in the opening. Every effort was made to 
accomodate the homeowner's wishes and schedule, and although time-consuming and tedious, these efforts paid off when not a single home had to be eliminated, nor was a single day or half day wasted due to a cancellation or inability to meet the homeowner's needs.

Prior to the opening of the walls, a file folder was prepared on each home. It contained several. sheets: a brief profile of the house, checklists from the initial inspection detailing where the walls were to be opened, the consent form. The folders were taken to the openings where additional checklists reflecting findings at the inspection were added. Pictures were taken and included, as well as results of the fan pressuration test. By the end of the study, each folder represented a "case history" of each house. Since all homes were assigned an identification number at the time of the initial interview, recording and retrieving information was simplified.

\section{4 .5 Followup}

Upon analysis of samples taken from each home, individual homeowners were notified of the results in a personally addressed letter. Unless something unusual was discovered at the house, the letter was standardized. Included with the letter was a form requesting homeowners to indicate their choice of which free gift they wanted to receive. Many expressed no interest in the gift, their primary motivation for participating in the project having been an interest in the condition of their home and the desire to take advantage of the free inspection and analysis. Participation in the project also entitled caoh homcowncr to a summary of the final report explaining the findings and recommendations of the entire study.

\section{TEST METHODOLOGY}

\section{5.]. Development of Test Methodology}

A standard procedure for the field testing and the home interview/inspection was developed and refined using several homes as a proving ground. A common crew, consisting of an engineer, a senior journeyman carpenter and a carpenter's helper were trained by the project manager. The training and consistent use of the same personnel resulted in an efficient and uniform opening and data/sample collection procedure. The major steps in the procedure are indicated in checklist \#3 (in Appendix 10.2), which was used in the field to provide a checklist as well as a data sheet for the completion of specific tasks.

\subsection{Wall Opening}

The walls of each test home were opened from the outside in the two locations selected during the initial house inspection. At each main location two openings were made - one near the first 
story ceiling height just below the upper plate and one near the floor just above the lower plate. Each opening was about 16 inches wide (one stud space) and about 12 inches high. The carpenter carefully removed the exterior siding and then cut through the exterior moisture barrier (typically 15\# felt) and the wood sheathing (typically $1 \times 8$ lapboard or plywood).

\subsection{Data Collection and Recording}

The data collection and recording was actually begun while the carpenter opened the wall. Indoor and outdoor $d r y$ and wet bulb temperatures were measured with a sling psychrometer; the corresponding indoor and outdoor relative humidities were found from a psychometric chart.

Immediately upon opening each hole, a sample of insulation was removed from the wall cavity and sealed full in a $100 \mathrm{ml}$ glass jar. The sample was removed quickly to avoid any change in its moisture content and treated carefully to avoid contamination with skin or other moisture. The samples were later gravimetrically analyzed in a laboratory for moisture content. The next step was the measurement of the surface and interior temperature of the plate, one stud, and the inside of the sheathing. An Alnor thermocouple probe with digital pyrometer was used to determine the wood temperatures, which were required to correct the wood moisture content readings. The wood moisture content of the plate, stud, and sheathing was then measured using a Delmhorst Model 26E penetrating resistivity-type probe with insulated pins. Measurements at both the surface and the interior of the wood were made so that if high moisture content was found, then an indication of its relative age might be discernible. To check the Delmhorst meter readings, wood samples were chiseled from the edge of the plate, stud and sheathing, then wrapped tightly in plastic film and sealed in a glass jar; their moisture contents were later gravimetrically analyzed. Finally, wood core samples were taken from the plate, stud, and sheathing with a simple leather punch. The samples, about $3 / 16$ inch in diameter and $1 / 4$ inch long, were sealed and stored in plastic straws and refrigerated until they were cultured in a laboratory to determine the presence or absence of decay fungi.

During the time the walls were opened and closed at many of the test houses, a fan depressurization unit (designed by Dr. David Harrje of Princeton University and provided by U.S. DOE) was installed in a doorway and the house slightly depressurized. By varying the pressure drop across the fan at known fan speeds, a measure of the "leakiness" or infiltration loss characterlstics of d liouse was ascertained. The pressure drop typically ranged from 0 to 0.500 inches of water in increments of either 0.025 or 0.05 inches of water. The fan deployment and test took about fifteen minutes to one-half hour. 


\subsection{Wall Closure}

Upon completion of the sample taking and measurements, each opening was closed up using the original materials, or appropriate substitutes in the few instances where siding was damaged during removal. Cracks were caulked and matching paint was applied in such a fashion that in most cases there was no visual evidence that the wall had ever been opened.

\subsection{Laboratory Analysis}

One sample of insulation and three wood samples for each wall opening were analyzed gravimetrically for moisture content by placing in an oven at 100 degrees $C$ and drying to a constant weight. The percentage moisture content (MC) by weight of each sample was determined on a dry basis from the relation:

$$
M C=\frac{W w-W d}{W d} \times 100
$$

where Ww and Wd are the wet and dry weights of the material, respectively. The minimum net sample weight was about one gram. The samples were analyzed as they became available each week throughout the test period. Three wood core samples from each hole were also bioasseyed to determine the presence or absence of decay fungi. All the core samples were kept in refrigeration and cultured at the same time at the end of the test period.

\section{STATISTICAL DATA ANALYSIS METHODOLOGY}

\subsection{Data Analysis Procedure}

A series of steps was followed in the data analysis:

1. Data collected in the field was edited and prepared for key punching.

2. Data was key punched.

3. A Statistical Package for the Social Sciences (SPSS) computer file was defined on a Computer. Science Corporation computer.

4. The data was read into the computer file.

5. The computer file was dumped and manually checked with original documents to insure 1008 integrity.

6. Frequency distributions on each variable were produced. This resulted in a profile of the homes investigated.

7. Bi-variate tests of correlation and significance were executed for all independent and each dependent variable. 
8. Independent variables which are significantly related to the dependent variables were identified and included in subsequent analyses.

9. Factor analysis was employed to identify any clusters which may exist among "significant" independent

variables. By employing a varimax rotation as part of the factor analysis, factors could be identified which constitute the greatest commonality or overlap among variables in a cluster and which also have the greatest dissimilarity to other factors.

10. All. independent variables significantly related to each dependent variable were included in a multiple regression equation.

11. For each dependent variable, the extent to which presence/absence and type of insulation "explains" variability was determined. The "explanatory" power of these variables was compared to that of other variables found to be significantly related to the dependent variables.

The analysis was conducted by Dr. John Stryker and Mr. Richard Rankin with the assistance of Dr. Greg Markus, who is also affiliated with the Institute of Social Research of the University of Michigan.

\subsection{Variables Included}

The study included 8 dependent variables per hole:

Moisture content in stud surface
Moisture content in stud interior
Moisture content in plate surface
Moisture content in plate interior
Moisture content in sheathing surface
Moisture content in sheathing interior
Insulation moisture content ( 1 measurement per hole)
Presence/absence of decay fungi (l measurement per hole)

The independent variables included in the analysis include all those items noted in Checklists 1, 2, and 3 (see Appendix 10.2).

\subsection{Choice of Statistical Tests}

The basic statistical test utilized in the analysis was multiple regression. Multiple regression facilitates, an analysis which gauges the "explanatory power" of each" independent variable separately (e.g. how much moisture content variability is accounted for by the type of wall insulation existing in the study population). Multiple regression allows a comparison analysis of the "explanatory power" of several. independent variables (e.g. does type of wall insulation "explain" more moisture content variability than is "explained" 
by interior relative humidity, and, if so, how much more variability is explained by type of wall insulation than interior relative humidity). In addition, multiple regression identifies the cumulative effects of a series of independent variables in explaining variability in a dependent variable (e.g. how much moisture content variability is accounted for by type of wall insulation, interior relative humidity, and infiltration rate?).

The variables included in the multiple regression analysis were those which were found to be significantly related to the dependent variables. "Significant relationship to the dependent variable" was determined by bi-variate (one dependent and one independent variable) analysis and significance test. Factor analysis and correlation analysis were executed for those "significant variables" to identify how extensively those items overlap or co-vary. Where several items were found to over lap, they were treated as a single factor in the subsequent analysis. When the multiple regression equations were formally executed, they included only variables known to be significantly related to the dependent variable and only "factors" which did not extensively overlap.

\subsection{Structure of the Analysis}

The final analysis had two broad aspects. The first major dimension was a study of how extensively the various dependent variables are inter-related. The second, bottom line analysis, was a study of relationships between independent and dependent val iables.

\subsection{Interpretation of the Analysis Findings}

The statistical analysis was originally intended to determine if a "significant difference" exists between homes which have been insulated without a vapor barrier and the control group of homes without insulation. The results indicated there was no alfference. The statistical analysis also attempted to identify what "accounts" for moisture levels found in side walls. This portion of the analysis basically involved an attempt to build a "model" which "explained" moisture in structural members and insulation material. This analysis included, but was not limited to, insulation type. The results, therefore, suggest how important insulation was in explaining moisture in side walls when compared to other factors. The model used to "explain" moisture in structural members could be compared to the model developed to "explain" moisture in insulation material. 


\section{RESULTS}

\subsection{Wood and Insulation Moisture Contents}

\subsubsection{Field Results}

In each wall opening the wood moisture content of the plate, sheathing, and stud both on the surface and in the interior was measured using a Delmhorst moisture meter. The meter is factory calibrated for use with a four pin electrode in Douglas $f$ ir at a temperature of 70 degrees $F$, so that it is necessary to correct for species and temperature if those conditions are not met. Hence, the temperature was also determined at each location where moisture content was measured. The moisture readings were then corrected for temperature. A small correction was also made to account for use of the meter with two insulated electrode pins rather than four. The combined correction seldom changed the value by more than one or two percent. No correction was made for type of wood since most of the wood tested was Douglas fir.

The results for the corrected wood moisture content are presented in Table 7.1. The -1 and -3 holes were lower wall openings, whereas the -2 and -4 were upper openings. The mean values for all stud, plate, and sheathing measurements were $11.6 \%, 11.9 \%$, and 12.18 , respectively. As expected, the sheathing had the highest moisture content, but it was not markedly higher. The average upper hole moisture content of 11.48 was slightly lower than the 12.28 average of the lower holes. Holes with a north orientation averaged $12.1 \%$, those with south exposure averaged $11.4 \%$, while those with east-west facings averaged 11.98; these differences are in agreement with Duff's results (Ref. 4) and were expected because of the southerly winter winds in portland. In addition, the interior values were consistently about one percent higher than the surface values. This appears consistent with the fact that wood generajly has a higher interior moisture content. The overall wood moisture content mean was 11.88 , as noted in Table 7.2. The mean values of wood moisture content measured in the field are presented by insulation type in that table. No significant differences were found between the wood in holes with the different kinds of insulation or in uninsulated holes. For reference purposes, air-dry wood typically has 12 to 158 moisture content (Ref. 14), and framing members in the Northwest typically fall in the range of 10 to 128 (Refs. 5, 6).

of major importance in this study is the fact that there were very few readings of high moisture content. Moisture content of about 208 or higher is generally required before decay will occur (Ref. 1). Yet no readings greater than 208 were found out of 1559 readings. The highest instrument measured moisture content was $20 \%$, and that occurred in only one case. 
TABLE 7.1 WOOD MOISTURE CONTENT IN WALL OPFNTNGS

\begin{tabular}{|c|c|c|c|c|c|c|}
\hline \multirow[b]{2}{*}{$\begin{array}{l}\text { Hole } \\
\text { No. }\end{array}$} & \multirow[b]{2}{*}{ Wood Member } & \multirow[b]{2}{*}{$\begin{array}{l}\text { Valid } \\
\text { Readings }\end{array}$} & \multicolumn{3}{|c|}{ Moisture Content ( $\left.\frac{o}{0}\right)$} & \multirow{2}{*}{$\begin{array}{l}\text { Number of } \\
\text { Readings } \\
\text { MC. } \geqslant 20 \%\end{array}$} \\
\hline & & & Avg & $\operatorname{Max}$ & Min & \\
\hline-1 & $\begin{array}{l}\text { Stud Surface } \\
\text { Stud Interior } \\
\text { Plate Surface } \\
\text { Plate Interior } \\
\text { Sheathing Surf. } \\
\text { Ehcathing Int. }\end{array}$ & $\begin{array}{l}89(87) \\
88 \\
88(86) \\
88 \\
70(71) \\
2\end{array}$ & $\begin{array}{l}11.5(11.0) \\
12.1 \\
11.6(11: 2) \\
12.6 \\
11.9(11.3) \\
14.5\end{array}$ & $\begin{array}{l}16(18) \\
16 \\
17(20) \\
17 \\
18(16) \\
16\end{array}$ & $\begin{array}{l}6(4) \\
7 \\
8(8) \\
7 \\
7(7) \\
13\end{array}$ & $\begin{array}{l}0(0) \\
0 \\
0(1) \\
0 \\
0(0) \\
0\end{array}$ \\
\hline-2 & $\begin{array}{l}\text { Stud Surface } \\
\text { Stud Interior } \\
\text { Plate Surface } \\
\text { Plate Interior } \\
\text { Sheathing Surf. } \\
\text { Sheathing Int. }\end{array}$ & $\begin{array}{l}89(89) \\
88 \\
59(54) \\
57 \\
72(72) \\
2\end{array}$ & $\begin{array}{l}10.7(10.2) \\
11.6 \\
10.8(10.0) \\
11.7 \\
12.0(11.1) \\
14.5\end{array}$ & $\begin{array}{l}17(19) \\
16 \\
15(14) \\
16 \\
18(30) \\
15\end{array}$ & $\begin{array}{l}6(8) \\
8 \\
8(7) \\
8 \\
8(7) \\
14\end{array}$ & $\begin{array}{l}0(0) \\
0 \\
0(0) \\
0 \\
0(1) \\
0\end{array}$ \\
\hline-3 & $\begin{array}{l}\text { Stud Surface } \\
\text { Stud Interior } \\
\text { Place Slurface } \\
\text { Plate Interior } \\
\text { Sheathing Surf. } \\
\text { Sheathing Tnt }\end{array}$ & $\begin{array}{l}87(85) \\
87 \\
85(82) \\
85 \\
70(68) \\
3\end{array}$ & $\left\{\begin{array}{l}11.9(11.1) \\
12.7 \\
11.8(10.9) \\
12.6 \\
12.4(11.3) \\
12.3\end{array}\right.$ & $\begin{array}{l}19(23) \\
19 \\
20(15) \\
20 \\
18(20) \\
15\end{array}$ & $\begin{array}{l}7(8) \\
9 \\
8(8) \\
9 \\
6(7) . \\
1.1 .\end{array}$ & $\begin{array}{l}0(2) \\
0 \\
1(0) \\
1 \\
0(1) \\
0\end{array}$ \\
\hline-4 & $\begin{array}{l}\text { Stud Surface } \\
\text { Stud Interior } \\
\text { Plate Surface } \\
\text { Plate Interior } \\
\text { Sheathing Surf. } \\
\text { Sheathing Int. }\end{array}$ & $\begin{array}{l}89(87) \\
88 \\
51(44) \\
47 \\
72(71) \\
3\end{array}$ & $\begin{array}{l}11.0(10.4) \\
11.6 \\
11.1(9.9) \\
11.8 \\
11.9(10.7) \\
13.0\end{array}$ & $\begin{array}{l}16(31) \\
17 \\
15(13) \\
16 \\
18(19) \\
15\end{array}$ & $\begin{array}{l}8(7) \\
7 \\
7(7) \\
9 \\
6(6) \\
11 .\end{array}$ & $\begin{array}{l}0(1) \\
0 \\
0(0) \\
0 \\
0(0) \\
0\end{array}$ \\
\hline
\end{tabular}

Note: The values shown without parantheses were obtained from the Delmhorst moisture meter, whereas the values in parentheses were obtained from laboratory analysis of wood samples taken from corresponding locations.

-1 and -3 are at bottom of wall cavity.

-2 and -4 are at top of cavity. 
TABLE 7.2

WOOD MOISTURE CONTENT FIELD RESULTS BY INSULATION TYPE

\begin{tabular}{|c|c|c|}
\hline & \multirow{2}{*}{\multicolumn{2}{|c|}{$\begin{array}{l}\text { Moisture Content }\left(\frac{\circ}{6}\right) \\
\text { Mean Std. Deviation }\end{array}$}} \\
\hline Insulation Type & & \\
\hline Mineral Wool & 11.8 & 1.52 \\
\hline Cellulose & 11.6 & 1.52 \\
\hline U-F Foam & 11.8 & 1.8 \\
\hline All Insulated & 11.8 & 1.74 \\
\hline Uninsulated & 11.7 & 1.50 \\
\hline All Homes & 11.8 & 1.68 \\
\hline
\end{tabular}

Note: Figures are average instrument-determined moistures for plate, stud and sheathing for all holes.

It is important to note that the data from 22 holes ( 12 houses) out of 372 holes were voided and not presented in Table 7.1. In each of those cases some type of water leak such as a roof leak or gutter leak or bathroom leak was found that might have biased the data. Those leaks were discovered after making the wall openings; they had not been noted during the initial home inspection when opening sites were determined. In some, but not all of those leak cases, high moisture content and/or moisture damage was found, but it was directly attributable to the leak. Moisture contents in those situations ranged as high as $30 \%$ in one case where the sheathing was soaking wet; however, in all other cases the highest reading was $23 \%$. Leaks were found in homes with all insulation types as well as uninsulated homes. It should also be reiterated that numerous other leaks were found when the RF surface type moisture meter was used to select opening sites. No openings were made in those leaky locations.

\subsubsection{Laboratory Results}

Wood and insulation samples were taken during the wall openings for laboratory analysis of their moisture content. The wood samples were taken from wood surfaces and analyzed as a check of the Delmhorst meter used in the field tests. The wood moisture content results are noted in parentheses in Table 7.1. The two sets of results are in good agreement, with the laboratory results consistently slightly lower $(0.78)$ than the surface field results. There are two jikely explanations for that behavior. First, the moisture content readings were always made in the field as soon as the wall was opened and 
exposed to the cool. outside air. The wood samples were taken some 5 to 10 minutes later, and some drying due to vapor loss to the air might have occurred prior to removing the sample. Moreover, the Delmhorst meter tends to read the highest moisture content in the area between the probe pins.

It should be noted that the maximum moisture content values determined from the wood samples exhibited slightly more scatter than the corresponding meter readings. However, only six samples out of the total of 896 had a moisture content equal to or greater than 208. It is believed that the two large values of $30 \%$ and $31 \%$, and perhaps others, must be in error because wood with that high a moisture content would be notably wet, and such was not the case. The samples might somehow have been contaminated or incorrectly measured. The meter readings were generally more consistent and would appear to be more valid.

In addition to taking wood samples for laboratory analysis of moisture content, insulation samples were taken and analyzed for molsture content. 'l'he results for each type of insulation are presented in Table 7.3 ; no results are presented for those holes invalidated because of leaks.

\section{TABLE 7.3 INSULATION MOISTURE CONTENT}

\begin{tabular}{|c|c|c|c|c|c|}
\hline \multirow{2}{*}{ Insulation Type } & \multirow{2}{*}{$\begin{array}{l}\text { No. of } \\
\text { sampios }\end{array}$} & \multirow[b]{2}{*}{ กท. } & \multicolumn{3}{|c|}{ Moisture Content (o) } \\
\hline & & & Мак. & Min. & Etd. Dev. \\
\hline Mineral Wonl & 50 & 0.1 & 2 & 0 & 0.4 \\
\hline Cellulose & 33 & 1.3 .4 & 18 & $\dot{6}$ & 2.4 \\
\hline $\bar{U}-\bar{F}$ Foam & 159 & 11.7 & 22 & 6 & 2.6 \\
\hline
\end{tabular}

The average moisture content of all the insulation samples was 9.5\%. Only two samples out of the 242 total had a moisture content of $20 \%$ or higher; those values were 208 and $22 \%$ and occurred in U-F foam. There were no significant differences among insulation moistures as $f a r$ as orientation and topness or bottomness of holes is concerned.

One of the more interesting results is the extrememly low average moisture content of the mineral wool insulation. Each houce had concistent results in all four holes, dild in nu case did the moisture content get above 28 . The weighing procedure was carefully checked, and there appeared to be no systematic measurement crrors. These results are in excellent agreement with those obtained by Weidt (Ref. 7); in that case four samples of mineral fiber insulation were removed from wall openings and were found to have moisture contents of less than 
18. The low moisture may be connected to the fact that the homes with mineral wool insulation had the highest mean air leakage rate of the three insulation types (see section 7.7). Probably, however, the result is more attributable to the fact that mineral wool is not hygroscopic, whereas the cellulose and $\mathrm{U}-\mathrm{F}$ foam both tend to retain moisture. Jespersen (Ref. 8) has measured the thermal conductivity of moist mineral wool and found that for 0.18 moisture content, the thermal performances would be essentially unaffected by moisture. Thus, it should perform as normally rated.

There was also a statistically significant (by T-test) percentage difference between the moisture content of cellulose and U-F foam, although the absolute difference may not be important. Weidt (Ref. 7) found the moisture contents of six samples of cellulose taken from homes in Minnesota varied from less than 18 to $6 \%$ with an average of 38 ; the moisture content of twel.ve U-F foam samples varied from 18 to 128 with an average of $5 \%$. Whil.e the Portland and Minnesota results differ somewhat, there is fairly close agreement with the results of Rossiter, Weidt, and saxler (Ref. 14) obtained from homes in a number of areas throughout the country during springtime. They found that the moisture contents of eight samples of celiulose had a mean value of 11.28 with a range of $8.8 \%$ to $13.4 \%$, and twenty-five samples of $U-F$ foam had an average moisture content of 12.18 with a range of 3.28 to 228 .

\subsubsection{Statistical Analysis Results}

The objective of the statistical analysis was to identify which plysical characteristics of the sample houses and living patterns of the owners had a significant effect on the moisture contents found in the structural members and insulation of the homes.

of primary interest is the role of insulation type in determining insulation moisture content. This is shown in Table 7.3, which shows substantial and statistically significant differences in the moisture content of different insulation types. On the other hand, the differences in wood moisture associated with different insulation types are very small (see table 7.2).

The differences between the average moisture contents of wood members of uninsulated, mineral wool, cellulose, and U-F foam insulated houses are neither statistically significant nor physically consequential. Furthermore, the variation in moisture content of wood members within any given insulation type is so small as to make detailed analysis of it an interesting statistical exercise of limited practical value. Nevertheless, substantial effort was put into it as a means of extracting the maximum value from the data base.

As detailed in section 6, the first step in the data analysis was bivariate correlations of independent variables with the 
two dependent variables (structural and insulation moisture). This involved determining whether a statistically significant relationship existed between moisture in structural members and factors thought to be related to moisture, such as number of occupants in the house, indoor temperature, orientation of the wall, number of showers taken daily, and insulation types. A similar analysis was executed comparing all factors thought to be related to insulation moisture for insulated homes. The results of these analyses are presented below. The items in each 1 ist are those variables significantly related to moisture. Variables found not to be significantly related to moisture are summarized in Appendix 1.0.3. The variables below are ordered according to the strength of the relationship existing between that factor and each moisture type. The sign $(+,-)$ indicates whether the relationship is positive or negative. For example, the negative relationship noted below indicates that as the number of windows increases, insulation molsture would be expected to decrease.

SIGNIFICANTLY RELATED

TO WOOD MOISTURE

- Presence of a basement

- Topness of hole's location in wall

- Whether the thermostat is lowered at night

+ Presence of electric heat

- Use of humidifier

- Southern orientation of the hole

- Existence of leaks in the floor

+ Number of showers taken daily

+ Number of occupants in the house

+ Presence of siding other than all wood

- Outside temperature at time of field measurements

- presence of window weather stripping

+ Whether the basement is heated

+ whether the ceiling has vapor barrier

- Use of a wood stove

- Presence of a kitchen fan

+ Indoor relative humidity at time of field measurement

+ Northern orientation of the hole

- Absence of celling insulation
SIGNIFICANTLY RELATED

TO INSULATION MOISTURE

- Number of windows in the house

- Age of the house

+ Presence of siding other than all wood

- Presence of leaks in the floor

+ Indoor temperature at time of field measurement

+ Non-heat pump, non-ducted heating system

- Abeencc of ceiling insulation

- Hollse sjize in square fret

- Presence of a wood floor

- Indoor relative humidity at time of field measurement

+ Presence of storm windows

+ Presence of central air conditioning

+ Presence of carpets

- Presence of a crawl space without a vapor barrier

+ Number of haths taken daily

- Presence of a basement

- Gas ducted heating system

- Outside temperature at tlme of field measurement 
+ Day time thermostat leve]

+ Presence of window air conditioning

+ Use of a bathroom fan

+ Electric heating system

- Whether the thermostat is lowered at night

+ Presence of a crawl. space with a vapor barrier

It is interesting to note that a number of factors which were related to insulation moisture were not related to wood

moisture. Among these items, the number of windows, age of the house, and size of the house were not related to wood

moisture. Each of these factors was related in a statistically significant way with the incidence of insulation moisture --

the more windows in a house, the lower the insulation moisture; the older the house, the lower the insulation moisture; the larger the house, the lower the insulation moisture. Two factors which were found extremely important in explaining structural moisture (topness/bottomness of the hole and north/south orientation) were not related to the incidence of insulation moisture.

Multiple regression analyses were completed to measure the extent to which these factors accounted for wood moisture and insulation moisture variability. Leaving aside insulation type, only 23.58 of all wood moisture variability could be explained by the 19 variables $(76.5 \%$ of the variability could not be explained by the combination of all 19 variables at once). Including insulation type extends our explanatory power to only $28.6 \%$ of all wood moisture variability.

We therefore conclude that the majority of the small observed variation in wood moisture results from random distribution and is not subject to modeling or explanation by the variables measured in this study.

The regression analysis related to wood moisture identified cellulose insulation, presence of a basement, U-F foam insulatiun alla topness/bottomness of the wall. opening as the factors most strongly related to moisture level. Interestingly, every one of these variables is negatively related to moisture: controlling for other factors, homes with cellulose and U-F foam have lower wood moisture than other homes; homes with basements tend to have less moisture; the top parts of walls have less moisture than the bottom parts of walls.

Although the 19 variables explain less than a quarter of the wood moisture variability, they explain enough to support a conclusion, based on the data, that for comparable locations in walls of home with comparable physical characteristics, one would predict less moisture in the wood members of insulated 
homes than in uninsulated homes. If the differences were large enough to be physically significant, this would be an extremely important and controversial conclusion; but as we have said, the differences are minimal and the conclusion is therefore not important.

The regression analysis related to insulation moisture produced results similar to those for wood moisture when controling for insulation type. All factors other than insulation type accounted for only 21.98 of the moisture variability in insulation. However, the type of insulation accounted for a great deal of the variability. If one were making predictions about relative amount of insulation moisture, one would not be appreciably more accurate knowing everything about a house (i.e. all variables in the study) including the type of insulation than simply knowing the type of insulaton (84\% of all insulaton variability explained versus $86.4 \%$ ).

Among the most important findings emerging from the statistical analysis are the importalle of cellulose and, to a eomcwhat lesser degree, $\tilde{U}-\mathrm{F}$ fnam in "explaining" moisture. These two insulation types are strongly negatively related to structural moisture and very strongly related to insulation moisture. If a home has either cellulose or U-F foam, structural member moisture is likely to be slightly lower than homes with mineral wool insulation or no sidewall insulation. Similarly, the insulation material itself is likely to be much more moist than mineral wool. A hypothesis which emerges from this analysis is that cellulose and U-F foam side wall insulation eerves as a molsture buffer -- absorbing moisture which would otherwise accumulate in the structural members of side walls.

\subsection{Moisture Damage}

\section{2 .1 Types}

Prior to opening any walls, a number of possible types of moisture damage were anticipated, including actual wood decay inside and outside the wall cavity, warped siding and/or dry wall, blistering and peeling paint, wood staining or discoloration, evidence of mold or mildew, termite or ant activity, corroding and rusting of nails and wire, and leaks around water, sewer, and electrical connections. Later, the opened wall cavities and the corresponding walls were inspected for signs of any of the above. In addition, moisture content data and wood samples were taken to test for high mnisture content and the pressence of decay fungi, the existence of which might point to potential future moisture problems.

\subsubsection{Visual Observations}

During the initial home inspection and interview, a relatively large number of possible moisture damage indicators were found in a number of homes. The frequencies of occurrence are presented in Table 7.4. 


\begin{tabular}{lc}
\hline \multicolumn{1}{c}{ Category } & $\begin{array}{c}\text { Frequency of } \\
\text { Occurrence in } \\
\text { Homes (8) }\end{array}$ \\
\hline Evidence of Discoloration \&/Or Staining in Attic & 15 \\
Warping of Siding \&/or Dry Walj. & 27 \\
Stained Interior \&/or Exterior Surfaces & 34 \\
Blistering \& Peeling of Paint & 39 \\
Evidence of Mold or Mildew & 33 \\
Evidence of Ant or Termite Activity & 10 \\
Evidence of Dry Rot - Wood Decay & 17 \\
Corroding \& Rusting of Nails, Wire, Etc. & 31 \\
Foundation Cracks & 11 \\
Leaks Around Water, Sewer, \& Electrical & 46 \\
Previous Moisture Problems (Homeowner Asked) & \\
\hline
\end{tabular}

It should be noted that previous moisture problems were frequently reported by homeowners. However, the type or extent of the problems is not known.

As noted earlier, during the wall openings a number of wall cavities were found to be adversely affected by a variety of leaks rather than by the addition of insulation. In many of those cases a number of the above noted types of moisture damage were observed. Even in those cases, however, there was relatively little actual wood decay. For those wali openings where leaks had not occurred, there was essentially no evidence of high moisture or moisture damage within the wall cavities. Only one small spot of wood decay about three inches in diameter was found, and that occurred in an uninsulated house and appeared to have been in the original lumber. Thus, while there were numerous suggestions of moisture damage outside the wall cavities, there was no correlation between them and the existence of moisture damage within the cavities due to retrofitting blown-in insulation. There was no visual evidence that the addition of wall insulation in existing homes leads to moisture damage, either inside or outside the wall cavity. In fact, just the opposite may be true. Comparison between insulated and uninsulated homes of the occurrence of pre-opening signs of moisture problems indicates that evidence of moisture in the attic, blistering paint, and previous moisture problems were found less frequently in the homes with insulation than in those without. There was no statistically significant difference in the frequency of occurrence of the other signs noted in table 7.4 .

\subsubsection{Presence of Decay Fungi}

Since decay fungi must be present in order for wood decay to occur, wood samples from each hole were taken for a laboratory 
bioassay (culturing) to determine if decay fungi were present or absent. Of the 1071 wood core samples, only two had decay fungi present. One was found in the upper hole shcathing of a U-F foam home, while the other was in the stud of an upper uninsulated hole. In neither case were there any signs of high moisture or moisture damage. It should be noted, however, that other non-decay fungi and bacteria were commonly present in the samples, but not decay fungi.

\subsection{Other Damage}

A number of other problems or damage of interest to the homeowners were uncovered during both the home inspection and wall openings. Numerous assorted leaks were discovered, including roof leaks, gutter leaks (with some full gutters overflowing behind the soffit and into the wall cavity), various bathroom leaks, and leaks through holes in siding. Most of those leaks were directly attributable to homeowner neglect; however, the homeowners were often unaware nf the existence of the leaks. In addition to lcaks, a number of homes or walls were found to have termites, carpenter ants, and even beetles in the foam insulation in one case.

\subsection{U-F Foam Shrinkage and Voids}

During the openings of homes with U-F foam, shrinkage in thickness (nominal $35 / 8 "$ ), width (nominal 14 l./2" cavity spacing between studs), and height (nominal $8 \mathrm{ft}$.) was measured. The results for thickness and width are given in Table 7.5. Top holes are -2 and -4 , whereas bottom holes are -1 and -3 .

TABLE 7.5 U-F FOAM SHRTNKAGE

\begin{tabular}{lcccccc} 
Shrinkage & Hole & No. of & \multicolumn{3}{c}{ Shrinkage $(\dot{8})$} \\
Dirertion & Number & Cagca & \multicolumn{2}{c}{ Avg } & Max & Mint \\
\hline \multirow{2}{*}{ Thickness } & -1 & 25 & 10.0 & 21 & 3 \\
& -2 & 18 & 10.6 & 17 & 3 \\
& -3 & 20 & 11.0 & 25 & 3 \\
& -4 & 15 & 10.9 & 25 & 3 \\
& Al1 & 78 & 10.5 & 25 & 3 \\
\hline \multirow{2}{*}{ Width } & & 35 & 8.0 & 19 & 3 \\
& -1 & 21 & 8.3 & 12 & 3 \\
& -2 & 32 & 7.6 & 1.6 & 4 \\
& -3 & 21 & 8.9 & 14 & 3 \\
\hline
\end{tabular}

The mean thickness shrinkage from 32 homes was 10.58 , while the mean width shrinkage from 41 homes was $8.1 \%$. The width shrinkage is in very close agreement with the average value measured in a National Bureau of Standards test house after a period of 26 months (Ref. 15). However, Weidt measured 
shrinkage in twelve samples (average age of 1.85 years) and found an average value of $4.5 \%$ with a range of 2.5 to $9 \%$ (Ref. 7). Eighty percent of the Portland U-F foam samples were 3 to 5 years old; and all installations occurred at least three years prior to the wall openings. It should be noted that the mean shrinkage values might have been slightly larger had it been possible to measure the shrinkage in more upper holes $(-2$ \& -4) since the upper hole shrinkage is slightly larger than that in the lower holes. In some cases the vertical shrinkage was large enough to make it impossible to reach the foam through the upper opening to measure its shrinkage in width.

An attempt was made to measure shrinkage in the vertical direction as well as in width and thickness. However, it was difficult to distinguish between actual shrinkage and a possible void at the top of the wall cavity due to incomplete filling. Sometimes it was clear from staining or from remnants of shrunk insulation on the plate or studs or wallboard that only shrinkage had occurred; in those roughly two dozen cases the vertical shrinkage was about $8 \%$. However, because the full. height of the wall cavity was not opened, it was impossible to tell if the foam had any horizontal. cracks in it in between the upper and lower holes. Such cracks would mean even larger shrinkage than that measured. Since such cracks were sometimes seen in the opened holes, it was decided not to tabulate the vertical shrinkage results because of the uncertainty in their interpretation. However, it should be noted that in a number of cases no insulation was visible upon opening the upper hole. That was due both to shrinkage and filling voids (because of shrinkage the insulation usually dropped to the bottom of the wall cavity). Furthermore, cracks many inches wide were observed in a number of cases. Examples of typical shrinkage, voids and cracks are shown in Figure 7.1. Note should be made that water stains were often seen on the gypsum board in U-F foam wall cavities; however, there were no corresponding indications of high moisture content or moisture damage.

It should be pointed out that shrinkage and cracking can have a considerable effect on the performance of U-F foam wall insulation. To bcgin with, the $10.5 \%$ measured reduction in thickness should reduce the actual total insulation R-value by 10.5\%. Similarly, the area reduction should lead to a further reduction in the effectiveness of the insulated wall. In fact, because shrinkage is known to occur, the U.S. Department of Housing and Urban Development has derated the nominal R-value of U-F faom by $28 \%$ (Ref. 9) and the Canadian government has derated it by $40 \%$ (Ref. 10). Vinieratos (Ref.11) has reported that a $10 \%$ linear shrinkage corresonds to a roughly $70 \%$ increase j.n heat loss with nominal 3-1/2 inch thick insulation, whilc with nominal R-19 insulation (5-1/2 inch thick) the heat loss increase would be about $170 \%$. That increase is considerably greater than would be expected based only on the reduced area, and may be due in part to the development of convection loops within the wall cavity. 


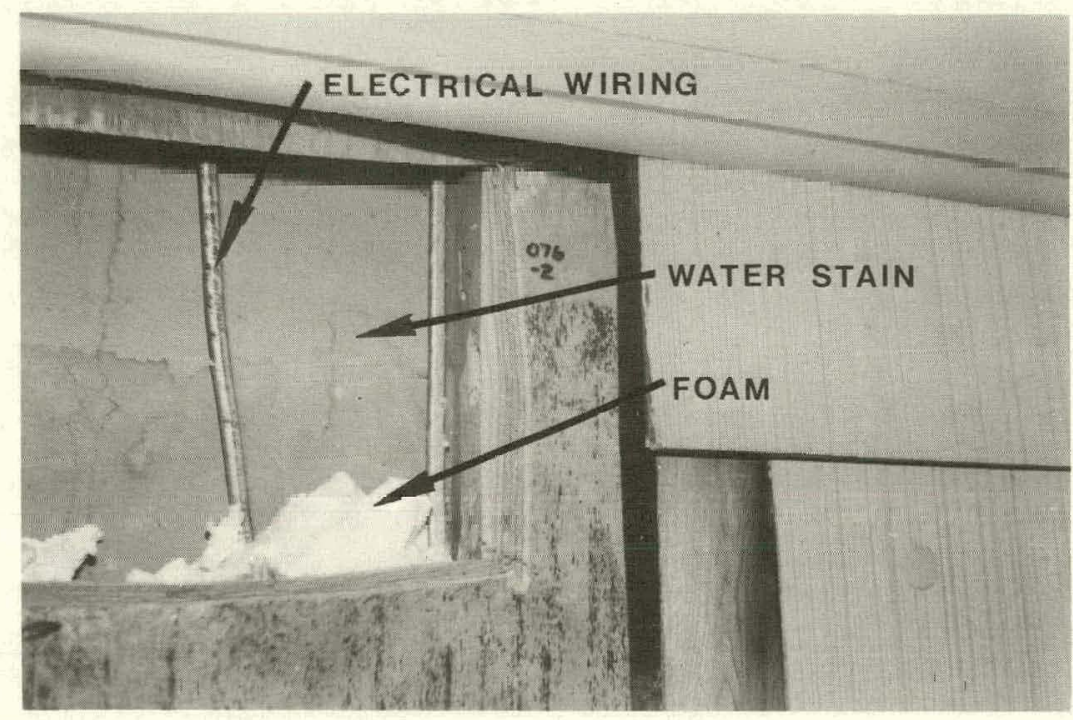

UPPER HOLE

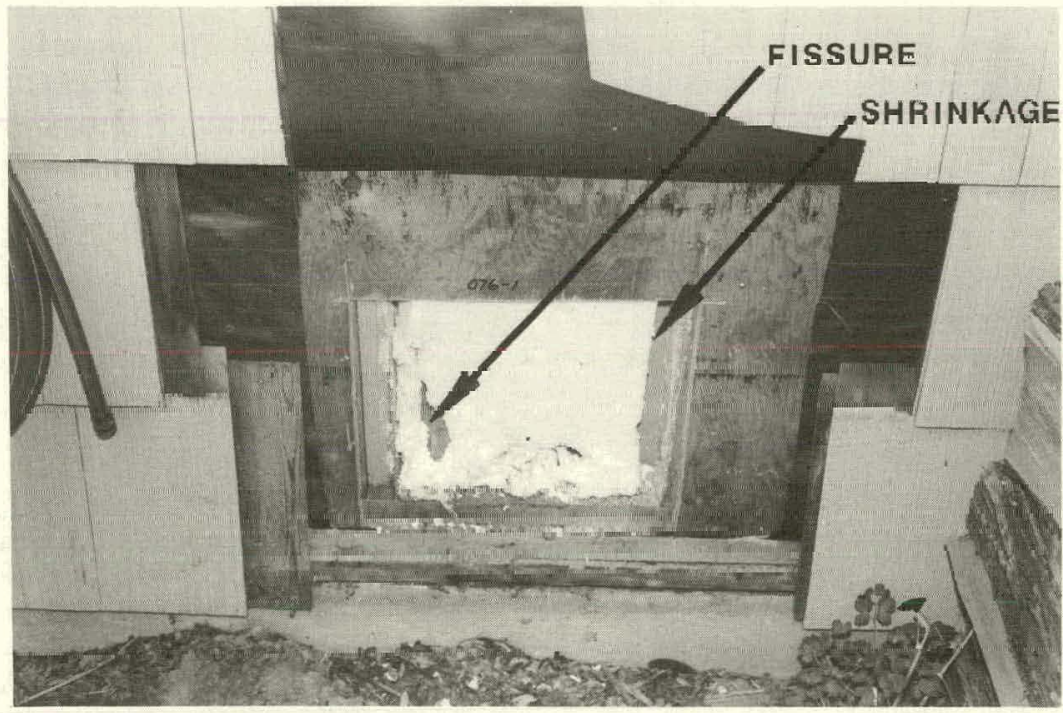

LOWER HOLE

FIG. 7.1 EXAMPLES OF SHRINKAGE AND VOIDS IN U-F FOAM. 


\subsection{Observations of Installation Quality and Settling}

Generally speaking the quality of insulation installation was poorer than expected, independent of type of insulation. Numerous empty cavities between studs were observed in many insulated homes. Moreover, those empty cavities were routinely found during the process of opening holes which were little more than one stud-to-stud cavity width wide in preselected locations rather than because of careful inspection for them. In a few cases different infrared thermographic equipment (Hughes Probeye, AGA Thermovision, and Barnes Thermotrace) were used to scan the walls for cavities and/or voids, and the existence of numerous voids was further verified. Full width cavities were found empty both where fill holes had been drilled and where none were drilled; in addition, many empty cavities between closely-spaced studs were noted. The latter were probably relatively hard to locate and fill. Nonetheless, improved quality control on the part of installers would appear to be needed. The fact that cavities are not all filled reduces the expected insulated wall performance considerably (see Ref. 11), and yet that reduction is seldom accounted for. This effect could be very important in any wall insulation conservation program and should be more thoroughly

investigated. Infrared thermography could be used to determine the extent of empty cavities.

Some settling or incomplete filling of cellulose or mineral wool was also observed. Of the twenty upper holes of the ten cellulose houses, eight had upper plates that were clearly visible. Of those, one cavity was totally void, and another in the same house was void in the top 18 inches. This appeared to be a case of incomplete filling. Of the other full cavities, the cellulose was tight up against the top plate.

of the thirty holes in the fifteen mineral wool homes, twelve had the top of the insulation and the upper plate clearly visible. Of the twelve, three cavities were partially void in the top or had settled by 2,8 , and 2 inches, respectively. In the last case an adjacent cavity was full, suggesting that the partially void cavity might not have been filled completely. Once again the others were filled right to the top, suqqesting that the other cavities with voids or settling might have been incompletely filled. Numerous cases were also observed where $\mathrm{U}-\mathrm{F}$ foam was clearly incompletely filled in wall cavities.

\subsection{Wiring Corrosion}

In three insulated home cases (two cellulose and one mineral wool) electrical wiring was observed during the hole inspection process. In those few cases, there were no signs of wiring corrosion. Wiring was also observed in a number of uninsulated walls, and once again no corrosion or other degradation was noted. Obviously, it would be unwise to generalize from the results of this small sample. 


\subsection{Fan Depressurization Air Leakage Tests}

In an effort to determine if the relative air tightness or leakiness of a home was an important parameter with respect to moisture damage, air leakage measurements were made using a fan depressurizaton unit (see Ref. 12). The unit was sealed in a doorguard, vents and fireplace dampers were closed and the furnace turned off, and then the house was depressurized by adjusting the fan speed (and hence the flow rate) to produce preselected values of pressure drop across the door. No pressurization tests were run. Using a calibration curve, the volumetric flow rate in cubic meters per hour (C.M./hr) at a standardized pressure drop of 50 pascals (Pa) (0.2 in. water) was determined for each house. Then knowing the volume of each house, the number of air changes per hour was determined for each of the 71 houses tested. While many houses were not tested because the owner could not be home during the daytime, a few others were not tested because one or more large leaks were present, such as a fireplace flue without a damper. The C.M./hr values ranged from 2,370 to 19,170 with a mean value of $4444 \mathrm{C} . \mathrm{M} . / \mathrm{hr}$. The number of air changes per hour at $50 \mathrm{~Pa}$ ranged from 5.5 to 31.0 with a mean value of $13.1 / \mathrm{hr}$. The mean value is quite similar to the average value of $13.3 / \mathrm{hr}$ found for four detached houses in Twin Rivers, New Jersey (Ref. 12). However, similar tests on Swedish tract housing built in the seventies and employing plastic vapor barriers produced exchange rates of $1-6 / \mathrm{hr}$ with an average value of $4.5 / \mathrm{hr}$ (Ref. 13). Moreover, the current Swedish standard for detached houses built after July 1978 is $3.0 / \mathrm{hr}$ maximum, thus requiring continuous plastic vapor barriers as an effective energy conservation measure.

It should be noted that an air leakage rate determined by test at a standardized pressure drop of $50 \mathrm{~Pa}$ corresponds to the rate the house would experience under a relatively high outdoor wind speed condition (about $30 \mathrm{mph}$ ). The natural ventilation or infiltration rate that is commonly quoted (typically $1 / 2$ to 2 air changes per hour) is considerably lower, especially in the major urban areas of the Northwest where the winter wind speeds are relatively low. No attempt was made to correlate the measured leakage rates with actual natural infiltration rates since experimental determination of the latter was beyond the scope of this study.

While no statistically significant correlation was observed between the measured air leakage rates and the moisture content of either wood or insulation, there was a considerable difference between the air leakage rates associated with insulated and uninsulated homes as well as between insulation types. The measured rates are presented in Table 7.6. The number of homes tested and the total number in each category are shown in parentheses. 


\begin{tabular}{lcc}
\hline & Air Leakage @ 50 Pa \\
\hline All Homes $(71 / 93)$ & Cu. Meter/hr Air Changes/hr \\
Uninsulated Homes $(18 / 25)$ & 4444 & 13.1 \\
Al Insulated Homes $(53 / 68)$ & 6105 & 15.8 \\
Mineral Wool Homes $(10 / 15)$ & 3880 & 12.2 \\
U-F Foam Homes $(35 / 43)$ & 4857 & 13.0 \\
Cellulose Homes $(8 / 10)$ & 3725 & 12.3 \\
\end{tabular}

It would thus appear that the addition of wall insulation substantially reduces air leakage and its associated energy loss. Yet that saving is seldom, if ever, accounted for when analyzing conservation options. of course these results simply could be due to differences in the characteristics of the selected homes. Unfortunately, tests of air leakage before and after retrofitting were not possible. If the interpretation is correct that adding wall insulation reduces infiltration

losses, then the results indicate that a substantial portion of the infiltration loss in an existing home without a vapor barrier is through the walls. Thus, methods for calculating infiltration rates based only on window or door leakage will most likely produce incorrect results. Moreover, it would appear that cellulose reduces air leakage the most and mineral wool the least. That result seems reasonable in light of the porosity and shrinkage of those insulation materials. While this effect is important for retrofitting existing homes, it would of course be unimportant in new houses with a continuous vapor barrier.

\subsection{Potential For Wall Insulation Retrofitting}

Another unexpected finding of the study is that there appear to be a good many more uninsulated homes in Portland's housing stock than are generally thought to exist. This conclusion is based on the returns of the study's solicitation questionnaire, which was carcfully designed to elicit response from owners of insulated homes. The fact that a large percentage of the questionnaires that came back were from uninsulated homes suggests that there is indeed a large potential remaining in Portland for additional retrofitting of wall insulation.

\section{APPLICABILITY OF RESULTS}

\subsection{General}

A number of questions regarding the applicability of the results from tests of homes in Portland, Oregon during the 1978-79 winter must be addressed: whether the weather was conducje to condensation occurring in insulated walls, whether the 1979-1980 winter was typical or atypical, and whether the results of this study can be applied to other areas in the 
region and/or nation. The initial portion of this section presents the results of an analysis of the number of hours during selected months of the test year when condensation could have occurred in the walls of Portland test homes. Then, based upon those results, the representativeness and applicability of the portland moisture study results will be discussed.

\subsection{Analysis of Condensation Potential During 1978-79 winter}

In order to analyze the amount of time that condensation could likely have occurred, a simplified model of the temperature and water vapor pressure variation through an insulated wall has been developed. The model is based on the discussion of condensation in walls presented in Appendix 10.1 and specifically on the temperature and pressure variations shown in Figure 3 of that Appendix. For simplicity of analysis the temperature variation between the indoor air temperaturc $T_{i}$ and the outdoor air temperature $\mathrm{T}_{\mathrm{O}}$ is assumed to take place only within the insulated portion of the wal1, as shown in Figure 8.1. The variation of the corresponding saturation proccurc $\mathrm{F}_{\mathrm{S}}$ is also shown, along with three possible variations of the vapor pressure $P_{y}$ within the wall. Condensation can occur within the insulated wall cavity only when the partial pressure $\mathrm{P}_{V}$ within the insulation is greater than the saturation pressure $\mathrm{P}_{\mathrm{S}}$.

The required vapor pressure drop is assumed to occur only within the two low permeability sections near the inner and outer wall surfaces (typically paint films) and not within the relatively permeable insulation. The relative amount of pressure drop at the two surfaces for any particular case depends strongly on the specific construction details. However, two limiting cases and one likely case are assumed for purposes of analysis.

The first case (1) assumes that all the pressure drop occurs at the inner wall. surface; in that siluation condensation will not occul since $\mathrm{F}_{\text {vo }}$ must by definition always be less than $\mathrm{P}_{\mathrm{SO}}$ except under conditions of $100 \%$ outdoor relative humidity. fact, because some temperature and saturation pressure drop must occur in the outer wall sheathing and/or siding, condensation will not nccur in this casc.

The third case (3) is the other limiting condition wherein all the pressure drop occurs in the outer wall section due to low permeability there. Condensation will occur most frequently in this case since the vapor pressure can most often be greater than the saturation pressure. The amount of time that condensation will occur depends on the actual indoor and outdoor temperatures and the indoor rclative humidity.

In the second case (2), it is assumed that the vapor pressure drop is equally divided such that the partial pressure within thc insulation is equal to the average of the indoor and outdoor partial pressures. Condensation can occur in this 


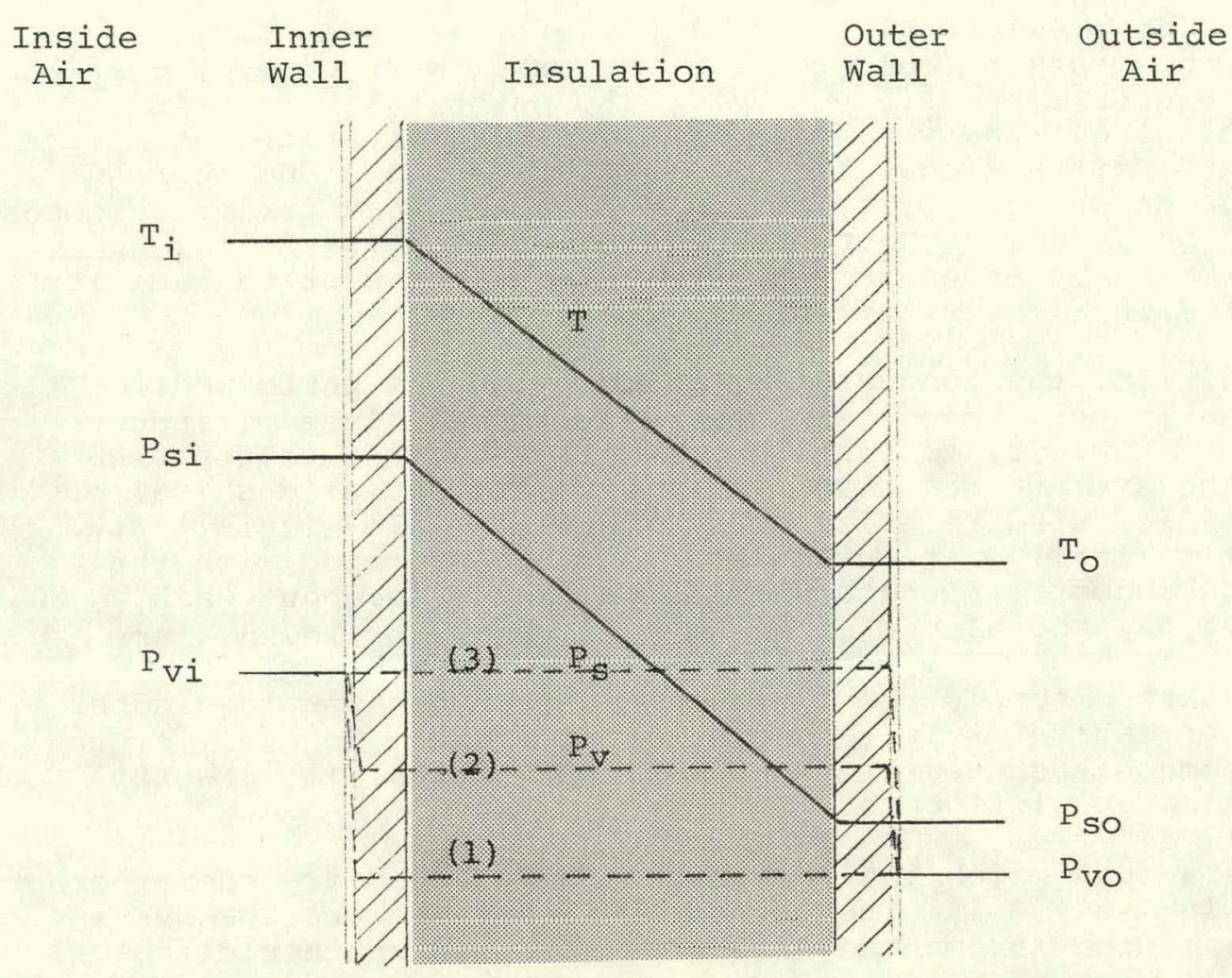

Fig. 8.1. Simplified temperature and pressure variation within an insulated wall. 
instance for some weather and indoor conditions, as illustrated in Figure 8.1. The number of hours when it can occur will depend on the actual conditions, but it will fall between the two extreme cases. It is assumed that this case reasonably represents what might actually occur for the average of all the test homes.

In order to determine the number of hours in which condensation could occur during a specific period of time, the partial pressure $\mathrm{P}_{\mathrm{V}}$ within the insulation can be calculated for the three cases described above and compared with the outside saturation pressure $\mathrm{P}_{\mathrm{SO}}$. If $\mathrm{P}_{\mathrm{V}}$ is greater than $\mathrm{P}_{\mathrm{SO}}$, then condensation could occur. The value of $P_{\text {so }}$ will vary with outdoor temperature. For purposes of this analysis, outdoor conditions were based on hourly observations at Portland International Airport for the months of October through March just prior to and during the test period. Indoor conditions, including an estimate of vapor pressure $p_{v i}$, were based on the average indoor temperature and relative humidity measured in all the test homes.

In addition, the condensation calculation was performed for the average indoor temperature and two extreme values of indoor relative humidity to examine its influence; the values used were the average value $\mathrm{RH} \pm$ two standard deviations (95\% of all the measured relative humidity values fell within that range). Finally, the calculations were performed with the average indoor temperature held constant throughout each 24-hour day and also with a $100 \mathrm{~F}$. setback for seven hours during the night (1l p.m. to $6 \mathrm{a} \cdot \mathrm{m}$.$) . More hours of$ condensation should occur without setback because the indoor vapor pressure $\mathrm{P}_{\mathrm{vi}}$ is then greater at night. However, since some homeowners used thermostat night setback, it is worth examining its influence.

The data upon which the calculations are based are summarized below in Table 8.1. The outdoor valucs shown are the average values of the six months of hourly portland weather data.

TABLE 8.1. SUMMARY OF INDOOR AND OUTDOOR CONDITIONS

\begin{tabular}{|c|c|c|}
\hline Variable & $\begin{array}{l}\text { Mean } \\
\text { Value }\end{array}$ & $\begin{array}{l}\text { Standard } \\
\text { Deviation }\end{array}$ \\
\hline $\begin{array}{l}\text { Indoor temperature } \\
\text { Indoor relative humidity }\end{array}$ & $\begin{array}{l}68.5 \% \mathrm{~F} \\
56.2 \%\end{array}$ & $\begin{array}{l}3.70 F * \\
9.6 \%\end{array}$ \\
\hline $\begin{array}{l}\text { Outdoor temperature } \\
\text { Outdoor relative humidity }\end{array}$ & $\begin{array}{l}42.10 \mathrm{~F} \\
79.68\end{array}$ & $\begin{array}{l}11.70 \mathrm{~F} \\
19.1 \%\end{array}$ \\
\hline
\end{tabular}

* Not used in the analysis 
In order to perform the calculations, an analytical expression for saturation pressure as a function of temperature is required. Corresponding values are typically presented in tabulated form and are found in steam tables. However, for a limited temperature range, an expression of the following general form can be used to fit the existing data:

$$
\ln P_{S}=A+B / T+C \operatorname{lnT}+D T
$$

For a data range of 32 to $780 \mathrm{~F} .$, the values of $\mathrm{A}, \mathrm{B}, \mathrm{C}$ and $\mathrm{D}$ were calculated to be $-101.253,-5.582 .65,19.5806$, and -0.0227254 , respectively, with temperature in degrees Rankine and pressure in pounds per square inch. Once $\mathrm{P}_{\mathrm{S}}$ is determined for a particular temperature, the following expression can be used to calculate the vapor pressure $\mathrm{P}_{\mathrm{V}}$ for indoor or outdoor conditions:

$$
\mathrm{P}_{\mathrm{V}}=(\mathrm{RH} / 100) \mathrm{P}_{\mathrm{S}}
$$

where $\mathrm{RH}$ is the relative humidity.

\section{2 .1 Results}

Using the assumed model, data, and equations noted, a computer program was developed and $r$ un to determine the percentage of the total of 4367 hours that condensation could occur during the October 1978 through March 1979 period in Portland. The results for each case are presented in Table 8.2 .

These results suggest that ample opportunity - from about 408 to $80 z$ of the time - existed for condensation to occur in the insulated walls of the Portland test homes during the October 1978 through the March 1979 period. Variation in conditions such as the indoor relative humidity and night setback simply vary the degree to which condensation could occur. However, it should be noted that the measured average indoor relative humidity of 56.28 for all the homes is relatively high, and since high indoor $R H$ produces a greater condensation potential, the test homes should have provided an excellent opportunity for finding moisture damage if it exists at all. While not directly analyzed here, it is clear that the opportunities for condensation in an uninsulated wal.j. cavity are considerably lower. Of course, the results give no indication as to the actual extent of condensation within the insulation or the amount of water vapor condensed.

The analysis presented above is also limited to the case of moisture migration through walls by diffusion rather than by leakage, due to the inherent difficulties in modeling the latter case. While some leaks such as those through switch boxes should reduce the vapor pressure drop across the inner section of a wall, and thereby increase chances of condensation occurring, the addition of that warm air directly into the cavity may also raise its temperature and thereby cause a reduction in the opportunities for condensation; which effect is dominant is not known. 
TAELE 8.2 PEECENTIGE OF HOUFS CONDENSATION OPPOFTUNITIES EXISTED IN POFTLANJ TEST HOME WALL CAVITIES (I0;73-3/79)

4367 Total Hours

\begin{tabular}{|c|c|c|c|c|c|c|c|c|c|c|}
\hline \multirow{2}{*}{$\begin{array}{l}\text { CASE } \\
\text { No. }\end{array}$} & \multicolumn{3}{|c|}{ CONDITICNS } & \multirow{2}{*}{$\begin{array}{l}\text { OCT } \\
78\end{array}$} & \multirow{2}{*}{$\begin{array}{l}\text { NOV } \\
78\end{array}$} & \multirow{2}{*}{$\begin{array}{l}5 \equiv C \\
7: 3\end{array}$} & \multirow{2}{*}{$\begin{array}{l}\text { JAN } \\
79\end{array}$} & \multirow{2}{*}{$\begin{array}{l}\text { FEB } \\
79\end{array}$} & \multirow{2}{*}{$\begin{array}{l}\text { MRE } \\
79\end{array}$} & \multirow{2}{*}{$\begin{array}{c}\text { MONTHLY } \\
\text { AVG. }\end{array}$} \\
\hline & $\begin{array}{c}\text { OPPCRTIUNITY FOR } \\
\text { CONDENSATICN }\end{array}$ & $\begin{array}{c}\text { INDOPR }{ }^{1} \\
\text { RH }\end{array}$ & $\begin{array}{l}10^{\circ} \mathrm{F} \\
\text { SETBACK }\end{array}$ & & & & & & & \\
\hline 1 & NONE & - & no & 0 & 0 & 0 & 0 & 0 & 0 & 0 \\
\hline 1 & & - & YES & 0 & 0 & 0 & 0 & 0 & 0 & 0 \\
\hline 2 & TYPIZAL & L.วW 1 & No & 3 & 43 & 58 & $85^{\circ}$ & 24 & 6 & 37 \\
\hline 2 & & L.OW & YES & 3 & 33 & 49 & 70 & 17 & 2 & 29 \\
\hline 2 & & IJG & NO & 32 & 80 & 96 & 99 & 82 & 46 & 72 \\
\hline 2 & & $\because J G$ & YES & 21 & 73 & $B 9$ & 99 & 68 & 28 & 63 \\
\hline 2 & & :AIGH & NO & 52 & 94 & 105 & 100 & 99 & 69 & 85 \\
\hline 2 & & :HIGE & YES & 43 & 90 & $3=$ & 100 & 95 & 63 & 81 \\
\hline 3. & MAX IY:UV & $=0 \mathrm{~W}$ & Wo & 9 & 61 & 71 & 98 & 37 & 10 & 40 \\
\hline 3 & & تכW & YES & 3. & 51 & 52 & 91 & 26 & 4 & 40 \\
\hline 3 & & AVE & NO & 41 & 91 & 160 & 100 & 97 & 68 & 83 \\
\hline 3 & & B.?G & YES & 28 & 85 & 94 & 100 & 84 & 49 & 73 \\
\hline 3 & & HIGF: & No & 71 & 100 & 100 & 100 & 100 & 87 & 93 \\
\hline 3 & & HIGE & YES & 60 & 97 & $\therefore \infty$ & 100 & 98 & 83 & 90 \\
\hline
\end{tabular}
NOTE 1 IndDor relati:re humidity is defired ir: relation to test hore measurements: Low=37\%, Avg=56\%,
High=75\% 


\subsection{Representativeness of 1978-79 winter}

A major question to be answered relative to this analysis is whether the 1978-79 winter weather was typical. To answer that guestion, the heating degree-days for 1978-79 obtained from the Bonnevilie Power Administration Weather office in Portland are compared in Table 8.3 with long term average values from the National. Weather Service.

TABLE 8.3 HEATING DEGREE-DAY COMPARISON

\begin{tabular}{lrrr}
\hline Month & $1978-79$ & Average & $\begin{array}{r}\text { Percentage } \\
\text { Difference }\end{array}$ \\
\hline October & 317 & 329 & -3.6 \\
November & 786 & 591 & 33.0 \\
December & 925 & 755 & 22.5 \\
January & 1059 & 835 & 26.8 \\
February & 621 & 621 & -26.0 \\
March & 444 & 600 & 11.3 \\
\hline
\end{tabular}

It can be seen that the six-month period in 1978-79 was generally colder than average and had about 118 more heating degree-days.

This comparison shows that the months of November, December and January were notably colder than normal, thereby providing a greater potential for condensation than a typical year. The moderate overall difference of $11 \%$ in degree-days between the winter of 1978-79 and the long term average is small enough, moreover, to justify the conclusion that there was ample chance for condensation conditions to exist within the insulated walls of the portland test homes during both the test winter season and typical preceding years.

\subsection{Applirahility of Results to Other Geographical Areas}

It should be noted that this analysis could be extended to other cities both east and west of the Cascades as well as elsewhere. For most areas west of the Cascades such as Seattle/Tacoma, Salem, Eugene, and the coastal region, the outdoor winter temperatures based on degree-day data are very nearly the same (degree-day differences within the western region do not vary by more than 208), and so the analysis results should be similar. East of the Cascades in cities such as spokane the winter weather is colder and greater opportunities for condensation should exist. 
Oregon and Washington west of the Cascades have been designated in the engineering 1 iterature as having a different potential for condensation than other parts of the central and northern tiers of states (Ref 16). Figure 8.2 shows the "condensation zones" defined by ASHRAE (American Society of Heating, Refrigerating, and Air Conditioning Engineers) according to approximate winter design temperatures which are:

$$
\begin{aligned}
& \text { Zone I }=\text { below }-20 \mathrm{~F} . \\
& \text { Zone II }=0 \mathrm{~F} \text {. to }-20 \mathrm{~F} . \\
& \text { Zone III }=\text { above } 0 \mathrm{~F} .
\end{aligned}
$$

According to Figure 8.2 , the results of the present study should be applicable throughout zone III during the winter, but it would be reasonable to expect somewhat different findings in zones I and II based on outdoor environmental conditions alone.

It is also of importance to note that other than temperature, one of the most important parameters is indonr relative humidity. High indoor relative humidity geneidlly increases the opportunities for condensation. West of the cascades, wood-frame construction is typical and one would expect relatively small variations in the tightness of houses. However, as homes are weatherized and so tightened, indoor relative humidities can be expected to rise, thereby producing additional opportunjties for condensation th oreur in homes with retrofitted wall insulation.

In conclusion, it seems clear based on the analysis results presented in this section as well as on the similarity of climate and housing characteristics within the western region of the Pacific Northwest, that the test results of this study should be applicable throughout the western section of the region. They should also apply to other areas of the country with similar or dryer indoor conditions and similar outdoor weather conditions and housing characteristics. 


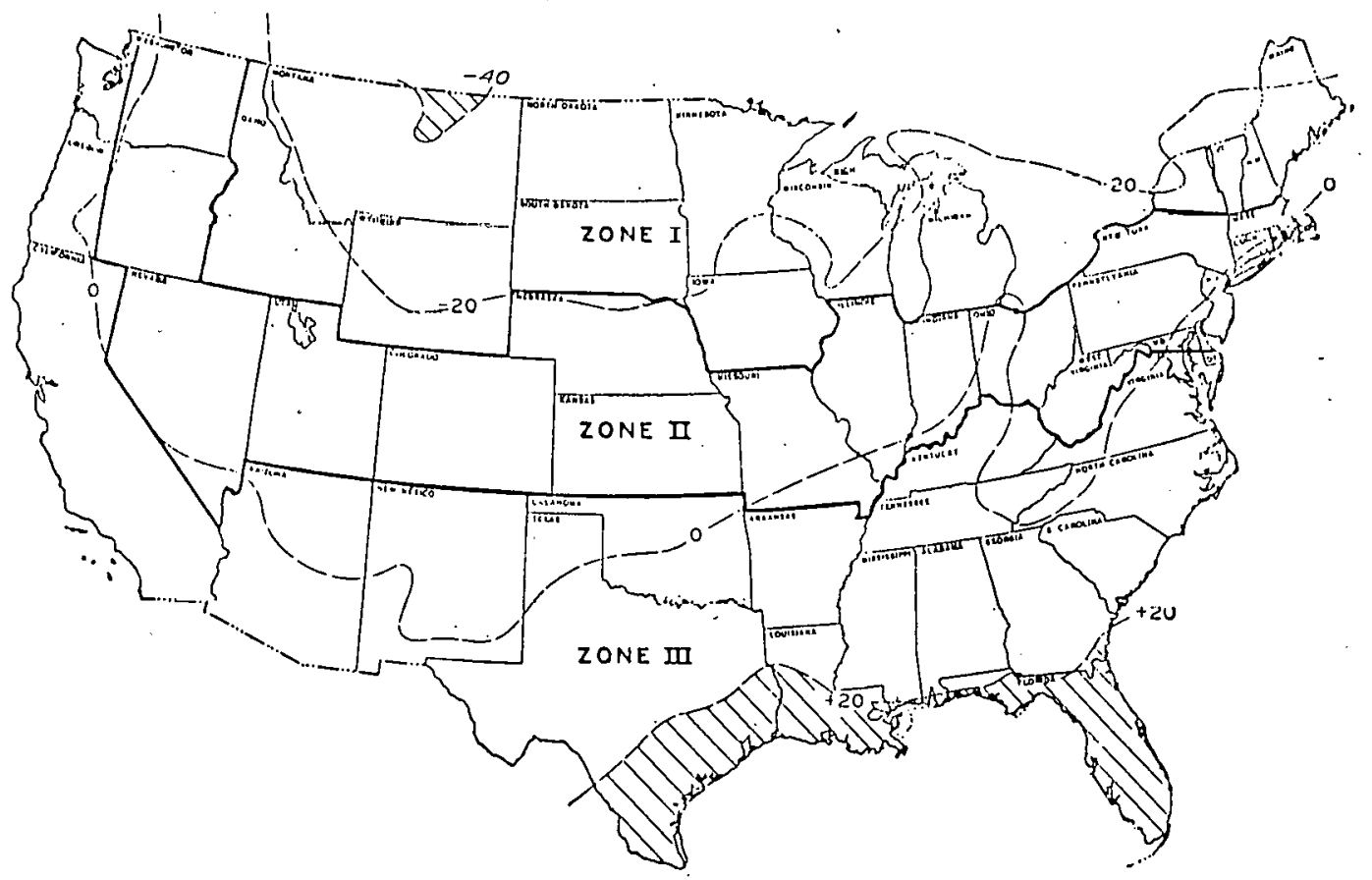

Zones Includa Areas with Design Temporatures aboul or follows: Zone I, - $20 \mathrm{~F}$ and lower, Zane $11,0 \mathrm{~F}$ to $-20 \mathrm{~F}$, and Zone 111 , above O F. Note that crous hatched areas ore oulside of Zones l and III.)

Fig. 8.2. Condensation Zones in the United States 


\section{REFERENCES}

1. Baumeister, T. (Ed), Marks Standard Handbook for Mechanical Engineers, 7th Ed. (MCGraw-Hill, 1967), p. 6-151.

2. Tsongas, G.A., et al, "Retrofitting Existing Residences: A Demonstration Project," proceedings of the First National Conference on Technology for Energy Conservation, Washington, D.C., June 8-10, 1977, pp 122-130.

3. Achenbach, P.R., et al, "The National Program Plan for Building Thermal Envelope Systems and Insulating Materials, Technology and Implementation For Energy Conservation," U.S. Department of Energy, Report No. DOE/CS-0059, January 1979 (available from NTIS or U.S. Government Printing office).

4. J.E. Duff, "Vapor Barrier Decreases Moisture Conditions in Wood Walls Exposed to Air Conditioning and Heating," U.S.D.A. Forest Service Research Paper SE-98, August 1972.

5. Peck, E.C., "Moisture Content of Wood in Use," U.S. Forest Products Laboratory Report No. 1655, 1960.

6. Hann, R.A., A.E. Oviatt, D.M. Markstrom, and J.E. Duff, "Moisture Content in raminated Timbere," U.S.D.A. ForesL Service Research Paper, FPLI49, 1970.

7. Weidt, John, "Minnesota Retrofit Tnsulatinn In situ Tcot Program," Minnesota Energy Agency Report No. HCP/W2843-01, June 1978; prepared for U.S. DOE under Contract No. $\mathrm{EY}-76-\mathrm{C}-02-2843$.

8. Jespersen, H.B., "Thermal Conductivity of Moist Materials and Its Measurement," Tournal of IHVE, 157-173, August 1953.

9. HUD Use of Materials Bulletin No, 74, Oetober 13, 1977.

10. Bowles, A.M, and C.J. Shirtcliffe, "Development of a Canadian Standard for Urea-Formaldehyde and Cavity wall Insulation," proceedings of the U.S. DOE/ASTM Thermal Insulation Conference, Tampa, Florida, October 22-25, 1.978 .

11. Vinieratos, E,R. and J.D. Verschoor, "Influence of Insulation Deficiencies on Heat Loss in Walle and Ceilings." Proceedings of the U.S. DOE/ASTM Thermal. Insulation Conference, Tampa, Florida, October 22-25, 1978.

12. Blomsterberg, A.K., and D.T. Harrje, "Approaches to Evaluation of Air Infiltration Energy Losses in Buildings," ASHRAE Transactions 85, 797 (1979).

13. Blomsterberg, A.K., "Air Leakage in Dwellings", Royal Institute of Technology Division of Building Construction, Stockholm, Sweden, Report \#15, 1977. 
14. Rossiter, W.J., Jr., J. Weidt, and R. Saxler, "The Properties and Performance of Insulations Used to Retrofit Cavity - Walls of Residences," Proceedings of the U.S. DOE/ASHRAE Conference on Thermal Performance of the Exterior Envelopes of Buildings, Orlando, Florida, December 3-5, 1979 (to be published).

15. Burch, D.M, and C.M. Hunt, "Retrofitting an Existing Wood Frame Residence for Energy Conservation - An Experimental Study," National Bureau of Standards, Report No. NBSIR 77-1274, U.S. Department of Commerce, July 1977.

16. ASHRAE (American Society of Heating, Refrigerating, and Air Conditioning Engineers) Handbook of Fundamentals, 1977. 


\author{
APPENDIX 10.1 \\ Excerpt From Status Report: Vapor \\ Barrier Research in the United States \\ Prepared For Oregon Dept. of Energy, By Alan \\ H. Boner, P.E. Nov. 11, 1977 \\ CONDENSATION IN WALLS: \\ A DISCUSSION OF THE PROBLEM
}

This discussion is directed only at walls of residences, but obviously any building with similar characteristics would have the same problems. Discussion is focused on heated buildings in winter which is assumed to be the worst situation for vapor flow in the Willamette valley. A complete study would have to lock at the entire annual weather rycle.

Figure 1 is a portion of the psychrometric chart, which shows graphically some important properties of moist air. We can find from the chart the vapor pressure at any given temperature and relative humidity. We can also find the maximum possible vapor pressure at any given temperature. This is given by the $100 \%$ relative humidity curve (the saturation curve). Water cannot exist as a vapor under conditions above and to the left of this curve. If, for instance, a condition of $70^{\circ} \mathrm{F}$ and $100 \%$ relative humidity existed and this air/vapor mixture were cooled to $60^{\circ} \mathrm{F}$ (moving to the left on the chart) some of the vapor would condense, becoming liquid water, and the amount of vapor in the air would decrease. A new equilibrium would be established at a lower vapor pressure, still at $100 \%$ relative humidity, at the new temperature.

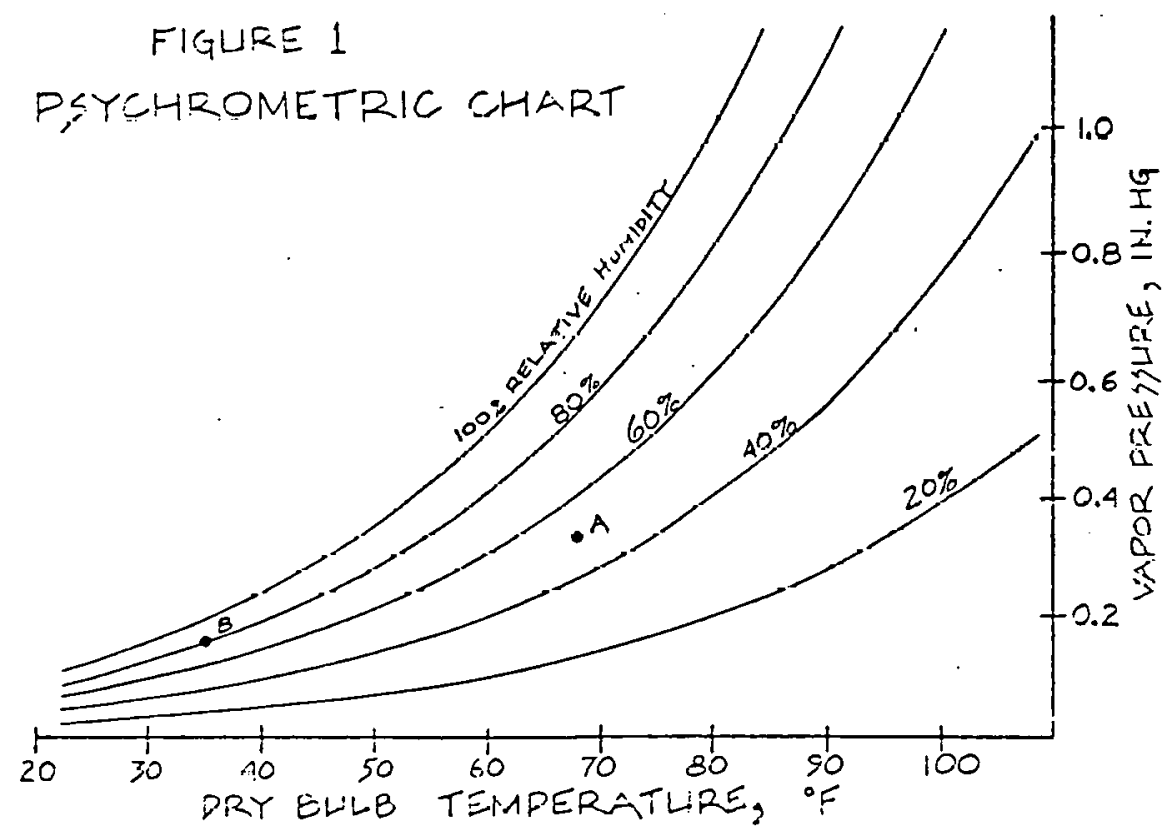


The Gibbs-Dalton law states that in a mixture of gasses (such as water vapor and dry air) each gas may be considered to behave independently of the others. We can therefore look at the water vapor pressure alone as a driving force in the flow of vapor through a permeable material.

Let us look, then, at some conditions which might exist on either side of the wall of a heated building in the winter.

Point A on the psychrometric chart (Figure 1) represents indoor conditions of $68^{\circ} \mathrm{F}$ and $50 \%$ relative humidity. The inside vapor pressure is then 0.34 inches of mercury (or about 0.17 psia.).

Point $B$ represents outdoor conditions of $35^{\circ} \mathrm{F}$ and $80 \%$ relative humidity. The outside vapor pressure is then 0.17 inches of mercury (or about 0.08 psia).

A vapor pressure difference of 0.17 inches of mercury exists between the inside and the outside of the wall, causing a continuous flow of vapor through the wall.

Figure 2 shows the conditions within an uninsulated wall as this flow process is taking place. The curve in the upper portion of Figure 2 shows the temperature profile through the wail. The saturation curve in the lower portion of the figure is determined by the temperature at each point through the wall.

The dashed clirve in the lower portion of the figure represents the vapor pressure thiough the wall. The greatest pressure drops occur through the lowest permeability materials--in this case the pairt films on the FIGURE 2- UNINSULTEC YALL inside and outside surfaces of the wall. The most important asnect of this curve is that it remains, throughout the wali, below the saturation curve: cordensation does not occur. 
Figure 3 shows what happens when insulation is added to the same wall. The temperature profile across a section of the wail is now different, with the greatest temperature drop occuring across the insulation. The saturation curve, then, drops more sharply, faliing to a much lower value within the wall. Since the permeability of most insulations is at least ten times higher than the paint films (which essentially control the flow in our example), the flow process is nearly the same as it is in the uninsulated wall. The vapor pressure curve is, therefore, virtually the same as in the unirsulated wall, but now the vapor pressure clirve crosses the saturation curve and condensation occurs within the wall.

FIGURE 3- INGLUTEO WNH
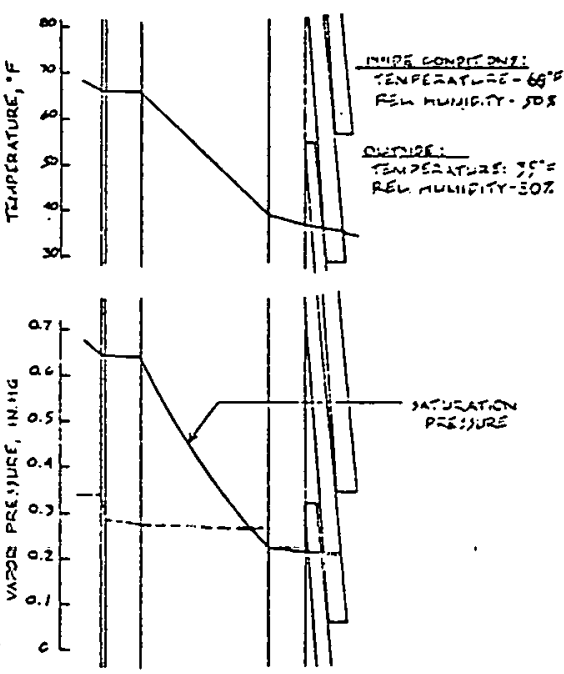

If there is a major flow restriction on the outside of the wall, a greater portion of the total vapor pressure drop will occur there; consequently, saturation is more likely to be reached inside the wall. This means that the permeability cf other materials in the wall determines the required permeability of an adequate vapor barrier.

The permeance ratio is the ratio of the permeance of the outside sheathing to the permeance of the vapor barrier. Permeance ratios as high as $3.8: 1$ have been found to be inadequate under conditions of high humidity. 1

Important points to remember are:

- Water vapor is generated continually in living spaces.

- Few building materials are impermeable to vapor flow.

- A continuous flow process takes place: greater fiow when vapor pressure difference is higher. Whas is essentially a gaseous diffusion process ar.e can take place in lived-in structuras without condensation occuring. 
- When energy conservation measures are taken to "tighten up" a house, reducing infiltration, the humidity (and vapor pressure) is likely to increase because there is less exfiltration of moistureladen air. Increasing the vapor pressure within a house will increase the possibility of condensation occuring.

- Electrically heated homes can have higher humidities than homes with non-electric heating devices where a combustion process helps draw humid air from the house and carries it up the chimney.

- Problems can occur when the vapor flowing through a wall reaches the dew point within the wall (condensation occurs): What happens inside the wall when condensation occurs is not well understood. It is only known that a combined diffusion and capillary flow then takes place.

- Increasing the humidity on the warm side of a wall has a greater effect on the vapor pressure difference through the wall than does lowering the humidity on the cold side by the same amoint. This can be seen on the psychrometric chart. The iines of constant humidity are steeper and farther apart at higher temperatures. This implies that the humidity maintained within a building could have a greater effect on moisture problems than differences in climate (it says nothing, however, about the effect of climate on indoor relative humidity).

- The process of condensation releases heat to the surroundings. This feedback mechanism has not been fully explored and may be one key to developing a model to describe the problem adequately.

- Most researchers suggest that condensation can occur within a wall with no damaging effects if the moisture buildup is not too great, if it does not last for too long a time, and if the wall is dried out within a reasonable period of time.

- Vapor barriers can be rendered virtually ineffective if the vapor flow path is short-circuited by holes. There are often holes in sill plates for wires and plumbing lines. Electrical switches and outlets are rarely sealed. These holes can allow an unimpeded 
flow of moisture-laden air into the wall cavity and overwhelm the flow restriction of a vapor barrier. The actual effect of these short circuits in the vapor flow path is unknown and needs to be evaluated.

- There are two problems associated with liquid water collecting in walls:

1. It reduces the effectiveness of wall insulation; data is lacking.

2. It increases the moisture content of wood members and can esiablish conditions for decay (above $20 \%$ moisture content).

The installation of vapor barriers in existing homes differs from new construction in that fairly simple and inexpensivc procedures are normally fulluwed in new construction to prevent condensation in walls (in fact, these precautions are included in building codes). A low permeance material is installed on the warm side of the wall of insulated homes between the insulation and the finish material. The commonly used vapor barrier materials are polyethelyne film and aluminum foil. Also used, somewhat less extensively, are various forms of asphalt impregnated paper. Note that these are all materials supplied in sheet form, sometimes as a backing on other wall materials, such as foil backed fiberglass batts or foil backed sheetrock.

It is not so easy when sidewalls are retrofitted with insulation. Retrofitting sheet type vapor barriers beneath finish materials is a prohibitively expensive procedure in existing structures. Applying new-building technology to homes retrofitted with insulation would imply, for example, that polyethylene sheets be stapled to the interior surface of all exterior walls, that new dryuall be nailed over the polyethylene (the interior trim would have to be altered), and that a new decorative finish be applied to the sheetrock. This procedure would be prohibitively expensive.

Some alternazives to the standard new-building technology might be:

- Vapor barrier in sheft form--this would be appropriate only if it is also decorative, such as vinyl, mylar, or metal foil wallpoper. This is an expensive approach and probably is not appropriate for all rooms in a home. 
- Vapor barrier as a liquid-applied coating (paint)-This could be decorative, or could be a primer coat over which a decorative finish might be applied. It would require that every room with an outside wall be redecorated.

Reliable data on the permeability of many building materials is not readily available. There are many potential vapor barrier materials, but the ultimate measure of their effectiveness., permeance or permeability, is generally not quantified.

The building industry has developed moisture control practices largely through trial and error. Building codes seem to evolve from this trial ard error process, sanctifying construction practices which seem to work. Most research programs appear to be aimed primarily at verifying experience, and secondarily at adding to the body of knowledge.

Generally speaking, the evolution of building technology and building codes has worked well because it has been slow, relying largely on the trial and error experience of the building industry.

The same evolutionary process can occur and indeed does take place within the field cf retrofit sidewall insulation. Innovative solutions to moisture control are being tried and, doubtless, appropriate, cost effective techniques will evolve. However, the built-in safeguards of the traditional evoluticnary process are being undercut by the need to insulate now tc conserve energy starting now.

A concentrated effort is therefore required to supplement slowly evolving practical experience, and to develop guidelines for retrofit sidewall insulation. We cannot expect the fragmerted construction industry to provide solutions. 
Introductory Letters and Questionnaire

Telephone Follow-up Questionairre

Information sheet

Checklist \#I = Family Lifestyle and llome Characteristics

Checklist \#2 = house Characteristics

Checklist \# 3 = Wall Opening Procedure/Data Sheet Infiltration Test Form

Consent Agreement 


\section{Department of Energy}

LABOR \& INDUSTRIES BUILDING, ROOM 111, SALEM, OREGON 97310 PHONE 378-

January 25,1979

Dear Homeowner:

The Oregon Department of Energy is conducting a study on the long-term effects of wall insulation in homes and invites your participation in the project.

Much uncertainty exists as to whether or not wall insulation installed without a vapor barrier causes an increased risk of moisture damage (dry rot) within walls. The Department of Energy, aided by specialists in this field, intends to resolve this question by closely examining homes that have been insulated without a vapor barrier and comparing them with homes that have not been insulated.

The study calls for inspection of some 100 homes in the Portland metropolitan area. After determining that a home meets all necessary criteria, professional engineers (Seton, Johnson \& Odell, Inc.) and carpenters (Neil Kelly Co.) will remove small, predetermined sections of outside walls to inspect for any moisture content. Test samples will be taken and the wall sections will be replaced. Techniques used in opening walls will be identical to those used in remodeling homes, leaving negligible traces of the openings. A more complete description of the program will be provided, and questions you might have will be answered prior to reaching final agreement for proceeding with any wall openings.

To succesfully complete this important project, the Department of Energy is entirely dependent upon the participation of homeowners like yourself who share an interest in determining if dry rot is indeed a threat to homes with certain types of wall insulation. In addition to discovering if your home is in need of repairs to correct or prevent serious or irreversible structural damage, other benefits of participating in the project include:

- A free, thorough, professional examination of the walls in your home will be conducted.

- Should moisture damage be found, you will receive a detailed report, as well as information on how to correct existing problems.

- If no moisture problems are discovered, a letter so indicating will be sent to you for use in any future sale of your home. 
Page 2

- For your participation in the project, upon final examination of your home, you will receive your choice of:

- a hot water heater wrap, which can cut your hot water heating bill by as much as $25 \%$.

or

- a shower flow restrictor to help you conserve water and cut your hot water heating costs.

The study calls for homes that have been insulated without a vapor barrier, as well as some homes - for control. purposes that have no insulation. Both cateqories of homes entities you to the same benefits. If you axe interested in participating in this study, please fill out the enciosed form and return it within one week. A self-addressed return envelope is enclosed for your convenience. If your home meets initial criteria and qualifies for examination, a representative of Seton, Johnson \& odell, Inc., our consulting engineers for the project, will be contacting you by telephone to arrange a time for further investigation and your free inspection.

If you have any questions, feel free to call the Department of Energy: toll-free at 1-800-452-7813; or directly at 378-4040

in Salem. Please fill out and return the questionnaire as soon as possible, as we intend to select qualifying homes by early February. Thank you for your interest in this project.

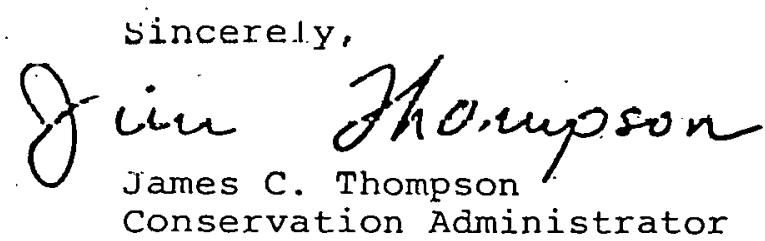

Enc. 
Page 2

- For your participation in the project, upon final examination of your home, you will receive your choice of:

- a hot water heater wrap, which can cut your hot water heating bill by as much as 258 .

Or

- a shower flow restrictor to help you conserve water and cut your hot water heating costs.

Since we have already completed our inspection of homes that are uninsulated, we need only those homes which already have insulation added to the walls. If you are interested in participating in the study, please fill out and return the enclosed questionnaire. If your home meets initial criteria and qualifies for examination, a representative of Seton, Johnson \& Odell, Inc., our consulting engineers for the project, will be contacting you by telephone to arrange a time for further investigation and your free inspection.

If you have any questions, feel free to call the Department of Energy: toll-free at 1-800-452-7813; or directly at 378-4040 in salem. Thank you for your interest in this projert.

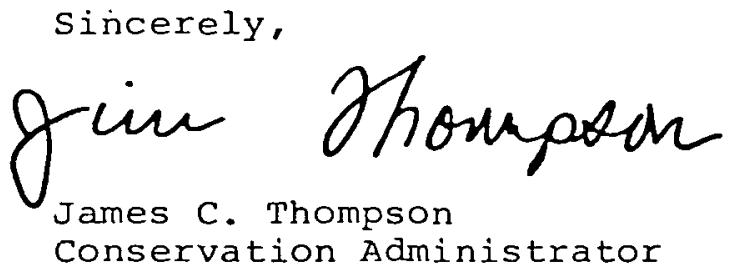

Fine.

REVISED PAGE 2 - Sent to Group III 
Honeounet's name: Telephone

Azdress

City Zip Code

Are valls insulated? Yes If yes, were valls insulated before

Feb. 1, 1976?

Type of wall insulation:

Type of exterior wall siding:

Type of heating syster:

Ko

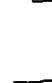

\section{Yes}

No

Don't lnow

Jrea-formalohyde foam

C.e] 7 nuse

Mineral wool (rock wool or fiber glass)

Other (specify)

Don't know

kione

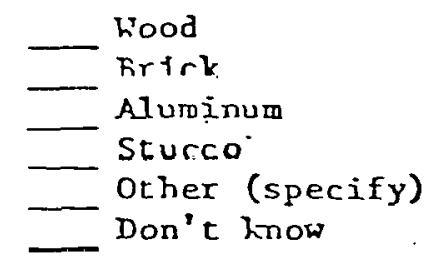

Electric resistance

Electric forced air

_- Electric for pump

- Natural gas

Dit

W Uthet (aperity)

Don't know
Approxinate date of insulating:
Number of occupants: Don't know \$izc of home (sq. feet of living space

$$
\begin{aligned}
& \text { Don't know } \\
& \text { If crawl space home, is a } \\
& \text { ploctir ground cover } \\
& \text { (vapor barrier) on } \\
& \text { ground in crawl space? }
\end{aligned}
$$

Time most conventently reached by pinone: morning,
evellity morning, atterivon, 
For: Oregon Department of Energy

(Note: Please do not submit addresses of homes where a vapor barrier has been Installed. Submit addresses for retrofit homes, not those insulated during new construction.)

Homeowner's name: Telephone

Address

City Zip Code

Are walls insulated? Yes Feb. I, 1976?

Type of wall insulation:

Type of exterior wall siding:

Type of heating system:

Number of occupants: Don't know $=$

Home has: Basement Crawl space

Time most conveniently reached by phone:

No - If yes, were walls insulated before Yes

No Non't know Dun't know insulating:

Approximate date of

Cellulose

- Nineral wool (rock wool or fiber glass)

- Other (specify)

Don't know

None

Wood

Brick

Aluminum

Stucco

Other (specify)

Don't know

Electric resistance

_ Electric forced air

- Heat pump

Natural gas

- 0 il

Other (specify)

Dun'L knuw

Size of home (sq. feet of living space

Don't know floor area):

If crawl space home, is a plastic ground cover (vapor barrier) on - No ground in crawl space? afternoon, 
PLEASE NOTE: Plcase fill out this form only if:

The wall insulation was NOT installed during construction of your home, but was adjed (retrofit) at a later time

Homeowner's Name: Telephorie

- Home

Address

City Z ip

Are Walls Insulated? Yes

No

When was insulation added to your walls? Date

Type of wall insulation: Urea-formal dehyde foam Celluluse Minerol Wool (rook woul ul ribel ylass) Other (specity) Dont' know

Type of exterior wall siding:

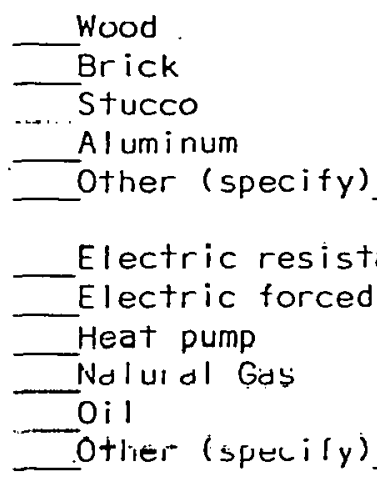

Do you have any vinyl wallpaper covering OUTSIDE walls? YES NO

If so, what percent of your outside walls are covered with vinyl? $q$ Number ot occupants;

Size of home (sq. feet of living space floor oreo): Don't know

Home has: Ba sement Crawl Space; If crawl space, is there a plastic ground cover (vopor borrier) on the ground in the crawl spacc? Crawl Space Yes

No Don't know

Time most conveniently reachied by phone; Morning; Afternoon; 
TELEPHONE FOLLOW-UP

Unmodified Questionnaire

Homeowner's Name

\#

Type of exterior wall siding: Wood

Stucco

Brick

Aluminum

Other

Are the walls of your home insulated?

If so, was the insulation installed when the house was built - or added at a later time?

when built

retrofit

Do you have any vinyl wallpaper on an "outside" wall?

If so, how much of the wall does it cover?

Does your home have more than one floor? (other than basement)

If so, did the square fee size of the home noted in the questionnaire include both floors?

If not, what is the upstairs floor area?.

downstairs floor 


\section{Department of Energy}

LABOR \& INDUSTRIES BUILDING, ROOM 111, SALEM, OREGON 97310 PHONE 378-

\section{INFORMATION SHEET}

The Oregon Department of Energy is conducting a study on the long-term effects of wall insulation in homes and appreciates your participation in the project.

Much uncertainty exists as to whether or not wall insulation installed withour a vapor barrier causes dn increased risk of moisture damage (dry rot) within walls. The Department of Energy, aided by specialists in this fleld, Inlends Lu resolve this question by closely examining homes that have been insulated without a vapor barrier and comparing them with homes that have not been insulated.

The study calls for inspection of some 100 homes in the Portland metropolitan area. After determining that a home meets all necessary criteria, professional engineers (Seton, Johnson \& Odell, Inc.) and carperters (Neil Kelly Co.) will remove small, predetermined sections of outside walls to inspect tor any moisture concent. Test samples will be taken and the wall sections will be replaced. Techniques used in opening walle will be identical to those nsed in remodeling homes, leaving neglibible traces of the openings. A more complete description of the program will be provided, and questions you might have will be answered prior to reaching final agreement for proceeding with any wall openings.

To successfully complete this important project, the Department of Energy is entirely dependent upon the participation of homeowners like yourself who share an interest in determining if dry rot is indeed a threat to homes with certain types of wail insulation. In addition to discovering if your home is in need of repairs to correct or prevent serious or irreversible structural damage, other benefits of participating in the project include:

A free, thorough, professional examination of the walls in your home wili be conducled.

Should moisture damage be found, you will receive a detailed report, as well as information on how to correct existing problcms.

If no moisture problems are discovered, a letter so indicating will be sent to you for use in any future sale of your home. 


\section{Department of Energy}

LABOR \& INDUSTRIES BUILDING, ROOM 111, SALEM, OREGON 97310 PHONE 378-

Page 2

For your participation in the project, upon final examination of your home, you will receive your choice of:

-a hot water heater wrap, which can cut your hot water heating bill by as much as $25 \%$

or

-a shower flow restrictor to help you conserve water and cut your hot water heating costs.

The study calls for homes that have been insulated without a vapor barrier, as well as some homes - for control purposesthat have no insulation. Both categories of homes entitles you to the same benefits.

If you have any questions, feel free to call Mr. Jim Thompson, Conservation Administrator at the Department of Energy: toll-free at 1-800-452-7813; or directly at 378-4040 in Salem. Should you have a specific question about your home, the engineer who visited your house - or another representative of Seton, Johnson \& Odell - would be happy to try and answer it for you; just call the number at the bottom of this page. Thank you very much for your interest in this study.

\section{Contact:}

Mitzi Scott

Seton, Johnson \& Odell, Inc. $226-3921$ 


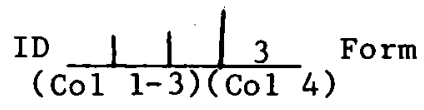

WALL INSULATION STUDY

\section{CHECKLIST 非 1}

Family Lifestyle and Home Characteristics

Homeowner's Name

Total number of occupants

$0-2$
$3-4$
$5-6$
$>6$

Age of house in years

$$
\begin{aligned}
& 0-5 \\
& 5-20 \\
& 20-40 \\
& >40
\end{aligned}
$$

$\left(\begin{array}{ll}\operatorname{Col} & 9)(1) \\ (\operatorname{Co1} & 9)(2) \\ \left(\begin{array}{ll}\text { Co1 } & 9)(3) \\ (\operatorname{Col} & 9\end{array}\right)(4)\end{array}-\right.$

Do you lower the thermostat at night? No
Yes
(Col 11)(1)
$(\mathrm{Co} 111)(2)$

Do you have and use a fireplace?

$$
\begin{array}{ll}
\text { No } & (\mathrm{Col} 12)(1) \\
\text { Yes } & (\mathrm{Col} 12)(2)
\end{array}
$$

in you have and use a wood stove?
No
Yes
$(\sin 13)(1)$
$(\operatorname{col} 13)(2)$

Do you have and use a humidifier in winter?
No
Yes
(Col 14)(1)
$(\operatorname{Col} 14)(2)-$

Do you have and use a dehumidifier?

$$
\begin{array}{ll}
\text { nos } & (\text { Cnl } 17)(1) \\
\text { Yes } & (\text { Col } 15)(2)
\end{array}
$$

Do you have and use central air conditioning?
No
(Col 16)(1, )
Yes
$(\cot 16)(2)$

Do you have and use a window air conditioner?

No

$(\mathrm{Col} 17)(1)$

$($ Col 17)(2)

Yes

Do you have a letechen cxhaust fan?

No

Yes

$(\operatorname{Col} 18)(1)$

(Col 18)(2)

If yes, do you use it regularly when cooking? No

Yes

(rol 19)(1)

$($ Col 19)(2)

Do you have and use a bathroom exhaust fan?

No

Yes
$(\operatorname{Col} 20)(1)$

(Col 20)(2)
Does condensation form on the inside of the

bathroom window during a shower or bath?
No
$(\mathrm{Co1} 21)(1)$

Yes

(Co1 21)(2)

Is a showerhead restrictor installed?

No

$($ Col 22)(1)

Yes

(Col 22)(2)

Is clothes dryer vented to the outside?

No

(Col 23)(1)

Yes

(col 23)(2)

CONSERVATION OR WEATHERIZATION STEPS TAKEN:

(Year Installed)

Wall insulation

No

$u-2$

$3-5$

6-9

$10+$

( Cul 24)(1)

(Col 24)(2)

$($ Col 24)(3)

(Col 24)(4)

$(\operatorname{Col} 24)(5)$

Ceiling insulation

No

$0-?$

3-3

6-9

$10+$

$(\operatorname{Col} 25)(1)$

( Cn 125$)(?)$

(C̄ol 25)(3)

(Col 25) (4)

$($ Col 25)(5)

Floor insulation

No

$0-2$

3-5

6-9

$10+$

$(\operatorname{Col} 26)(1)$

$(\operatorname{Col} 26)(2)$

(Col 26)(3)

(Col 26) (4)

$($ Col. 2B) (5)

Duct insulation

No

0-2

3-5

6-9

$10+$
$(\operatorname{Col} 27)(1)$

(Co1 27)(2)

(Col 27)(3)

$(\operatorname{Col} 27)(4)$

(Co1 27)(5) 
ID $\frac{1}{\left(\left.\operatorname{Co} 1 \frac{1}{1-3)}\right|_{(\operatorname{Co} 14)} ^{4} 1\right.}$ Furm

WALL INSULATION STUDY

Date $\frac{1}{\left(\cos \frac{1}{5-8)}\right.}$

CHECKLIST 俳 2

House Characteristics

Home owner's Name:

1. Do walls contain retrofitted wall insulation? U-F Foam Ure thane Foam Cellulose Rock Wool Fiberglass Other Other described

2. Exterior wall siding Wood Brick

Aluminum Stucco Other Other described

3. Heating System

Ducted Systems: Combustion System Using Inside and/or Outside Air: Oil Forced Air (Col 16-17)(01) Oil hot water/steam ( Col 16-17)(02) Natural Gas. (Col 16-17)(03) Wood Furnace Stove Fireplace $(\mathrm{Col} 16-17)(04)$ $(\mathrm{Col} 16-17)(05)$ (Col 16-17)(06)

Ducted Systems: Forced air with ducts outside heated space:

Non Heat Pump (Col 16-17)(07)

Hcet Pump

(Col 16-17)(08)

Non-Ducted Systems :

Electric Resistance (Baseboard and/or cable) (Col 16-17)(09)

Electric forced air, all ducts within heated space

Non Heat Pump

Heat pump

$($ Col 16-17)(10)

$(\operatorname{Col} 16-1 \%)(11)$

4. Heated Floorc

Basement heated
First floor heated
Second floor heated
Three plus heated

$(\mathrm{Col} 18)(1)$

( Col 19) (1)

(Col 20) (1)

(Col 21) (1)

5. House has basement No ( $\operatorname{Col} 22)$ (1) Yés (Cul 22) (2)
6. House has crawl space

$$
\begin{aligned}
& \text { No craw1، space } \\
& \text { No Vapor Barrier } \\
& \text { Vapor Barrier }
\end{aligned}
$$

$(\operatorname{Col} 23)(1)$

$(\operatorname{Col} 23)(2)$

$(\operatorname{Col} 23)(3)$

7. Ceiling Insulation

No
Rockwool
Cellulose
Fiberglass
Other

$($ Co1 24)(1)

(Col 24)(2)

$($ Co1 24)(3)

$(\operatorname{Col} 24)(4)$

$(\operatorname{Col} 24)(5)$

8. Vapor Barrier

$\begin{array}{ll}\text { No } & (\text { Col 25)(1) } \\ \text { Yes } & (\text { Col 25)(2) }\end{array}$

Type

9. Evidence of moisture (discoloration, etc.) in attic

$$
\begin{aligned}
& \text { No } \\
& \text { Yess }
\end{aligned}
$$

$(\operatorname{Col} 26)(1)$

$(\operatorname{col} 26)(2)$

10. Floor Insulation

$$
\begin{aligned}
& \text { No } \\
& \mathrm{RO}-\mathrm{R} 13 \\
& >\mathrm{R}-13
\end{aligned}
$$

$(\operatorname{Col} 27)(1)$

$(\mathrm{Col} 27)(2)$

$(\mathrm{Col} 27)(3)$

11. Floors

Wood
Linoleum
Carpet

$(\operatorname{Col} 28)(1)$

$(\operatorname{Col} 29)(1)$

$(\operatorname{Col} 30)(1)$

12. Leaky Floor Trap Joor

$$
\text { No }
$$

$(\operatorname{Col~31)(1)~}$

$(\mathrm{Col} 31)(2)$

13. Duct Insulation

$\mathrm{No}$

Yes

$($ Col 32)(1)

$(\operatorname{Col} 32)(2)$

14. Storm Windows

$$
\text { No }
$$

$(\operatorname{Col} 33)(1)$

$(\operatorname{col} 33)(2)$

15. Insulated/double glass

$$
\begin{array}{ll}
\text { No } & (\text { Col } 34)(1) \\
\text { Yes } & (\text { Col } 34)(2)
\end{array}
$$

16. Window weather stripping No

Yes

$(\cos 35)(1)$

( Col 35)(2) 
1. Homeowner's name:

2. Date:

Check upon completion:

3. Project members present (initials):

4. Home floor plan sketch with orientation of openings:

5. Outdoor Temperatures:

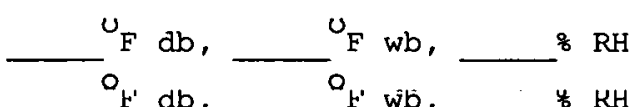

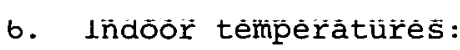

$\mathrm{O}^{\prime} \mathrm{db}$

7. Insulation sample removed \& bottled 1 , 2 3 4

8. Wall wood temperature (odd nos. down, even nos. up)

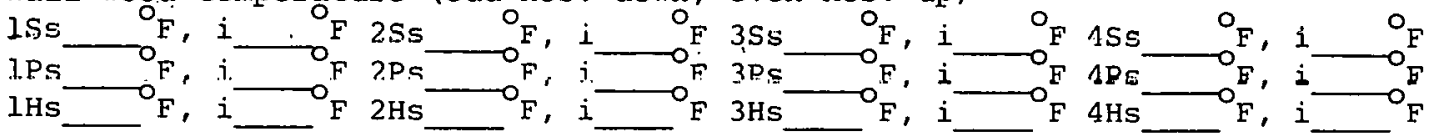

9. Wood moisture content

\begin{tabular}{|c|c|c|c|c|c|c|c|}
\hline 158 & i. & 256 & $i$ & $3 S c$ & $i$ & 180 & i \\
\hline IPs & & $2 \mathrm{Ps}$ & & $3 \mathrm{Fs}$ & $i$ & $4 \mathrm{Fs}$ & $i$ \\
\hline 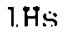 & & $2 \mathrm{Hs}$ & $i$. & $3 \mathrm{HS}$ & $i$ & $d \mathrm{He}$ & \\
\hline
\end{tabular}

10. Wood samples cored (for bioassay):

\begin{tabular}{|c|c|c|c|}
\hline 1S & $2 \mathrm{~S}$ & 35 & $4 \mathrm{~S}$ \\
\hline $1 \mathrm{P}$ & $2 \mathrm{P}$ & $3 p$ & $4 \mathrm{P}$ \\
\hline $\mathrm{IH}^{-}$ & $2 \mathrm{H}$ & $3 \mathrm{H}$ & $4 \mathrm{H}^{\circ}$ \\
\hline
\end{tabular}

11. Wood Samples removed (for moisture content check):

$1 \mathrm{P} \longrightarrow 2 \mathrm{H}$

$2 \mathrm{P}$

$3 \mathrm{P}-4 \mathrm{P}-4 \mathrm{P}$

12. U-F foam shrinkage: Shrinkage (in.) ravity spacing (in:) Thickness :

width :

Height:

13. Visual inspection remarks:

a. Signs of wood decay: Yes

b. Wiring corrosion: Yes

14. Wall cavity photographs taken:

1 , 2 3 , 1

15. Wall details noted:

Exterior siding:

Exterior moisture barrier:

Sheathing :

Insulation:

Other features: 
Sic

Nome:

Tel:

Address No. of Floors

Year of Canst: Floor Area: Envelope: Type of Canst: Volume:

Temp: Inside outside sketch of Orientatia Wind Velocity Pernarkes

Basement/Cawlspare Included | Eascment/crawlspace Excluc'so

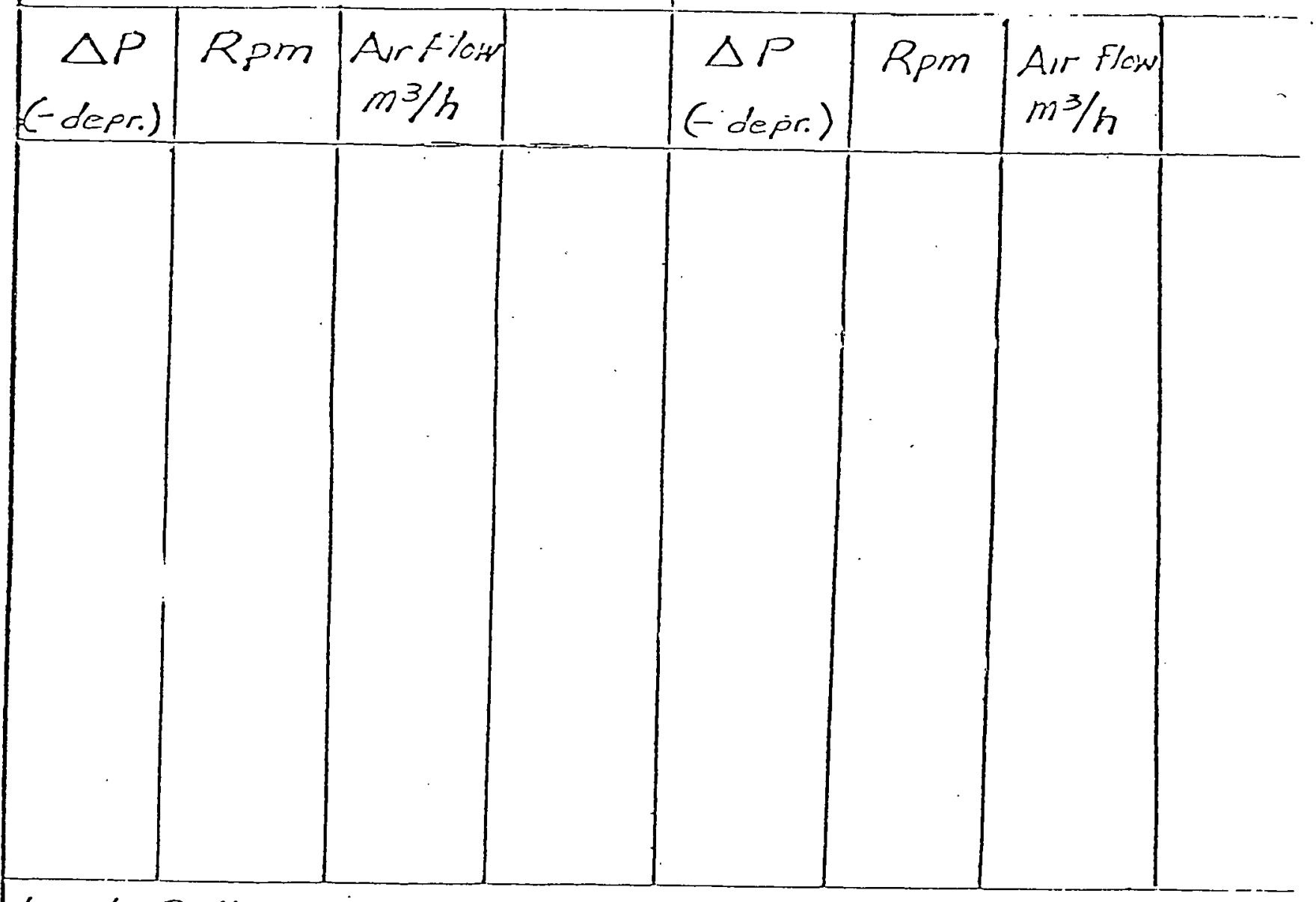

Leak Paths:

Remarks om hume:

$-75-$ 


\section{NEILKELIY}

DESIGNERS / REMODELERS

735 N. ALBERTA PORTLAND, OR 97217 $503 / 288-7461$

The undersigned homeowner hereby agrees to assist the State of Oregon Department of Energy in its wall insulation research project by allowing the Department of Energy and its agent to do the following to the home with the below address:

1: Allow up to four square holes approximately $14 \frac{1}{2}$ " "wide by 12 " high to be placed in the home's exterior walls;

2. Enter the home at reasonable times acceptable to the homeowner to take required readings inside the home :and

3. Allow the use of a small amount of electrical power to operate the instruments necessary to accomplish the above.

The undersigned warrants and represents that he/she has the right to grant the above consents.

The State of Oregon Department of Energy and its undersigned agent agree; as follows:

1. All of the tests and samplings will be done in a workman like manner and at reasonable times;

2. All of the holes to be placed in the home will "be made and repaired at agent's cost in a workmanilke manner, closely matching the existing paint on the home and

3. All of the above work will be completed within a reasonable time using materials of compatible quality with the home.

The undersigned homeowner agrees that "so long as the agent performs as recited above, the state of oregon Department of Energy seton,Johnson \& Odell. Inc. . Professor G.A.T Tongas Neil Kelly Co. Inc.. their agents and representatives will be forever held harmless from any and al damage and expenses other that as may be caused by their own negligence by reason of their above listed research activities and specifically acknowledges that the above are not responsible for the condition of the home as disclosed by the research:

$$
\text { Dated }
$$
1979

Homeowner ( $\mathrm{s})$ :
Neil Kally Co... InO. By: Taxid Aloper Seton, Johnson \& Odell. Inc. witncssed by:

Address of Home:

\begin{tabular}{|c|c|c|}
\hline $\begin{array}{l}\text { RESIDENTIAL } \\
\text { COMMERCIAL }\end{array}$ & $\begin{array}{l}\text { CERTIED DESGN } \\
\text { AND REMODEUNK } \\
\text { SERNIES: }\end{array}$ & $\begin{array}{l}\text { SINCE MA7, TII } \\
\text { REMOOELER FIAENDS } \\
\text { RECOMMEND }\end{array}$ \\
\hline . & $\begin{array}{l}\text { KITCHENS } \\
\text { BATHS : } \\
\text { ADDITONS } \\
\text { SUINS SIKXYHNE } \\
\text { RESTOKATION }\end{array}$ & \\
\hline
\end{tabular}


APPENDIX 10.3

STATISTICAL ANALYSIS RESULTS

\subsubsection{General:}

The statistical analysis was structured in a fashion which would measure the differential impact of insulation on the accumulation of moisture in sidewalls. The first broad concern was to identify factors related to moisture -- holding insulation constant. This first "cut" at the analysis involved development of a basic model including all variables found to be related to moisture except insulation. The second "cut" in the analysis introduced insulation as an additional factor which might account for moisture. By using multiple regression, the analysis sought to "explain" moisture rather than simply identifying factors "related" to moisture.

The basic unit of observation was a sidewall opening or hole. Measurements for two dependent variables were taken at each hole. The first dependent variable -- a measurement of moisture -- consisted of the average of all valid surface and interior field moisture levels of three wood members (stud, plate and sheathing). The second was the moisture level of the insulation, measured by laboratory test.

As noted in Appendix 10.2, extensive information was collected about the physical characteristics of each house and the lifestyle attributes of occupants (see checklists 1,2 and 3 ). Bivariate pearson product moment correlation coefficients were produced for all possible pairs of all causal factors (independent variables) and both of the two dependent variables. 
Variables measuring symptoms of moisture (e.g. blistering paint, previous moisture problems, etc.) were eliminated from the model building because causes were looked for, not simply relationships (see Table 7.3).

TABLE I VARIABLES ELIMINATED DUE TO REFERENCE TO MOISTURE SYMPTOMS

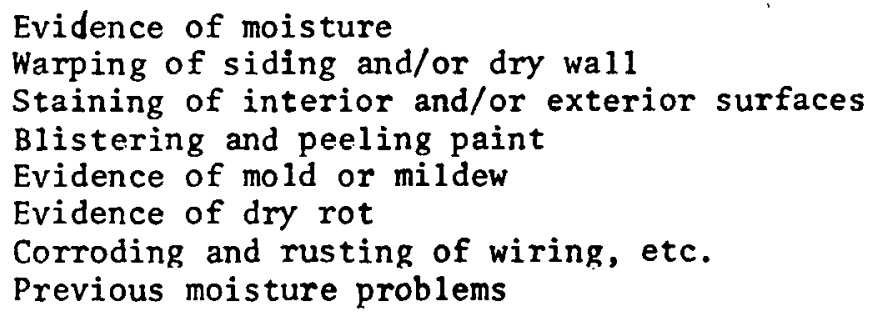

The analysis proceeded separately for each dependent variable -- all factors considered for wood moisture and all factors considered for insulation moisture. The bivariate correlation coefficients for each dependent variable were examined and two preliminary lists of all the independent variables that were candidates for inclusion in the basic (not including insulation) models were selected. The initial eriterion was that the magnitude of the bivariate correlation coefficient be .1 or greater. This would include any variable which accounted for $1 \%$ or more of the variance in the respective dependent variable.

Tho initial list of candidates was further examined for relationships which appeared to be purely spurious and for variables with a large number of missing values which would cxcessively redues the sample size. The two resultiting subsets of independent variables (obe for each of the two dependent variables)

that are displayed in Table II along with the sign of their respective bivariate correlation. The bivariate $r$ squared indicates the pro- 
portion of variance in the dependent variable of interest that can be accounted for by variance in the independent variable. Although these numbers are statistically significant, their magnitude is not large for any factor.

An example

Topness of holes location in the wall -

if the hole was at the top of the wall, the predicted moisture woild be lower than if it was at the bottom.

Number of showers taken daily +

As the number of showers taken daily goes up, ones

prediction of member moisture goes up as well.

TABLE II SELECTED INDEPENDENT VARIABLÉS

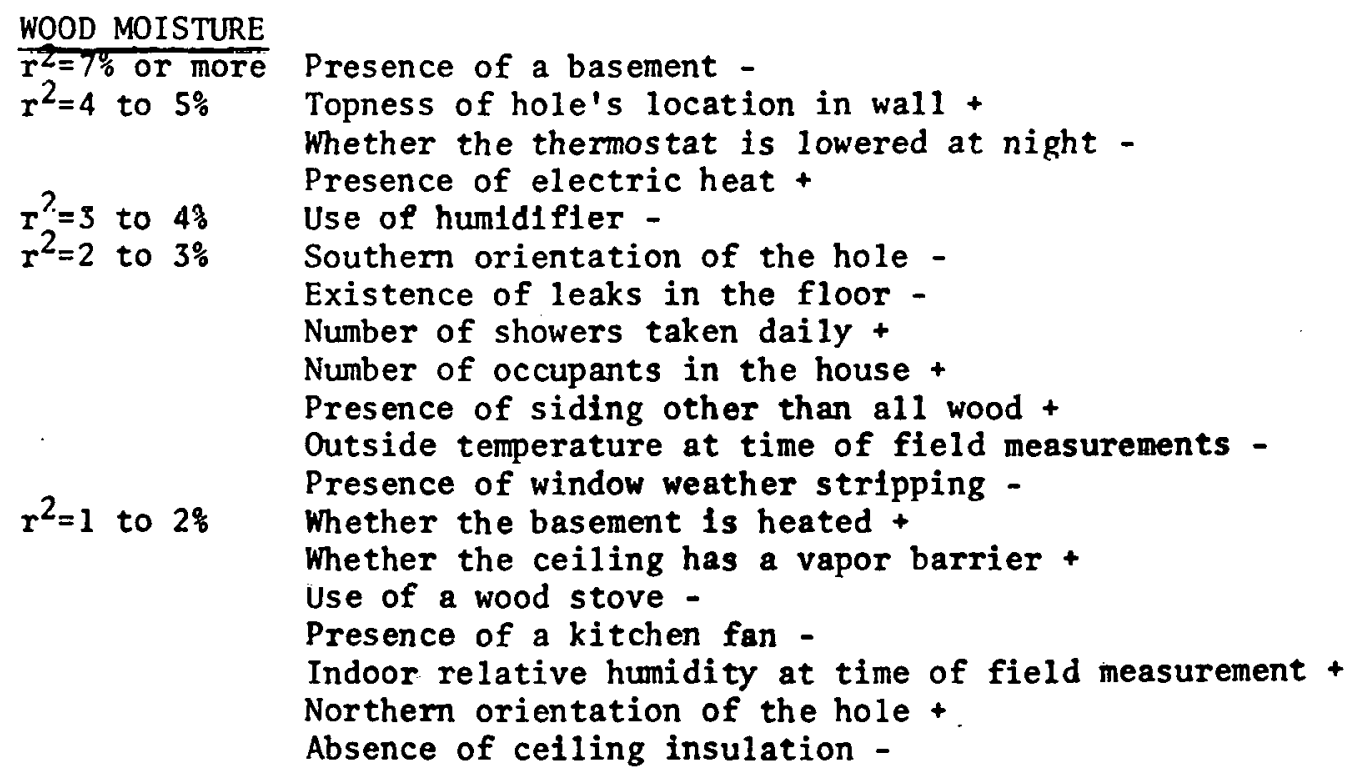


TABLE II -. CONTINUED

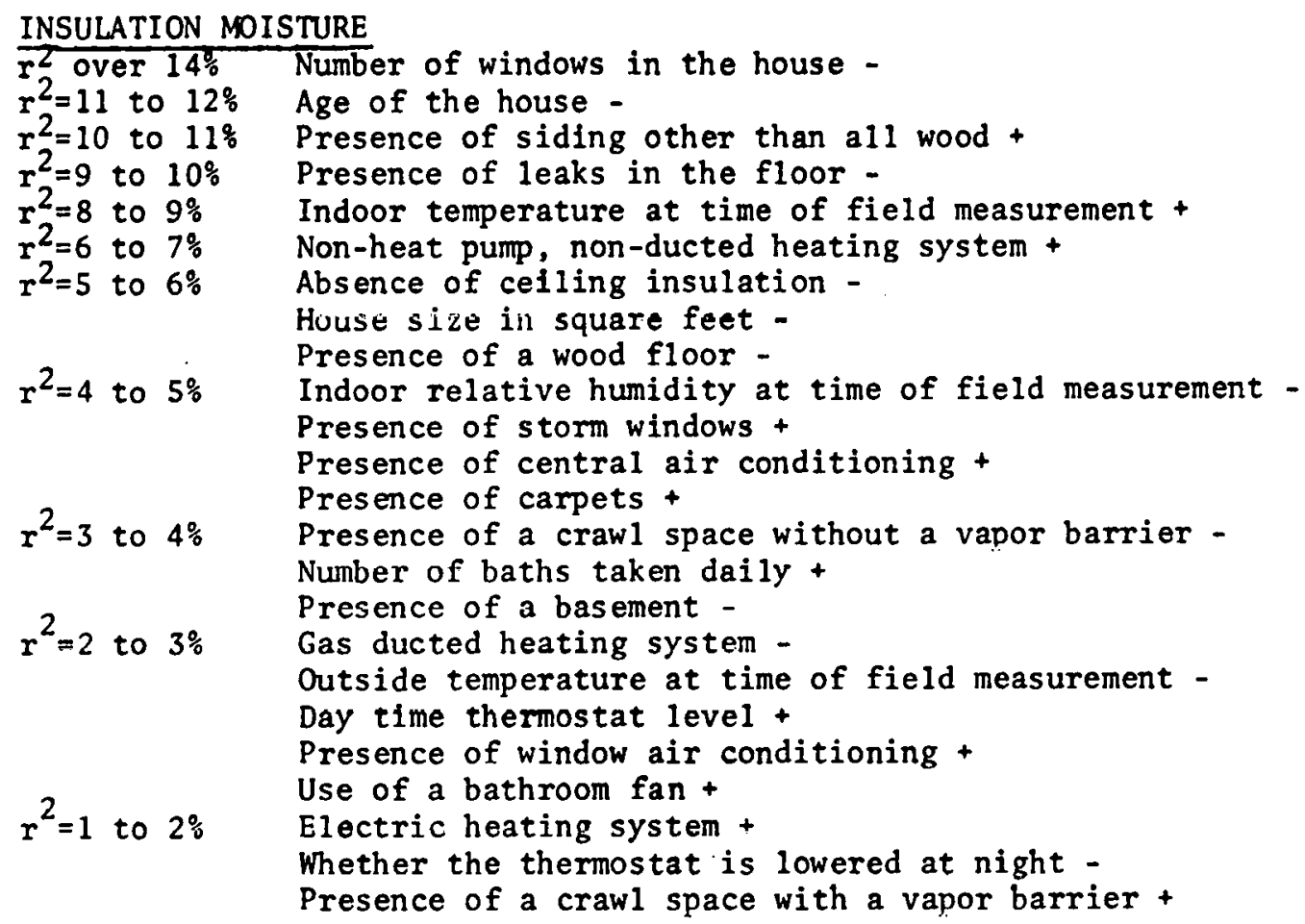

Fach set of independent variables significantly related to one of the moisture measures contained items which were related to other independent variables as well as to the dependent variable (i.e. there was a high degree of inter correlation among some independent variables). In order to insure that the regression analysis included variables significantly related to the dependent variable and not related to other independent variables in the regression equations, each data set was subjected to a factor analysis. The intention in factor analyzing is not to identify any underlying theoretic dimensions but rather to capture some large measure of the common variance of each respertive subset of independent 
variables. The factoring provides uncorrelated factor scores for use in building a more stable regression model.

The factoring method used was principal factoring with iterations. The initial commonalities used were squared multiple correlations. The iterations were performed using the variance accounted for by the factors. This resulted in inferred factors which were subjected to a varimax criterion rotation. Factor scores were produced for each case and used in the subsequent regression analysis. 10.3.2 Wood Member Moisture:

Regarding wood moisture, there were 314 holes were used in the factor analysis. The ten factors accounted for $73.6 \%$ of the total variance within the subset of independent variables. The rotated factor loadings and their signs are displayed in Table III. The ten factors did poorly in capturing the variance of the presence of other than all wood siding and the presence of a kitchen exhaust fan. If these two variables contain some measure of unique explanatory power of member moisture this power will not be contained in the factors. The holes location in the wall (topness) was not captured at a11. Topness was fairly strongly associated with member moisture and completely unassociated with any common variance of the other variables. It was not uscd in creating the factor scores (i.e. all factor scure coefficients for topness were 0 ). Therefore, topness was directly used as an independent variable in the regression. 
TABLE III MEMBER MOISTURE ROTATED FACTOR LOADINGS

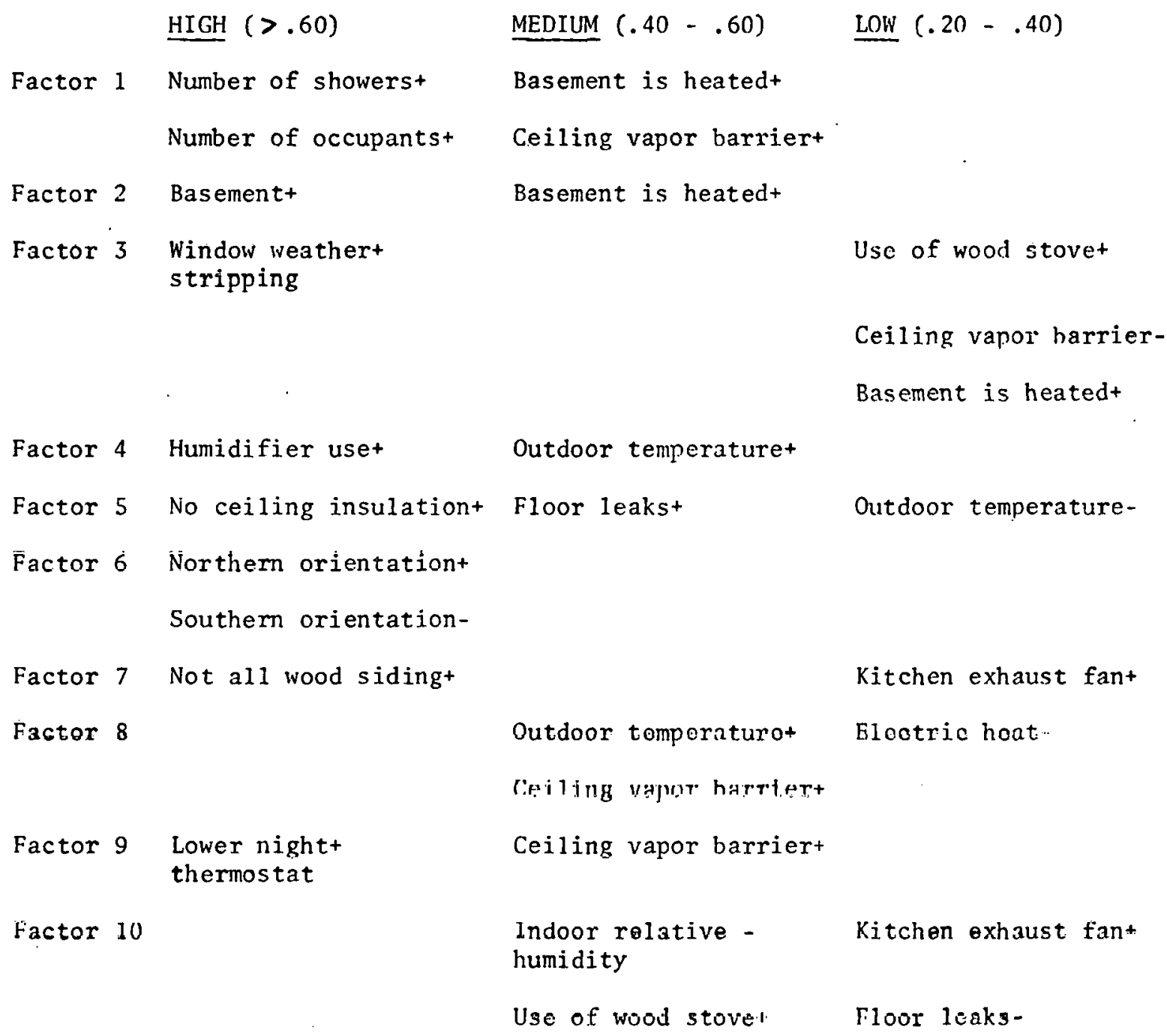


Bivariate intercorrelation among the factor scores and topness: showed that, of the 55 unique intercorrelations, 44 were .05 or lower with only two above .10 (at .11 and .13). These numbers were sufficiently small not to warrant further concern about the instability of the regression equation as a result of multicolinearity among the factors. The results of the regression equation will yield coefficients which suggest how much of the total variability in moisture is uniquely accounted for by each factor. With minimal intercorrelation problems, the analysis is not confused by having one variable disguise similar "effects" which might have been found for other vartables.

The basic model regression (excluding insulation) using the ten factors and topness produced a multiple squared of .235 (i.e. $23.5 \%$ of the variance in average field member moisture can be accounted for by topness and the factors produced by the subset of independent variables). Taking into account al1 11 components of the regression analysis, on $1 y 23.5 \%$ of all wood moisture was "explained" by the basic model. An F test of overall goodness of fit is statistically significant (statistical significance is specified at the .0 confidence level throughout this analysis). The deviation of observed moisture about its mean value of $11.7 \%$ is $1.59 \%$ (i.e. standard deviation). Its deviation about the least squares regression line produced by topness and the ten factors is $1.41 \%$ (i.e. standard error of the estimate).

Statistically significant coefficients are present for the following components. They are listed in the order of the magnitude of their contribution to the regression equation (i.e. Beta weights):

Topness-, factor 2-, factor 4-, factor 6+, factor 9-, factor 3-, factor $7+$ 
The full model, consisting of the ten factors, topness, and wall insulation types, employed a stepwise regression procedure. The order of entry (related to the statistical significance of a variable) and the corresponding multiple $R$ squared values are displayed below:

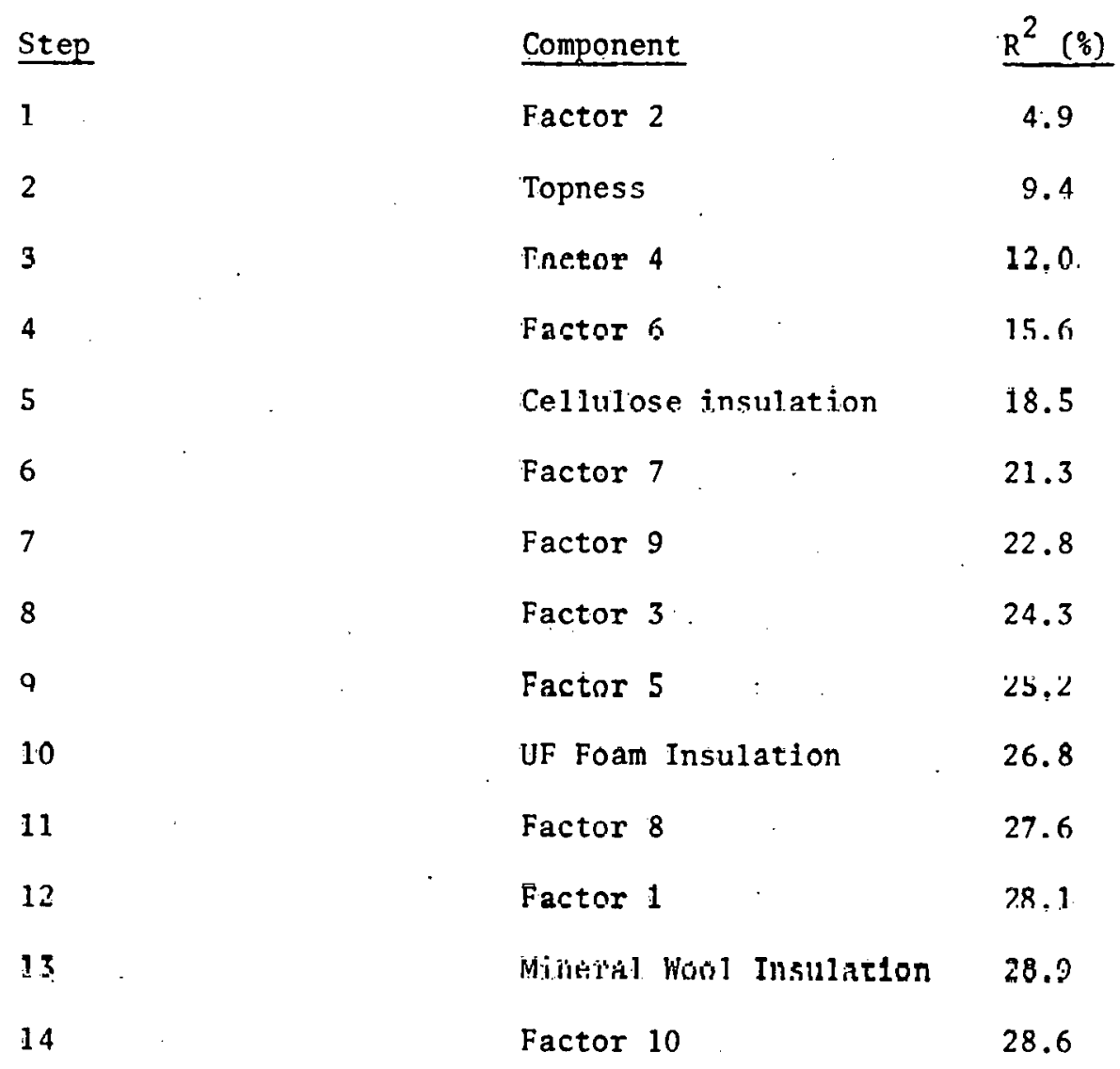

The full mode1 regression results in a multiple $R$ squared of .286 ; 2.8.6\% of all moisture variability is accounted for by all models. An F test of overall goodness of fit is statistically significant. The deviation of observed moisture about the full model regression prediction is $1.37 \%$. 
Statistically significant coefficients are present for the following components. They are listed in the order of the magnitude of their contribution to the regression equation:

Cellulose insulation-, Factor 2-, UF foam insulation -, topness -, factor 4-, factor $7+$, factor $5-$, factor $6+$, factor 9-.

Observations on the member models are:

1) The increase in multiple $R$ squared by adding insulation type into the equation was from .235 to .286 . The addition of knowledge of the type of insulation present accounts for a $5 \%$ increase in the explained variance of the member moisture.

2) The presence of cellulose or foam insulation lowers the prediction of member moisture compared to that of the noninsulated house by $1.6 \%$ and $0.7 \%$, respectively. These regression coefficients reflect the effect of the equation in controlling for contributory effects of the other components (i.e. topness and factors). The contract between bivariate and multiple regression coefficients is as follows:

\section{Approximated bivariate Regression Coefficients between insulation types and. member moisture}

Multiple regression coefficients from the equation with topness and factors
U-F foam
$+.138$
$-.7 *$
Cellulose
$-.200$
$-1.6^{*}$
Mineral Wool
$+.074$
$-.4$

Statistically significant result; the remaining elements of the table are not statistically significant.

Perhaps moisture which would otherwise be present has been absorbed by the insulation in the walls. This would reduce the member moisture and account for the negative coefficients. 
3) The "standard deviation" of member moistures is as follows:

Standard deviation about its mean $1.50 \%$

Standard deviation about the base model prediction $1.41 \%$

(reduction of $11 \%$ )

Standard deviation about the full model prediction $1.37 \%$

(reduction of $3 \%$ )

\subsubsection{Insulation Moisture:}

The same process followed for member moisture was repeated for insulation moisture. The list of variables significantly related to insulation moisture was subjected to a factor analysis. There were 324 valid holes used in this portion of the analysis. This number constitutes all valid holes in the entire data set. The ten factors accounted for $69.3 \%$ of the total variance within the subset of independent variables.

The rotated factor loadings are displayed in Table IV. 'The ten factors did poorly in capturing the variance of the presence of other than all wood siding and the presence of storm windows.

of the 45 unique intercorrelations between the ten factors, 25 were .05 or lower with 3 above $.10,9$ at $.11, .14$ and .18 . These numbers were sufficiently small that we were not concerned about the stability of the resulting regression models. 
TABLE IV INSULATION MOISTURE ROTATED FACTOR LOADINGS

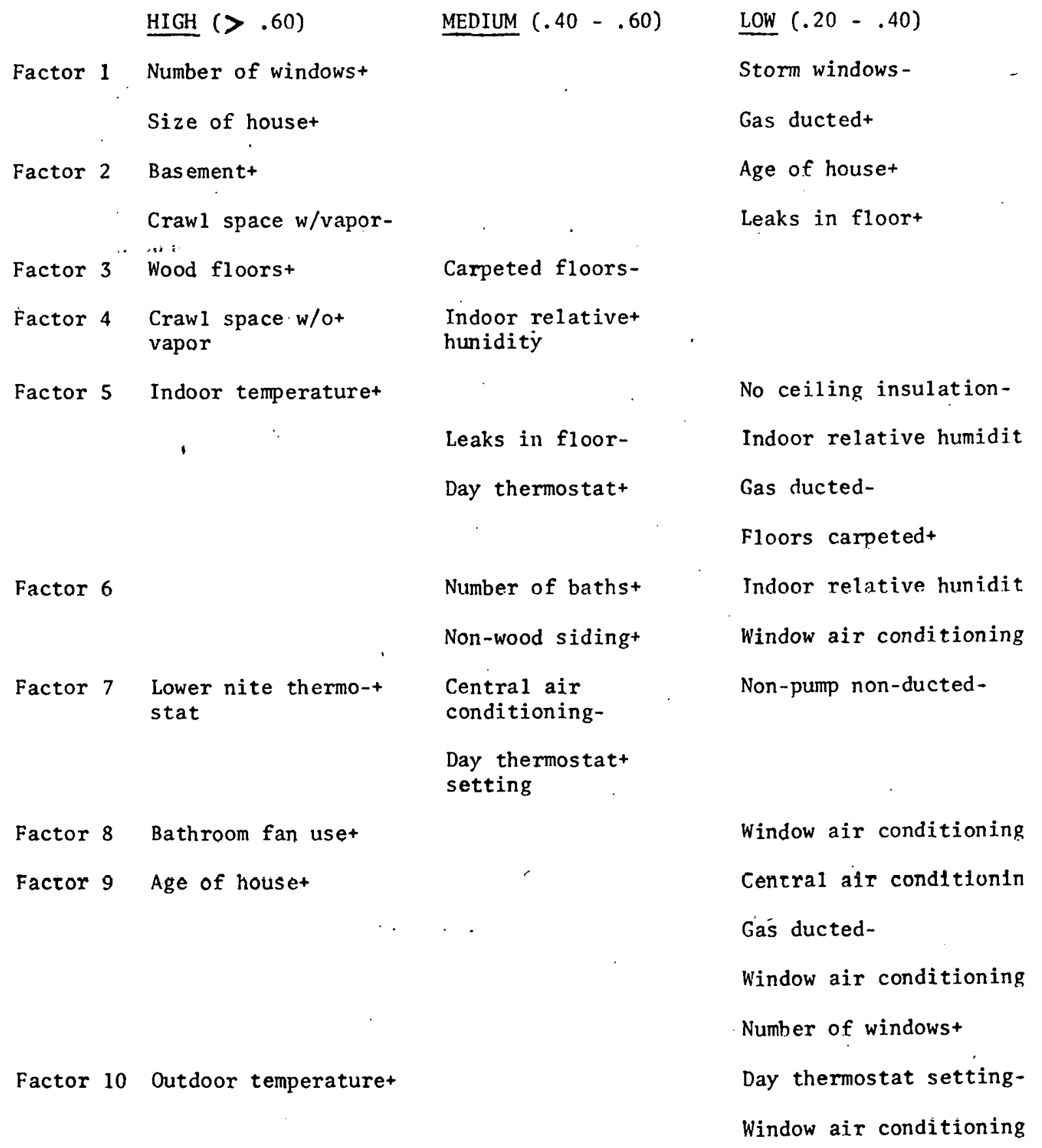


The basic model regression using the ten factors only resulted in a multiple $R$ squared of .219. A model using the ten factors produced from a subset of the independent variables could account for $21.9 \%$ of the variance in insulated moisture. An F test of overall goodness of fit was statistically significant. The deviation of observed insulation moisture about the model's prediction is $4.95 \%$.

Statistically significant coefficients were present for the following components. The components are listed in the order of the magnitude of their contribution to the regression equation:

Factor 6+, factor $4-$, factor $9-$, factor $1-$

The full model, including insulation type, was subjected to a stepwise regression analysis. The order of entry and corresponding multiple $R$ squared at each step is as follows:

\begin{tabular}{|c|c|c|c|c|c|}
\hline STEP & COMPONENT & $($ in $\%)$ & STEP & COMPONENT & $\mathrm{R}($ in $\%)$ \\
\hline 1 & iif foam insulation & 38.9 & 7 & Factor y & 86.0 \\
\hline 2 & Cellulose insulation & 84.0 & 8 & Factor 8 & 86.2 \\
\hline 3 & Factor 10 & 84.8 & 9 & Factor 1 & 86.3 \\
\hline 4 & Factor 2 & 85.3 & 10 & Factor 6 & 86,4 \\
\hline 5 & Factor 4 & 85,6 & 11 & Fastor 7 & 86.4 \\
\hline 6 & Factor 3 & 85.9 & 12 & Factor 5 & 86.4 \\
\hline
\end{tabular}

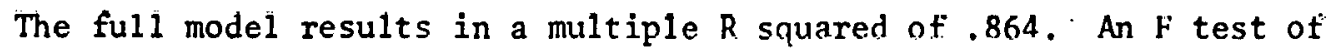
overall goodness of fit is statistically significant. The deviation of observed insulation moisture about the prediction based on the full model is $2.07 \%$. The following components had statistically significant coefficients. They are listed in an order based on their contribution to the regression equation. UP foam insulation + , cellulose insulation + , factor $10-$, factor $2+$ 
Observations based on the regressions of insulation moisture are:

1) The variance in insulation moisture that can be accounted for by the basic and the full models increased from $21.9 \%$ to $86.4 \%$. Clearly information about the presence and type of insulation is extremely helpful in modeling insulation moisture.

2) It is somewhat more insightful to observe that our prediction of insulation moisture in UF foam and cellulose holes is $12.2 \%$ and 13.3\% higher (respectively) than that of mineral wool holes. These regression coefficients reflect the effect of the regression equation to control the influences of the independent variables $\therefore$. represented by the factors. The contrast between bivariate and regression coefficients is as follows:

Approximated bivariate Regression Multiple regression coefficients Coefficients between insulation from the equation with factors types and insulation moisture

UF Foam

$+9.223$

$+12.2$

Collulose

$+7.053$

$+13.3$

Mineral Wool

$-7.449$

* All are statistically significant

3) The "standard deviation" of insulation moisture is as follows:

Standard deviation about its mean $5.47 \%$

Standard deviation about the base model prediction $4.95 \%$

(reduced by $10 \%$ )

Standard deviation about the full model prediction $2.07 \%$ (reduced by $58 \%$ )

4) Note that mineral wool is very low in lab insulation moisture (a maximum of $2 \%$ ). It was used as the base case to approximate a no insulation moisture condition: 
Observations based on the regressions of insulation moisture are:

1) The variance in insulation moisture that can be accounted for by the basic and the full models increased from $21.9 \%$ to $86.4 \%$. Clearly information about the presence and type of insulation is extremely helpful in modeling insulation moisture.

2) It is somewhat more insightful to observe that our prediction of insulation moisture in $U-F$ foam and cellulose holes is $12.2 \%$ and $13: 3 \%$ higher (respectively) than that of mineral wool holes. These regression coefficients reflect the effect of the regression equatefon to control the influences of the indepcndent variables represented by the factors. The contrast between bivariate and regression coefficients is as follows:

Approximated bivariate Regression Multiple regression coefficients coefficients between insulation from the equation with factors types and insulation moisture

UF Foam

Cellulose

Mineral Wool
$+9.223$

$+7.053$

$-7.449$
$+12.2$

$+13,3$

- All are statistically significant

3) The "standard deviation" of insiliation molsture is as foilows: Standard deviation about its mean $5.47 \%$

Standard deviation about the base model prediction $4.95 \%$ (reduced by 10\%)

Standard deviation about the full model prediction $2.07 \%$ (reduced by $58 \%$ )

4) Note that mineral wool is very low in lab insulation moisture (a maximum of $2 \%$ ). It was used as the base case to approximate a no insulation moisture condition. 


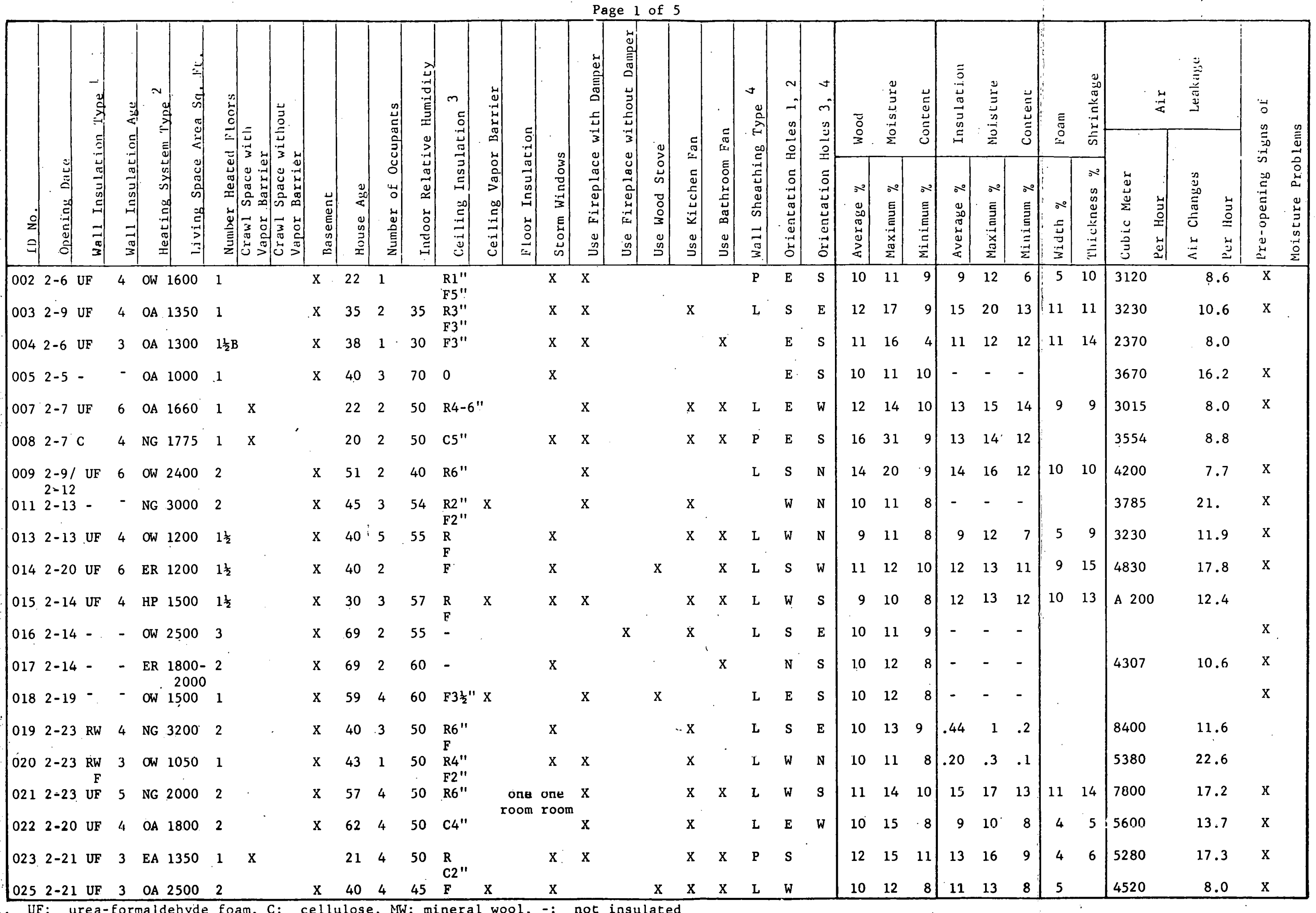

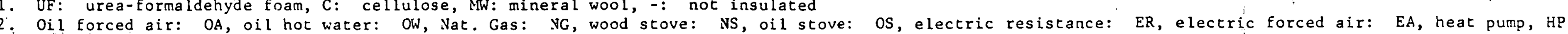

3. Type of insulation and tinickness in inches: $R$ : rock wool, F: fiberglass, C: callulose, 0 : none

4. Lapboard: L, Plywood: ?, Ce!lorex: 


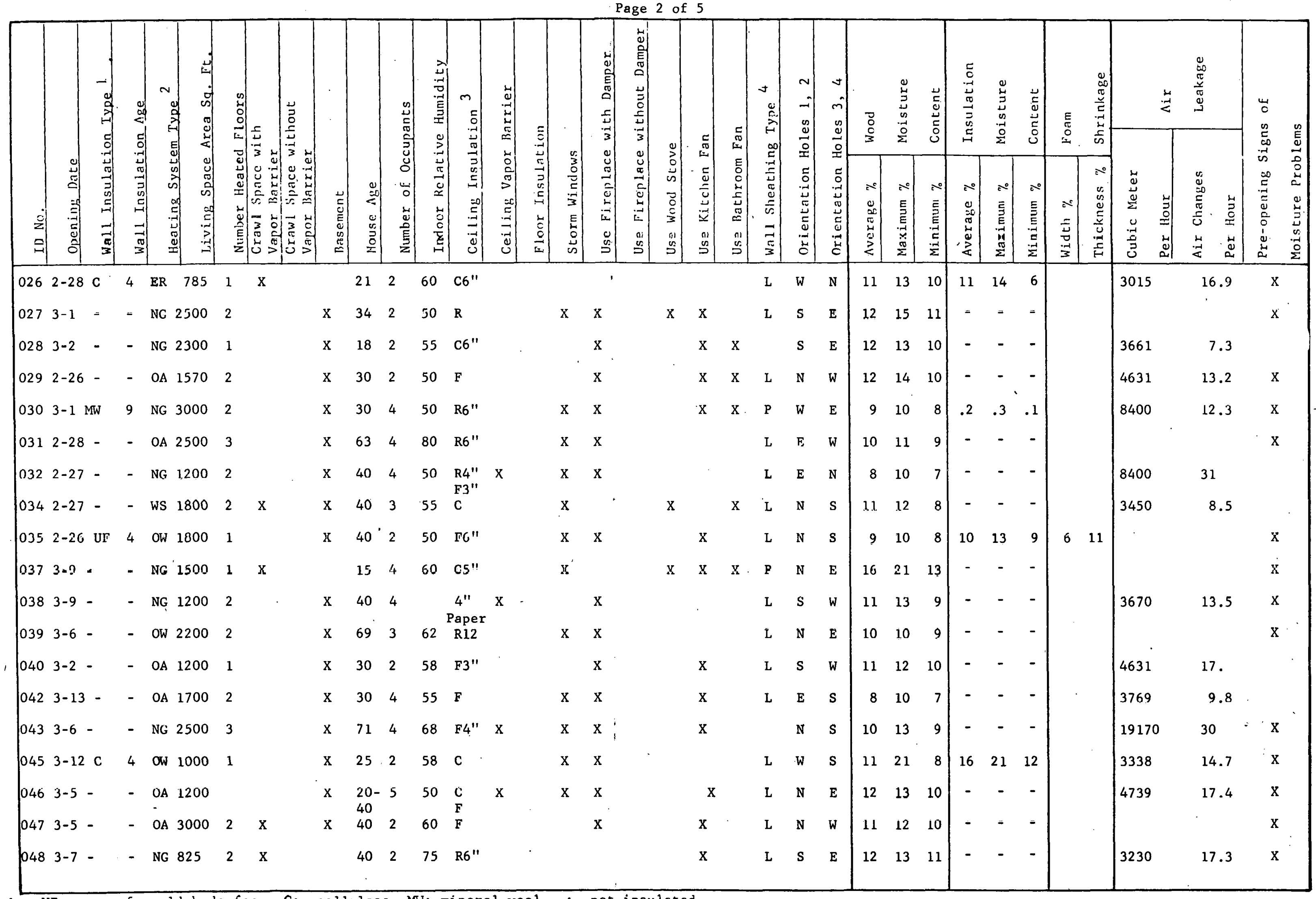

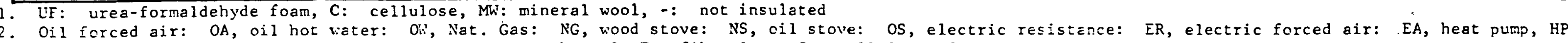
3. Type of insuletion and thickress in inches: R: rock wool, F: fibergless, C: cellulose, 0 : none

-. Lepjoard: L, Plywood: P, Cellotex: 


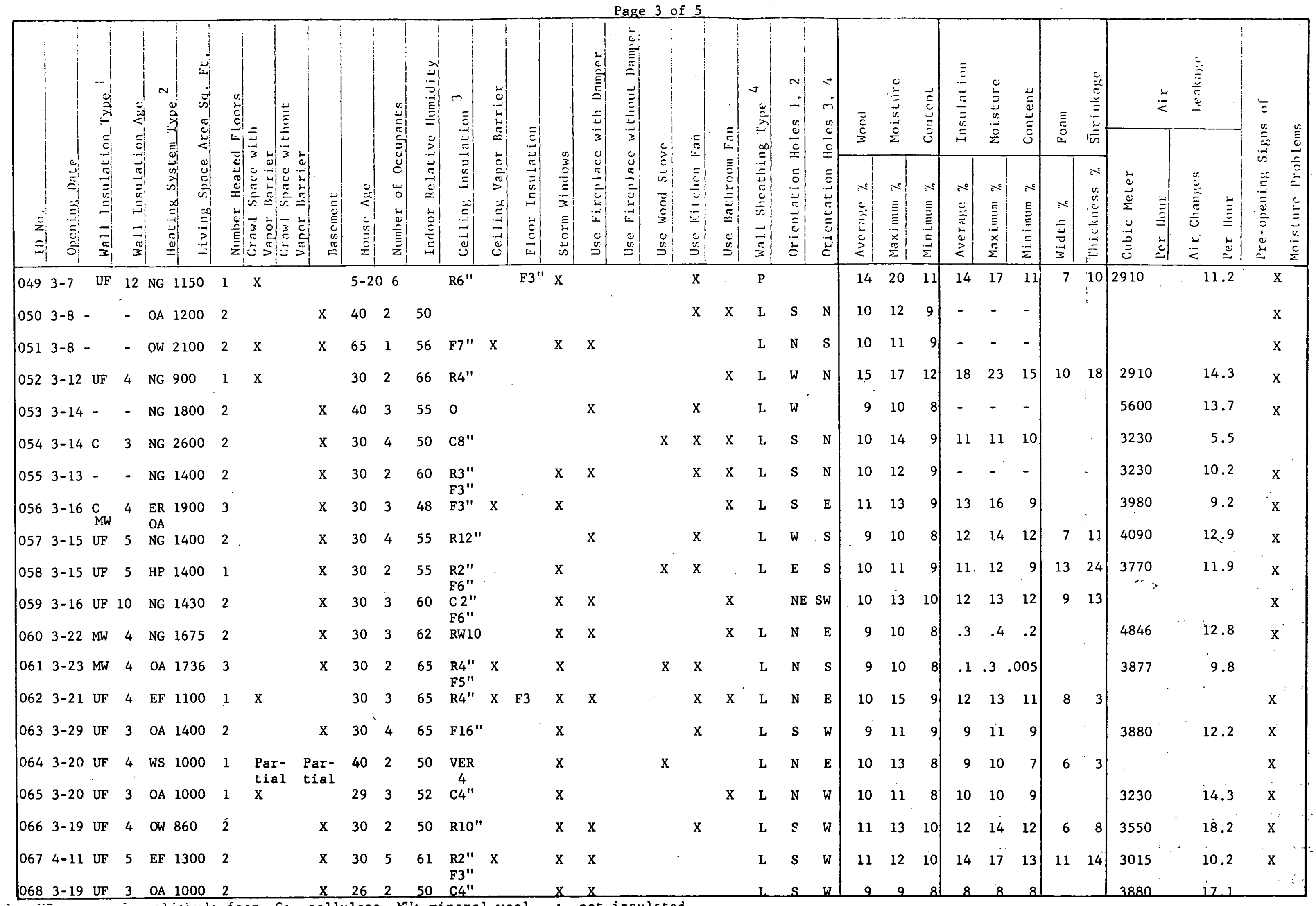

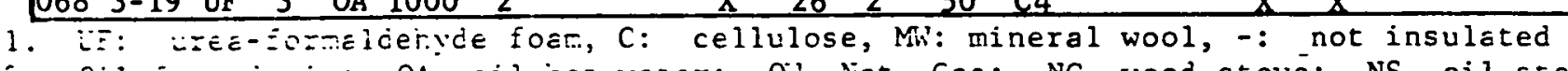

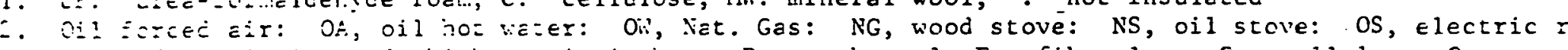

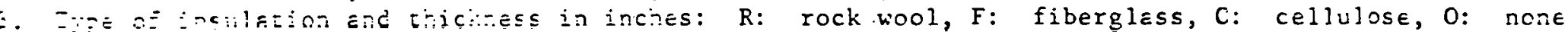

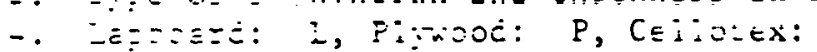




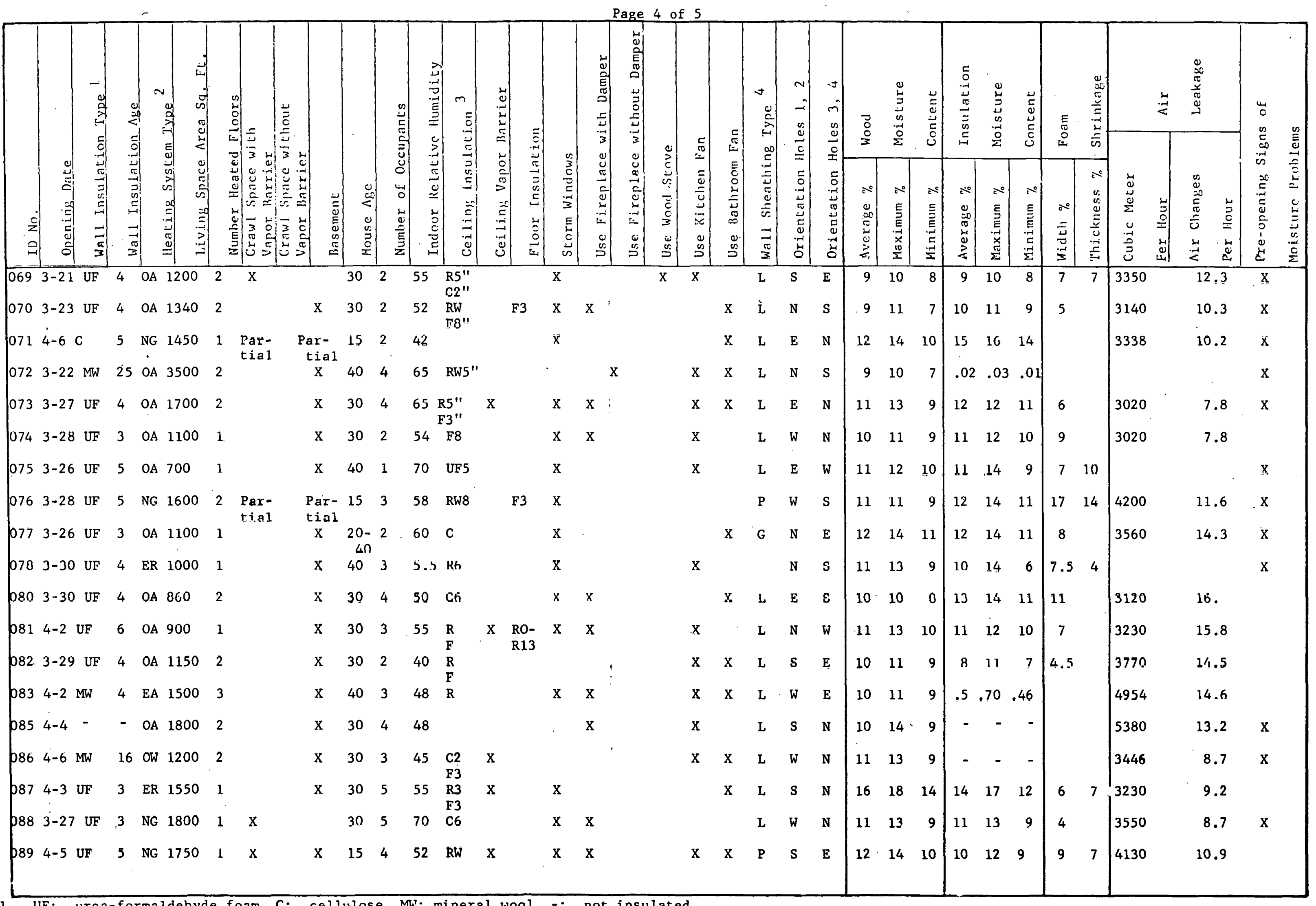

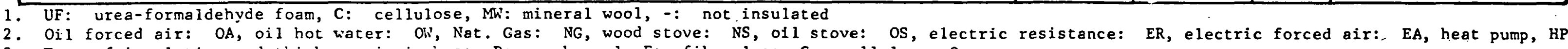
3. Type of insulation and thickness in inches: $R$ : rock wool, F: fiberglass, $C:$ cellulose, 0 : none

4. Lapboard: L, Plywood: P, Cellotex: C 
APPENDIX 10.4 SURRIARY OF TEST HOUSE CHARACTERISTICS AND DATA

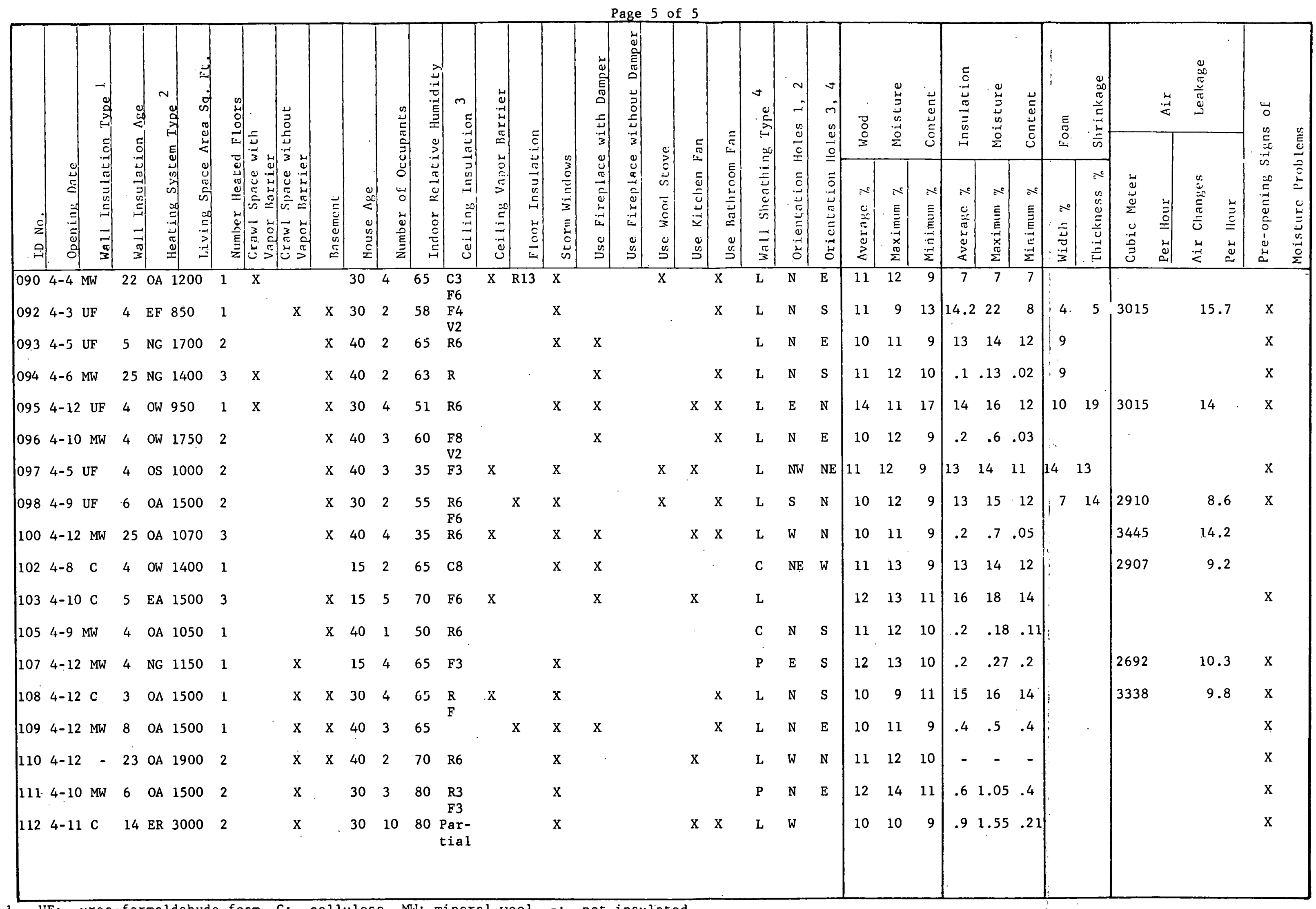

1. UF: urea-formaldehyde foam, C: cellulose, MW: mineral wool, -: not insulated

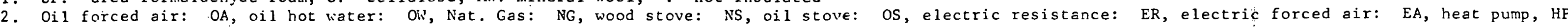

3. Type of insulation and thickness in inches: $\mathrm{R}$ : rock wool, $\mathrm{F}$ : fiberglass, $\mathrm{C}$ : cellulose, $\mathrm{O}$ : none

4. Lapboürd: L, Plyzood: F, Celluiex: C 
ORNL/SUb-78./97726/I

Dist. Category UC-95d

\section{INTERNAL DISTRIBUTION}

1. R. S. Carlsmith

2. K.W. Childs

3-52. M. C. Clary

53. F. A. Creswick

54. R. G. Donnelly

55. C. S. Dudney

56. W. Fulkerson

57. D. R. Johnson

58. T. S. Lundy

59. D. L. MCElroy

60. J. W. Michel

61. R. E. Minturn

62. J. N. Robinsgn

63. M. W. Rosenthal

64. T. F. Scanlan

65. A. C. Schaffhauser

66. E. G. Shields

67. D. B. Trauger

68. P. J. Walsh

69. J. R. Weir, Jr.

70. D. J. Wilkes

71-74. Laboratory Records

75. Laboratory Records - RC

76. ORNL Patent Office

77-78. Central Research Library

79. Document Reference Section

80. P. R. Achenbach, 1322 Kurtz Road, McLean, VA

81. R. W. Anderson, Diversified Insulation, Inc., Hame 1, MI

82. E. L. Bales, Stevens Institute of Technology, Hoboken, NJ

83. J. Barnhart, Thermal Insulation Manufacturers Association, Mt. Kisco, NY

84. A. L. Berlad, State University of New York, Stony Brook, NY

85. H. E. Buryer, Building Research Advisory Board, Washington, DC

87. J. J. Boulin, DOE/BCS, Washington, DC

88. R. L. Bullock, NIBS, Washington, DC

89. J. Bushong, Technology Insulation, INc., Boonton, NJ

90. J. Cable, DOE/BCS, Washington, DC

91. G. D. Carver, TVA, Chattanooga, TN

92. A. Castle, CPSC, Washington, DC

93. M. Chiogioji, DOE/BCS, Washington, DC

94. H. I. Cohen, CPSC, Washington, DC 
95. G. E. Courville, Fairleigh-Dickinson University, Teaneck, NJ

96-105. D. Davey, Bonneville Power Admin., P0 Box 3621, Portland, OR

106-115. T. Dolan, DOE, Region X, Seattle, WA

116-125. D. Dyer, Double D Construction, 999 Circle Blvd., Corvallis, OR

126. A. E. Fiorato, Portland Cement Association, Skokie, IL

127. G. J. Fitzgerald, American Cellulosic Manufacturers Association, Upper Mariboro, MD

128-157. E. C. Freeman, DOE/BCS, Washington, DC

158. B. F. Gilmartin, Owens-Corning Fiberglas, Washington, DC

159-168. R. Hamilton, R\&R Insulation, 4781 Niles Rd. NE, Salem, OR

169-178. R. Hansen, Portland General Electric, 121. SW Salmon,

Portiand, $O R$

179. R. F. Hemphi11, TV , Chattanooga, TN

180. C. D. Hollowell. LBL. Berkeley, CA

181. J. G. Hust, NBS-Buulder, Boulder, CO

182-191. H. Jahns, Puget Sound Power \& Light, Puget Power Bldg., Bellevue, WA

192. N. W. Johnston, Owens-Corning Fiberglas, Granville, $\mathrm{OH}$

193-202. J. King, Civil Engineering Lab., NCBC, Port Hueneme, CA

203. D. Lamb, TVA, Chattanooga, TN

204. T.P.R. Lant, The Agrement Board, PO Box 195, Bucknalls Ln., Garston, Watford, Herts WD2 7NG

205-214. S. Launey, DOE/BCS, Washington, DC

215. K. R. Long, University of Iowa, Oakdale, IA

216. J. T. Miller, GSA, Washington, DC

217. W. V. Miller, Civil Engineering Laboratory, Port Hueneme, CA

218. J. P. Millthone, DOE/BCS, Washington, DC

21.9. D. F. Morgenroth, Owens-Corning Fiberglas, Toledo, $\mathrm{OH}$

220. W. R. Newton, TVA, Chattanooga, TN

221-230, G. Ode11, Seton, Johnson \& Ode11, Portiand, OR

231. T. J. Ohlemiller, National Bureau of Staridards, Gaithersburg, MD

232. A. Paladino, National Bureau of Standards, Gaithersburg, MD

233. W. T. Phelan, Owens-Corning Fiberglas, Washington, DC

234. F. J. Powe11, National Bureau of Standards, Gaithersburg, MD

235. H. D. Ross, DOE/BCS, Washington, DC

236-245. T. Sadowski, Seattle City Light Co., Seattle, WA

246. E. Schaffer, Forest Products Laboratory, Madison, WI

247-250. J. Scofield, EWEB, 401 [. 10th, Eugene, OR

257. S. Selkowitz, Lawrence Berkeley, Laboratory, Berkeley, CA

258. C. J. Shirtliffe, National Research Council, Ottawa, Canada

259. R. Sonderegger, Lawrence Berkeley Laboratory, Berkeley, CA

260-269. C. Stultz, Pacific Power \& Light, Portland, OR

270. J. Tanck, DOE/BCS, Washington, DC

271. G. J. Teitsma, Dow Chemical Company, Granville, $\mathrm{OH}$

272. F. Terracina, State University of New York, Syracuse, NY

273-323. J. Thompson, State of Oregon Dept. of Energy, Salem, OR

323-373. G. Tsongas, Portland State University, Port1and, $O R$

374. R. P. Tye, Dynatech R/D Company, Cambridge, MA

375. C. R. VanderLinden, Johns-Manvilile Sales Corp., Denver, CO

376. K. Z. Velentgas, 47 Clinton St., Portland, ME

377. J. D. Verschoor, Johns-Manville Sales Corp., Denver, CO

378. S. S. Waddle, DOE/ORO, Oak Ridge, TN 
379. J. L. Weidt, John Weidt Associates, Chaska, MN

380. R. Weil, Stevens Institute of Technology, Hoboken, NJ

381. G. R. Williamson, CERL, Champaign, IL

382. Assistant Manager, Energy Research and Development, DOE/ORO, Oak Ridge, TN

383-656. For distribution as shown in TID-4500 under category UC-95d 